\title{
Excluding the Included: Citizenship, National Identity Discourse and Racialized Welfare Stratification in Brazil
}

\author{
by \\ Matthew Lymburner \\ of the requirements for the degree of Master of Arts \\ Department of Sociology and Anthropology \\ Carleton University
Ottawa, Ontario \\ August 2010
}

A thesis submitted to the Faculty of Graduate Studies and Research in partial fulfillment

(C) 2010, Matthew Lymburner 


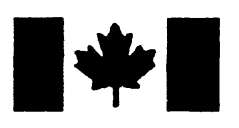

\author{
Library and Archives \\ Canada \\ Published Heritage \\ Branch \\ 395 Wellington Street \\ Ottawa ON K1A ON4 \\ Canada
}

NOTICE:

The author has granted a nonexclusive license allowing Library and Archives Canada to reproduce, publish, archive, preserve, conserve, communicate to the public by telecommunication or on the Internet, loan, distribute and sell theses worldwide, for commercial or noncommercial purposes, in microform, paper, electronic and/or any other formats.

The author retains copyright ownership and moral rights in this thesis. Neither the thesis nor substantial extracts from it may be printed or otherwise reproduced without the author's permission.
Bibliothèque et

Archives Canada

Direction du

Patrimoine de l'édition

395, rue Wellington

Ottawa ON K1A ON4

Canada
Your file Votre référence

ISBN: 978-0-494-71684-7

Our file Notre référence

ISBN: 978-0-494-71684-7
In compliance with the Canadian Privacy Act some supporting forms may have been removed from this thesis.

While these forms may be included in the document page count, their removal does not represent any loss of content from the thesis.
AVIS:

L'auteur a accordé une licence non exclusive permettant à la Bibliothèque et Archives Canada de reproduire, publier, archiver, sauvegarder, conserver, transmettre au public par télécommunication ou par l'Internet, prêter, distribuer et vendre des thèses partout dans le monde, à des fins commerciales ou autres, sur support microforme, papier, électronique et/ou autres formats.

L'auteur conserve la propriété du droit d'auteur et des droits moraux qui protège cette thèse. $\mathrm{Ni}$ la thèse ni des extraits substantiels de celle-ci ne doivent être imprimés ou autrement reproduits sans son autorisation.

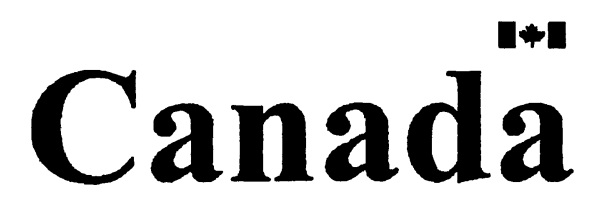

Conformément à la loi canadienne sur la protection de la vie privée, quelques formulaires secondaires ont été enlevés de cette thèse.

Bien que ces formulaires aient inclus dans la pagination, il n'y aura aucun contenu manquant. 


\begin{abstract}
This thesis examines the formation of Brazil's welfare state through the lens of 'race'. Chapter 1 explains the persistence of white supremacy during a period of intense social upheaval by examining how elite attitudes regarding 'race' from the late $19^{\text {th }}$ century to World War II became infused into the discourse of the nation, and ultimately became part of national culture. It concludes by linking the relationship between national identity discourse and state power to the operation of citizenship. Chapter 2 demonstrates how national identity discourse and racial ideology translate into citizenship and welfare rights through the experience of Afro-Brazilian and indigenous peoples. Chapter 3 is concerned with the exclusion of 'race' from dominant accounts of the Brazilian welfare state, exemplified by the developmentalist variant, and the significance of this exclusion. The conclusion notes the challenges in eliminating white supremacy entrenched through racial democracy, despite some limited shifts since re-democratization.
\end{abstract}




\section{Acknowledgements}

Theses are collective works at all stages of the project, and this is no different. While I owe far too much to too many people to do them all justice in this short page, a few warrant special consideration. Alejandra Bronfman, Sonya Lipsett-Rivera, Rianne Mahon and Wallace Clement are all owed great thanks for providing feedback on related, though considerably different, earlier papers. Their comments kept my passion piqued while helping me hone the project into its present form. I would also like to acknowledge the countless discussions I've had with friends and colleagues over the last four years that, in one way or another, impacted my thought process in formulating, reformulating and transforming this project.

Great thanks is owed to my supervisor, Daiva Stasiulis, who got me organized and focused when I especially needed it, and also asked difficult questions when they had to be asked. Considerable input from my internal committee member, Wallace Clement, was also a great help for me in situating the project within larger disciplinary paradigms. Cristina Rojas, the external examiner who I've now had the pleasure of working with in multiple capacities, asked pointed questions in a constructive and encouraging way. The entire committee was engaged and dedicated - two traits that make all the difference.

I owe thanks to my entire family for all of their continued support. Special mention is due to the outgoing members, and the incoming ones on both sides of my family, the former who have contributed so much to who I am, and the latter who will undoubtedly contribute to who I'll become. Knowing I can count on them in difficult times is a heartwarming relief.

Finally, my partner Yumi is owed the biggest thanks for her unwavering love and support. While we both have struggled recently, it was a great pleasure to do it together, and I look forward to more as we start the next stage of our life journey together.

To all, and to all those that I've missed here - thank you. 


\section{Table of Contents}

Introduction 1

Cutting Across Regimes: The Political Context of Brazil's History 5

$\begin{array}{lr}\text { The Developmentalist State } & \mathbf{8}\end{array}$

Categories of Analysis $\quad \mathbf{1 0}$

Complexities within Complex Categories $\quad \mathbf{1 5}$

$\begin{array}{lr}\text { Thesis Outline } & 18\end{array}$

Chapter 1: The Persistence of White Supremacy: Racial Ideology and Brasilidade, 1870-

1945

Between Culture and 'Race': the Roots of Brasilidade in Context 24

Simmering in Society: Racism from Colony to Empire $\mathbf{2 8}$

Grappling with European Racial Views: The Rise of Scientific Racism 33

The Reverse Prism: Whitening to Racial Democracy 39

Traversing Discursive Fields: Racial Ideology and State Machinery $\quad \mathbf{4 6}$

Discourse and Citizenship in a Racial Democracy $\mathbf{5 2}$

Chapter 2: Citizenship and Welfare Stratification in a Racial Democracy: 1870-1950 55

Citizenship as National Identity, Rights, and Welfare $\quad \mathbf{5 6}$

Brazilian Citizenship: Janus-Faced Rights 5

Deflective Democracy: Erasing 'Race' from Citizenship and Welfare $\quad \mathbf{7 0}$

The Birth of the Brazilian Welfare State under Vargas 78

Discourse over Rights, Law over Practice: Racial Democracy and Segmented

$\begin{array}{ll}\text { Citizenship } & \mathbf{8 3}\end{array}$

Chapter 3: The Historical Foundations of the Brazilian Welfare State: Rereading

Traditional Accounts $\quad 86$

What Kind of Stratification? Welfare States and Identity Categories $\quad \mathbf{8 8}$

The BDWS: Locating the Source of the Contradiction 91

Towards Decommodification: Why Exclude 'Race'? 97

'Developing' the BDWS $\quad 101$

Conclusion: New Paths, New Promises, Persistent Realities 103

Appendix 1: Schematic of Substantive Citizenship in Brazil, 1870-1950 110

References $\quad 111$ 


\section{Introduction:}

In the last three decades, the literature on the welfare state has grown in both breadth and complexity. The inclusion of new analytic foci to a body of work that had traditionally emphasized expenditure levels, administrative features, and policy history has broadened contemporary understanding of the processes of welfare state formation and its operation. If the 1970 s and 1980 s initiated this trajectory with the labor politics boom introduced through Power Resources Theory (see O'Connor and Olsen 1998) and the 1980s and 1990s responded with the gender boom driven by feminist theory (see Orloff and Pallier 2009), then the last fifteen years has witnessed the growth in the interest of 'race' as a key stratifying element embedded in the logic of certain welfare states. Yet this latter growth has hardly been ubiquitous or integrated into existing approaches to the study of the welfare state in a seamless fashion. Rather, it has been

taken up unevenly, with the bulk of the attention initially geared toward Great Britain and the United States. Part of the reason for this has been the emphasis on historical factors contributing to the salience of 'race' in these countries. Both the United States and Britain were major actors in the slave trade, with the United States receiving a large percentage of slaves, and Britain's imperial dominance throughout the eighteenth and nineteenth centuries led many in their colonial holdings to eventually migrate to the metropole in the twentieth century. Yet what of other countries of the Americas, whose predominantly white elite struggled to manage the systems of inequality engendered first by colonialism and slavery, then by nation-building and capitalism? 
Brazil was, in fact, the largest recipient of slaves during the slave trade ${ }^{1}$, and European settlers encountered a sizeable, if dispersed, indigenous population before disease and exploitation decimated their numbers ${ }^{2}$ (Egerton et al. 2007: 203). Brazil, however, has largely been excluded from the above expansion of the welfare studies literature, along with most other Latin American states, due to a different set of historical circumstances. As a perennially 'less-developed' country, Brazil has been relegated to a circle of welfare studies that has magnified the developmental aspects of the state and economy as overriding features of state-society relations. Consequently, less attention has gone towards applying the analytic developments of recent generations to studies of the Brazilian welfare state. This is not to say that no work has been conducted on gender, 'race', and class in relation to different aspects of Brazilian social policy. Considerable research, especially on the myriad manifestations of racial discrimination, has emerged since the late 1980s, most notably in the fields of history and sociology (see Lovell 1994. 1997, 2001). However, usually studies of 'race' have not engaged directly with the discourse of welfare studies, and welfare studies, until recently, have not engaged with the discourse of 'race' in Brazil. Instead, the predominant narratives of the Brazilian welfare state have emphasized the patrimonial character of economic development and class placation that characterized the corporatist orientation of the state. While this frame of reference has been incredibly insightful, it has largely excluded one of the defining

\footnotetext{
${ }^{1}$ Herbert S. Klein estimates 4.8 million that arrived in Brazil alone out of a total estimate of 10.7 million ${ }^{2}$ While figures of the indigenous population are dubious prior to the 1872 census, there were likely a few million who lived throughout modern day Brazil, with the Tupi occupying much of coastal Brazil, the Guarani in the southern part of the country, and the Tapuia - a term denoting diverse peoples distinct from the Tupi - interspersed along the coast (Fausto 1999: 7; see Denevan 1992: 205 for a review of the estimates)
} 
features of Brazilian social relations since conquest - 'race' - and the way it has been enacted in discourse and practice.

This thesis aims to engage this relative gap in the literature by exploring the historical implications of Brazilian 'race' thinking on the formation of the Brazilian welfare state, as it arose during the tenure of Getúlio Vargas (1930-1945; 1950-54). In the last twenty years, the explosion in interest and study around the discursive strategies employed by Vargas' administration as they relate to national identity discourse has provided fertile ground for scholars seeking to better understand the way political elites, interacting with the machinery of the state and with the support of economic and cultural elites, have shaped social institutions in ways that have suited their own ends (see e.g.: Williams 2001; McCann 2004; Davis 1999). Yet the extension of this approach to studies of the formation of the welfare state, along with the explicit emphasis on 'race' as a key analytic category influencing the negotiation of social policy has been far sparser. As a defining feature of Brazilian social life however, both historically as well as in the present, 'race' has worked itself into all aspects of social relations, especially those between agents of the state and its constituents (cf Hall 1996: 411-41). This thesis is particularly concerned with the meta-project undertaken by the political elite of the Vargas era - namely the actualization of a coherent national identity discourse that filtered into the contestation over citizenship, and concomitantly, access to the welfare regime. Hence, rather than conducting detailed analyses of individual social policies, the overall policy framework of the Brazilian welfare state is considered.

This thesis ultimately asks what is lost when studies of the formation of the Brazilian welfare state exclude 'race' as an important analytical category. Given the 
historical significance of Brazil as a settler society and the largest recipient of African slaves, as well as its role as a major source of both European and Asian immigration in the $19^{\text {th }}$ and $20^{\text {th }}$ centuries, Brazil has come to occupy the role of the quintessential multicultural society in the popular imaginary. This has been abetted by proclamations of racial equality by state officials at least since the Vargas era, when the notion of 'racial democracy' was formulated from the ideas of various Brazilian intellectuals reconciling the position of their nation in relation to other nations in the international arena. The Vargas administration eagerly consumed the works of these intellectuals - chief among them the transformative sociologist Gilberto Freyre - to construct an image of Brazil as harmonious, inclusive, egalitarian, and above all, free of racism. Yet this version of Brazil masked the continuation of white supremacy bequeathed by scientific racism in the late nineteenth century, forming a powerful myth that deflected both domestic criticisms of structural racism, and foreign complaints that Brazil was not 'modernizing'. The myth failed to persist unchallenged, however, as cracks began to splinter this racial ideology with the groundbreaking UNESCO-sponsored studies of the 1950s. As more and more domestic and foreign scholars demonstrated through the 1980s and 1990s that racism existed rather virulently in the country and 'race' was in fact a key stratifying element in access to social resources, the myth was shattered. Yet it continued to play an important role in state discourse and in the minds of many Brazilians and foreigners alike until at least early in the $21^{\text {st }}$ century.

The myth of racial democracy erased 'race' from determinations of substantive equality in Brazilian social discourse, even while it continued to be a critical stratifying marker through the welfare state. This thesis examines both the insertion of racial 
democracy into Brazil's national identity discourse and the consequences this had for citizenship (Chapter 1), as well as the practice of white supremacy that persisted unchallenged as evidenced through welfare stratification (Chapter 2). This task cuts across a large historical period and distinct political regime types to follow the persistent relationship between national identity discourse, citizenship, and the racialized welfare stratification as Brazil's welfare state was being formed.

\section{Cutting Across Regimes: the Political Context of Brazil's History}

Brazil's political history is as rich and complex as its social history. While Pedro Álvares Cabral first located the coast of modern-day Brazil from the Portuguese vantage point in 1500 , settlement was sparse until about the 1530 s. Fifteen land grants, or donatários, were given to twelve noblemen with good court connections as a hedge against French incursion in the local economy, and each captain was expected to "colonize and defend his captaincy in return for a number of revenues, the right to grant land and name numerous officials, and jurisdiction in most criminal and civilian matters" (Burkholder and Johnson 2001: 89). Over time, as the focus of the Portuguese Crown moved from Asia and Africa to its South American holding, it began centralizing and asserting its control more systematically. Successive booms in sugar and gold captured the attention of the Portuguese court, and made Brazil one of the most lucrative colonies of the Americas. Hence, when in 1807 Napoleon invaded Portugal, the Bragança family (the ruling family of Portugal from 1640 to 1910) opted for Brazil as their home in exile.

This unprecedented move, involving the transfer of some ten to fifteen thousand administrative, military and ecclesiastic officials, along with the royal treasury and official records, to Rio de Janeiro laid the foundation for the only true empire of the 
Americas, when the son of John VI, Dom Pedro I, declared independence from Portugal and proclaimed himself emperor in $1822^{3}$ (Burkholder and Johnson 2001: 309, 327-9). When Pedro I abdicated his throne in the wake of a series of financial and political crises after less than ten years of rule, Pedro II assumed the throne, first as a five year old regent, and later as a world renowned Emperor whose reign lasted more than a half-century. Under the rule of Dom Pedro II, the political elite centralized their authority, and enacted a heavily Enlightenment-influenced domestic policy that included patronage for the arts and sciences. Even though his popularity remained high, agitation for change boiled over during the 1880 s, culminating in a republican coup in 1889 that saw the Emperor and his family leave for Portugal (Skidmore and Smith 1989: 141-148).

The ensuing republican regime, which lasted until 1930, saw consecutive economic and political crises, including general strikes in Brazil's largest cities, food price speculation, and outright rebellion. The Old Republic emphasized decentralization, and catered to particular economic interests - namely coffee and dairy - that dominated the Southern part of the country. Formal politics were controlled through coronelismo, a system of patron-client relationships that effectively secured authority in the hands of local landowners (Topik 1987). With the repressive arm of the state the primary form of policy intervention in the life of the masses, labor unrest intensified and Communistinspired revolts by junior military officers became features of the political landscape of the 1920 s, greatly contributing to the impetus for change embodied by Getúlio Vargas and his 1930 revolution (Dulles 1973; Wirth 1964).

\footnotetext{
${ }^{3}$ Mexico had two brief experiences with Empire, once in 1822, and later with the French-supported proclamation of Maximilian I, who reigned from 1864 to 1867 before being executed by the followers of Benito Juarez (Eakin 2007: 192, 224).
} 
This brief political history outlines the complexity of regime types exemplified throughout Brazil's history - first decentralized then centralized colonial administration, later a heavily executive-centralized, positivist and liberal-inflected constitutional monarchy, then a comparatively decentralized oligarchic republicanism with a liberal veneer, and leading into the populist coup of the Vargas rebellion (1930-37). This plethora of political regimes underpinned by a mixture of ideologies is to some extent captured in its entire gamut during Vargas' tenure, which included a coalition-supported provisional presidency (1930-4), a constitutionally-supported President elected by parliament (1934-7), an authoritarian corporatism with the declaration of the Estado Novo (1937-1945) and finally, a democratic populism when Vargas reemerged on the political scene (1950-1954). The variance of these postcolonial regimes ${ }^{4}$ reveals a predisposition of the elite to an eclectic array of ideological and state forms, but also the comparative flexibility of the state apparatus to adapt to new regimes. Hence, we see a vibrant political culture assimilating divergent ideas in conjunction with both the desire and ability to actualize them institutionally as a result of the exile of the Portuguese monarchy to Rio de Janeiro 5 . This thesis focuses on the late Imperial period $(\sim 1870)$ through the Old Republican period to the Vargas regime, which is ultimately the end point of this analysis. Hence it traces the relationship of the political elite under different administrations and under different regime types to broader intellectual currents as constructed primarily by the cultural elite (academics, cultural and literary critics), and to a lesser extent, the economic elite (planters and capitalists), and how these ideational

\footnotetext{
${ }^{4}$ Including distinct stages of what Guillermo O'Donnell has dubbed "bureaucratic authoritarianism" dominated by the military when they seized power from 1964 to 1985 (1973). This thesis, however, does not cover the post-Vargas era.

${ }^{5}$ For more on this complex ideological backdrop, see Bethell (1996: esp. pp. 3-205).
} 
currents were subsequently transformed into state practice. And yet, where scholars who focus only on the politics and regime-types driving the formation of the Brazilian welfare state see a chaotic flourish of diverse ideas divided by various administrative forms, this thesis traces the continuity, or persistence, of the guiding ideological principle of white supremacy across different regimes. This substratum of brasilidade, or Brazilian national identity, which swirls below fleeting bureaucracies, offers a complementary perspective to mainstream approaches to the creation of Brazil's welfare state under Vargas.

\section{The Developmentalist State}

Studies of the Brazilian welfare state have been slow to incorporate 'race' as an important variable in their accounts of its emergence. For the most part, scholars have focused on the most overt features of the formation of social policy under Vargas namely patrimonialism, corporatism, developmentalism, and a watery liberalism that served as a prevailing aspiration rather than an active ideological commitment in the legislative attempts of the state. Elisa P. Reis, for example, points to an "ideological compound involving nationalism, statism, and developmentalism" as the hegemonic force shaping most of twentieth century Brazilian social life (2000: 190). In this formulation, Vargas derided individualism and upheld the notion of an "organic statism" that blended the divergent concerns of citizens into a 'compromise' overarched by the authority of state aimed along a linear developmental telos. This classic form of corporatism was overlaid by vivid populist attempts at incorporating the masses through welfare programs that targeted certain occupational classes in the urban labor market (2000: 173-4). Moreover, inherited from the Republicans, Vargas embraced the formal universalism of liberalism through the law, though this was hardly more than a token 
gesture. Robert Levine, while not studying the welfare state per se, upholds this portrait of the hybrid state strategy in his seminal work on Vargas. He identifies three distinct periods that span Vargas' nineteen-year tenure: a broad-based populism with the 1930 Liberal Alliance platform that ran until Vargas committed a coup against himself and declared the Estado Novo in 1937; a heavily corporatist period that lasted until Vargas was deposed in 1945; and what Levine calls an "authentic populism" characterized by calls for democracy with his 1950 election (1999: 9).

Sônia Draibe, whose mature account of the history of the Brazilian welfare regime is treated in detail in Chapter 3 , similarly points to these predominantly political economic features. Draibe emphasizes the absorption of national labor unions to the purview of the state, the social security system, a national minimum wage, and certain labor regulations as critical to the emergence of Brazil's welfare regime, which she characterizes as 'developmentalist' owing to the strong degree of state intervention in the overall orientation of the economy. Here, the agitation of the urban working class in the late 1910s and 1920s served as the impetus for Vargas' social policy interventions, while the comparatively decentralized political structure of the Old Republic (1889-1930) urged him to seize more direct control over the state apparatus (Draibe 2007). This political centralization was mingled with the justificatory ideology of nationalism, which Draibe argues formed the framework for the inauguration of limited but clearly identifiable social rights.

As Chapter 3 argues, this thesis is not interested in challenging these narratives of the development of Brazil's welfare state. They reflect accurate yet partial readings of a tumultuous period of social, political and economic change that spanned the first four 
decades of the twentieth century. Yet the focus on the most overt aspects of political change enabling the formation of a new welfare state obscures the persistence of other ideological processes underlying them, at the substratum of Brazilian society. As Chapter 1 will demonstrate, Brazilian political elites, in conjunction with intellectuals in the academic and cultural spheres, and in dialogue with European thinkers of 'race' and national identity, struggled to maintain the practice of white supremacy that had existed since early colonial rule while negotiating between a variety of competing racial ideologies. The dramatic shift in the state structure that marks the Vargas years coincides with the institutionalization of the 'victor' of this long-term contestation - the ideology of racial democracy - represented through the work of Gilberto Freyre. Unlike developmentalist approaches to the welfare state, this thesis considers the creation of the myth of racial democracy as a primary rather than tangential justificatory force guiding state practice, ultimately enabling Vargas government officials to deflect domestic criticisms of unequal actualization of citizenship, as well as foreign accusations that Brazil was failing to keep up with modernity by continuing to uphold $19^{\text {th }}$ century racial orders - all while maintaining the structure of white supremacy in place. Accentuating this category of analysis - racial ideology - as an illuminating force structuring the policy context offers a vivid complement to traditional readings, and also helps to explain the persistence of racialized inequality in Brazil today (see e.g.: Telles 2004, and the Conclusion).

\section{Categories of Analysis}

This project is informed by Fiona Williams' seminal 1995 article "Race/Ethnicity, Gender and Class in Welfare States: A Framework for Comparative Analysis". Writing in 
part about the need for a historical-discursive approach to welfare states, she notes the limitations of typological constructions in helping to explain the full expression of the relationship between the construction of the nation and the basis for inclusion in, or exclusion from the fruits of it, namely the rights associated with citizenship. Heuristic constructions such as Castles and Miller's citizenship and immigration models (1993), Esping-Andersen's three worlds of welfare (1990) - or the developmentalist approach to the Brazilian welfare state - are insightful, but they "tell us little about the citizenship rights of indigenous, minority, or racialized groups" (Williams 1995: 144). In order to "fill the gap in the social policy literature", she argues, a broader range of analytic criteria need to be emphasized, especially if we want to get at the "complexity of social divisions that have a bearing on people's lives" and the "social relations of power that emerge from these divisions" (1995: 127-8). In particular, she calls for a thorough intersectional analysis that engages 'race', class, and gender through the interrelated dynamics of "family, work, and nation" in the actualization of welfare settlements, drawing attention to the discursive formulation of these categories alongside the ways they are enacted in practice, and the ways social movement mobilization and contestation develops around these discourses (1995: 149).

This thesis draws inspiration from Williams' work, rather than attempts to put her framework into practice in a systematic and faithful manner. In the first case, it is not a comparative study, although it tacitly lays the foundation for future comparative work by linking the struggles of Brazilian elites in crafting their own national identity, citizenship and welfare regimes to European (and later American) intellectuals - a relationship that is certainly mirrored by other postcolonial or peripheral states engaged in the production 
(and reproduction) of global racial formations (see Conclusion). Second, while limited reference is made to the contestation of Brazil's racial ideologies by nascent social movements and the masses more generally, this thesis is primarily concerned with how the elite grappled with the relationship between 'race' and nation, how this relationship was used to facilitate segmented experiences of citizenship, and how this was ultimately embodied in the construction of the nation's welfare state ${ }^{6}$. While the tradition of social history has bequeathed the recognition of the importance of the everyday to all social science and humanities disciplines - an incredibly important aspect of historiography for students of the welfare state - this thesis is directly concerned with the discursive environment of Brazilian elites ${ }^{7}$. Third, this thesis does not conduct intersectional analysis, though by necessity it hews close to class and gender identities in its exposition of 'race'. As Fiona Williams points out, "in general, class, gender, and race can be seen as the most salient divisions in twentieth-century industrialized societies, but their constitution and significance vary" (1995: 128). In Brazil, all three have been integral categories of importance, both in the discursive negotiation of social policy, as well as in the substantive distribution of social resources. Yet as Chapters 1 and 2 demonstrate, Brazil's demographic realities created the discursive space, when European thinkers constructed it as a problem, in which the racial composition of the population took center stage in addressing the anxiety of the political elite over the future prospects of their nation.

\footnotetext{
${ }^{6}$ However, contestation between different elites is something taken up in considerable detail in Chapter 1 . ${ }^{7}$ An approach that may be returning as the general awareness of the limitations of the linguistic turn in cultural history gives way to idealist-materialist syntheses in historical studies (see e.g.: Iggers et al. 2008; Iggers 2005).
} 
This final point deserves more detailed attention. Both class and gender have played incredibly important roles as key elements of social relations since colonial settlement in Brazil. The drastically uneven distribution of wealth created by the donatários provided the original framework for the massive class inequality that still plagues Brazil today. The uneven gender distribution of European immigrants, both through the colonial period, and in the late nineteenth and early twentieth century immigration booms helped to solidify the regime of patriarchy already present in the cultural heritage of early Iberian settlers. And indeed, both of these early facts helped constitute the experience of nonwhites in Brazil. Huge tracts of land with little settlement required laborers to render it 'productive' which meant the importation of slaves and the exploitation of the indigenous population. The low proportion of white women to men during the colonial period meant that indigenous and African women were frequently subjected to violent acts of rape - a factor that Freyre cites as a formative element in the creation of Brazil's 'racial democracy' (1963a; 1963b). Indeed, because of the close linkages between these three central identity categories in Brazil, focusing on stratification in one often reveals it in the others. As Chapter 2 discusses, Jerry Dávila demonstrates how Afro-Brazilian women occupied the bottom rungs of society when it came to literacy (and much else) during the Vargas era (2003: 73). And yet, black (preto) and brown (pardo) women in the Federal District (Rio de Janeiro) experienced higher rates of literacy than either white men or women in Bahia - a sign that the class position conferred by geographical proximity to the sources of welfare privileges (the urban industrial labor market) trumped either 'race' or gender in this case. However, within that locus, the main groups excluded from the welfare programs mandated by the state were 
domestic servants and workers in the informal labor market -dominated by nonwhite women foremost, as well as nonwhite men.

This thesis emphasizes 'race' as the key analytic category underlying the formation of Brazil's welfare state, not to elevate it above class and gender, but rather as an important heuristic contribution to the heavily class-oriented focus of the developmentalist approach. This is done primarily for reasons of analytic clarity and scope, although in dismantling the ideology of racial democracy, this thesis attempts to bring 'race' back in where it had been erased and supplanted by class (see Chapter 2). Susan K. Besse, in her outstanding study of changing gender ideologies in Brazil in the interwar period takes a similar approach: while stressing the important ways women of different class positions experienced the restructuring of patriarchy, she focuses on the urban middle and upper class women who played important roles in contesting the technocratic attempts to redefine it while maintaining the system of gender inequality. While avoiding discussion on how the exclusion of working class women from the heights of power was also highly racialized, her study creates insight into the processes of exclusion that cut across gender and 'race' - strikingly similar processes to those that this thesis documents (1996: 201-202). Thus, while this thesis does not pursue gender as a central analytic category, it does shed some insight into the multiple axes of stratification along which welfare was distributed. The tandem insights of gender and racial welfare stratification ultimately need to be pursued in conjunction with the class-oriented literature of the formation of the Brazilian welfare state. 


\section{Complexities within Complex Categories}

Dismantling the lived experience of people into the three categories of 'race', class and gender - as complex as this is in itself - is further challenged by the immense differences within these categories. Gender is not an essential binary category, but a spectrum of identities that differ in time and place, and from person to person. The vast literature on class demonstrates the nuances of experiences based on class position, reflected in the widely divergent methods of measuring it. So too with 'race', a socially constructed but incredibly meaningful category for people's lives - both in the importance people give it in their own lives, and as an external constraint imposed by others (Outlaw 1991). In Brazil, the complexity of 'race', as a situational-dependent, color-based construct is strikingly clear. In 1976, IBGE, the Brazilian census-taking organization responded to complaints that the official census categories of white (branco), black (preto), brown (pardo), Indigenous (indígena), and Asian (amarelo) were too rigid by soliciting the self-identification of respondents. The result was 134 categories capturing minute differences in skin pigmentation, facial features and hair color! (IBGE 1999: 386-390) The impossibility of accounting for this dramatic spectrum is handled by simplifying in this thesis, following the conventions of both census-takers and most sociologists and historians studying 'race' and color in Brazil (see Telles 2004: 21-3). Such simplification allows for the demonstration of the broad strokes of Brazil's racial ideology and its historical genealogy that more complex expressions of the color continuum make difficult. Moreover, as Chapter 1 explores, G. Reginald Daniel points to elite fascination with the ternary racial project along the white-mulatto-black continuum, 
although indigenous peoples formed an equally important discursive construction elites engaged with in the late Imperial period (2008: 27-9; 35-6).

In terms of demographics, estimates of the nonwhite population are themselves complicated by Brazil's racial ideology. The 1890 census, the first after the full abolition of slavery (1888), counted 2.09 million blacks (pretos), 4.63 million of mixed parentage $\left(\operatorname{pardos}^{8}\right)$, and 1.29 million indigenous, or of indigenous descent (caboclos) out of a total population of 14.3 million, or approximately $56 \%$ of the population (Directoria Geral de Estatistica 1898: 2-3). The census did not account for 'race' again until 1940 (see Chapter 1), however, as a result of significant immigration from Europe and Asia during this time, the proportional composition changed significantly. The census reported 6.03 million pretos, 8.74 million pardos (which now included any response that was not 'white', 'black', or 'yellow') and nearly 250,000 amarelos (Asian) out of a total population of 41.2 million, or $36 \%$ of the population (IBGE 1950: 6). These census numbers should be taken cautiously however, since Brazil's racial politics overlay everything that IBGE was involved in (see Nobles 2000: 98-106). Geographically, the populations are distributed throughout the country, however as noted in Chapter 2, the Northeast has larger concentrations of nonwhites, while the Southeast received the bulk of European immigration. Brazil is now a predominantly urban society (over $80 \%$ urbanity), however, even today, best estimates for the number of indigenous Brazilians living in urban centers is about 100,000 , or approximately a fifth of the total indigenous population (see Oliveira 2001). Since most of Brazil's urbanization occurred in the post-war era, in discussion of the indigenous population, specifically in their relation to the state agency SPI, this thesis refers to reserve and rural populations.

\footnotetext{
${ }^{8}$ This census used the term mestiço.
} 
Brazil also become home to a variety of non-African and non-Portuguese immigrant peoples over the course of the $19^{\text {th }}$ and $20^{\text {th }}$ centuries, including large proportions of Italians, Spaniards, Germans, Japanese, and Lebanese. While Chapter 2 discusses the preferential treatment granted to the European migrant populations in the early twentieth-century urban labor market, this thesis does not generally engage with immigrant populations (except at the end of Chapter 1). This is done in part because a different set of dynamics are involved when dealing with 'voluntary' migrant populations - their interiority to national identity and thus citizenship (even when legally held) was something that was continually called into question ${ }^{9}$. By contrast, although former slaves and indigenous groups discomforted the Brazilian elite in terms of their substantive equality in society, their formal inclusion as citizens was something that was rarely questioned, and more frequently lauded by elites, especially with the emergence of the ideology of racial democracy. Hence, the focus on indigenous and Afro-Brazilians indeed leaves out critical aspects of the complete process of segmented citizenship along racialized lines, yet helps to hone in on the logic of white supremacy that, especially during Vargas' xenophobic rule, might appear to be driven by other factors than 'race', such as national identity. Since the primary goal of this thesis is to show how national identity discourse was itself racialized, and how this structured the operation of social institutions involved in the determination of substantive equality, more recent migrant populations are excluded from the analysis.

Finally, a point on terminology is important. While this thesis follows the conventions used by other authors, it often refers to 'nonwhites' to make more general

\footnotetext{
${ }^{9}$ See Jeffrey Lesser's excellent book Negotiating National Identity, which looks at non-European migrant groups and their struggle for inclusion in Brazilian society (1999).
} 
points reflecting the differences between whites and all else. At other times, where stylistically possible, the term 'racialized' is used primarily to account for the active processes of negotiated social relations that are fixed by the term 'race' (Miles 2000: 13641; Satzewich 2000$)^{10}$. Frequently, when referring to descendants of Africans, this thesis uses the term Afro-Brazilian in deference to the black movement (see Telles 2004: 22), whereas the term indigenous is used instead of Indian or Amerindian (the former is common in the literature), for reasons of descriptive accuracy. This agglomeration of indigenous peoples and Afro-Brazilians, as well as mulattos, under the rubric of 'nonwhite' can be a problematic one in some cases. However, throughout the thesis, attention is paid to the different policy context, circumstances, and logics that each group encounters in their interactions with the state. Generally, the terms 'nonwhite' or 'racialized' are used only when highlighting the more general similarities of each group's experience vis-à-vis white Brazilians and the state ${ }^{11}$.

\section{Thesis Outline}

Chapter 1 focuses on the persistence of white supremacy during a period of intense social upheaval by examining how elite attitudes regarding 'race' from the late $19^{\text {th }}$ century to World War II became infused into the discourse of the nation, and ultimately a part of national culture. Responding to changing racial ideologies emanating

\footnotetext{
${ }^{10}$ Throughout the thesis, scare quotes are used for 'race' to remind the reader of this fact, as even in some quarters of the social sciences it continues to be treated as a reified category. Although the focus of this thesis is on nonwhite stratification in Brazilian welfare, whites are not exempt from racial identities, despite a common framing of whiteness as neutral or invisible. This has largely arisen out of the hegemonic status of whites throughout the world, as the whiteness literature has unpacked (see e.g.: Baum 2006). This thesis acknowledges whiteness as a real racial identity through consistent discussion of white supremacy, even if the term 'racialized' is largely used to refer to nonwhites.

${ }^{11}$ Gail Triner, in calling for studies of 'race' in the aggregate, argues for fewer distinctions - of immigrant vs. Afro-Brazilian, of 'ethnicity', of cultural and phenotypical elements vs. biological, etc. This, she argues, helps "enhance our understanding of what it means to be white in Brazil" (2005: 13). While this thesis defines more determinate boundaries than Triner would like to see, it takes her call to heart in attempting to tease out the logic of white supremacy as it was enacted by elites through the interrelationship of national identity discourse, citizenship and the welfare state.
} 
from Europe, Brazilian elites creatively and cautiously managed them in the formation of a national identity that both enabled their own capacity at home, and sought to appeal to their European interlocutors. This attempt to match European notions of modernity ultimately led intellectuals to the erasure of racism from national identity discourse as it became increasingly challenged by the early twentieth century, and this process was actively encouraged and absorbed by a state that, through the centralizing regime of Getúlio Vargas, was reasserting its power in Brazilian society. The chapter concludes by linking the relationship between national identity discourse and state power to the operation of citizenship in practice: with the ascension of racial democracy, nonwhites found they had limited ability to decry the uneven manner in which the distribution of social resources was occurring.

Chapter 2 continues this thread by emphasizing the experience of nonwhites in the political economy of Brazil by looking at their access to state resources, and to a lesser extent, their experience in the labor market. It first conceptualizes citizenship not in terms of its legal construction, but as a substantive negotiation over rights to welfare embodied through discourses of national identity in greater detail before turning to this dualsidedness of Brazil's citizenship in greater detail. The circumvention of the law - even while it served as an important reference point - in the adjudication of the rights of citizenship is unpacked historically from the Imperial period through the Old Republic, when state welfare policies were systematically initiated for the first time. Next, the chapter turns to the consolidation of racial democracy under Vargas and deconstructs his relationship with nonwhite Brazilians by demonstrating how his rhetoric was belied by his actions. Finally, the chapter concludes with an account of the introduction of 
systematic welfare policies assembled to form the welfare state and how this long process further excluded nonwhite Brazilians from access to the majority of programs and changes to the operation of the state that Vargas was implementing.

Chapter 3 is concerned with the exclusion of 'race' from dominant accounts of the Brazilian welfare state, exemplified here by the developmentalist variant, and the significance of this exclusion. After a brief review of key trends in welfare studies in general, the developmentalist account of Brazilian welfare state formation is considered in some detail. Next, the chapter turns to the consequences of excluding 'race' from accounts of welfare state formation and argues for the complementary inclusion of racial stratification to the developmentalist account in order to capture the complexity of welfare stratification in Brazil.

The conclusion briefly notes the difficulties in producing substantive change to the persistence of white supremacy entrenched through racial democracy, despite limited shifts since re-democratization in the late 1980s. In summarizing the main argument, the conclusion notes a few areas that need closer attention, emphasizing idea transfers between seldom compared, but similarly situated countries in the postcolonial order. Such comparisons, it is argued, are likely to reveal the inner-workings of global racial formations in greater detail, which in turn could yield new insights for nation-based studies. Ultimately, critical scholarly work on the welfare state should help to erase the divergence between formal guarantees and substantive reality, and studies of racial inequality are a key area in which developments need to continue to occur. 


\section{Chapter 1: The Persistence of White Supremacy: Racial Ideology and Brasilidade, 1870-1945}

All we are good for is carnival, football, and making love - Pelé (quoted in Gunther 1966: 69)

Scholarly approaches to national identity discourse may have moved beyond the circulation of basal stereotypes, such as those suggested in the quote above, in their interrogation of the smoky sentimentality that binds people together. Yet it is exactly the quality of smoke - not so concrete as to exert an intractable pull on the individual, but simultaneously so definitive that it becomes inescapable - that explains the persistence of these shorthand signifiers in capturing the complexity of a social formation such as Brazil. Persistence itself, however, is not a homogenous phenomenon, uncontested and contiguous, but rather one negotiated through processes of reconstitution and even rupture (Adelman 1999: 1-13). Like smoke, national identity discourse swirls and dances in the hands of its various promulgators. It changes form in response to social and intellectual currents, and fractures when force - ideological or otherwise - is applied to it. Yet it still persists, never truly transmutating into something wholly different. Hence, when Pelé was appointed the first Minister of Sport under the regime of Fernando Henrique Cardoso in 1994 and sought to challenge the endemic corruption in the nation's sports industry by instituting neoliberal reforms aimed at enlarging the role of the private sector and imposing national policy guidelines for the sector, he transformed what football meant within the national patrimony and imagination without destroying the trope itself (Aidar et al. 2004: 255-7). In the process, Pelé demonstrated his own personal aptitude, as well as that of the ambitious new government, at challenging the resignation implicit in his earlier statement. No longer would Brazil remain beholden to this resignation, but through the exercise of state power, redefine the terms under which it 
was earlier defined. Such an act was hardly the first or widest-reaching intervention of the state and its contingent actors in the construction of national identity.

This chapter is concerned with the role that the state plays in facilitating, fomenting and furnishing Brazilian national identity towards a construction that serves the interests of both state power and its principal clients. However, the state does not operate in a vacuum, but draws from and influences a variety of fields as diverse as literary criticism, epidemiology and sociology. Moreover, it expresses itself and incorporates independent expressions that have deeper repercussions than what is simply apparent on the surface. While many popular portrayals of brasilidade produced both within and outside the country have focused on the multitude of cultural aspects that form Brazilian national identity - food, music, literature, and sport for example - it is the assumptions that underpin national culture, and thus national identity, that have been, until recently, less developed. Specifically, this chapter is interested in how shifting racial assumptions circulating around the globe between the nineteenth and twentieth centuries, when assembled into more or less coherent racial ideologies by Brazilian elites, established the bedrock upon which brasilidade was created. Indeed, not only did these ideologies persistently structure the material products of culture and their expressions, they also filtered, and continue to filter, into the whole range of discourse and practices that affect formal and substantive equality in the national context. In short, they integrally form the foundation on which the rights and claims of citizenship are negotiated and contested.

Pelé is not an insignificant insertion point to this discussion since, as the first black cabinet minister in Brazil (in a post specially created for him), his life and career on 
and off the pitch represent an engagement with some of the claims of and claims to equality in the country. Pelé once remarked in a 1980 interview with Playboy that racial discrimination does not exist in Brazilian sport or in social life more generally - only 'social' discrimination (Nascimento da Silva 2001: 255). And indeed, as perhaps the most prominent Brazilian in the latter half of the twentieth century, it appeared that way to him. Yet unmistakable evidence procured by countless scholars especially in the last twenty years suggests that if social discrimination is the only problem in Brazil, it is markedly tinged by questions of color.

Of course, racial ideology in Brazil both outstrips and predates Pelé. Racist beliefs formed the foundation of colonial Brazilian society, and were assembled into coherent ideological packages amenable to state building with independence early in the nineteenth century. Indeed, Brazil's racial ideology only assumed the much celebrated form of 'racial democracy', which this chapter will unpack in detail below, in the last 75 years. While this view has guided the popular eye both in and outside Brazil for many of those subsequent years, a burgeoning literature critical of it has developed, owing its most visible genesis to the UNESCO studies of the 1950s initiated by Florestan Fernandes and Roger Bastide. ${ }^{12}$ What on the surface appears as a paradox - of a national identity that shirks any discussion of documented racism within a lively discussion on color - is actually part of a well articulated historical logic that has persisted despite incredible adaptations from the late nineteenth through the twentieth centuries.

This chapter will unpack this genealogy of racial ideology in Brazil, paying close attention to the continuities of exclusion within the radical transformations it underwent

\footnotetext{
${ }^{12}$ See, for example, Bastide, Roger and Florestan Fernandes. (1955). Relações Raciais entre Negros e Brancos em São Paulo. São Paulo: Anhembi; also, Fernandes, Florestan. (1969). The Negro in Brazilian Society. Trans. Jacqueline D. Skiles et al. New York, NY: Columbia University Press.
} 
from the late-Imperial period ( 1870) to WWII. First, it situates the racial ideology of brasilidade within larger debates over Brazilian national identity, demonstrating how assumptions about 'race' were systematically embedded within influential material products of culture. Next, it unpacks the assumptions behind Brazil's racial ideology taken up into national identity and nationalist discourse from its early roots in scientific racism to the culturalist work and legacy of its most forceful and widely acknowledged proponent, Gilberto Freyre. The work of this eminent sociologist effectively served to suture debate on 'race' in Brazil once it was taken up as state policy by the Vargas regime in the 1930s in the form of racial democracy. Finally, the chapter looks at the power of discourse in facilitating socio-economic exclusion, and attempts to bridge the practice of discourse with its tangible effects: material access to the fruits of societal organization provided through various dimensions of the welfare regime.

\section{Between Culture and 'Race': the Roots of Brasilidade in Context}

Explorations and expositions of Brazilian national identity have been perennial endeavors from the late nineteenth century on, for as Ludwig Lauerhass Jr. points out, "a constantly changing social, political, economic, and intellectual background" necessitates constant reappraisal (2006: 1). Though discussions and publications about an independent Brazil emerged at least as early as the Bragança exile in 1808 (see, e.g.: Schultz 2001; Barman 1988), it is predominantly with the advent of republican rule, and the shifting intellectual currents associated with the Age of Nationalism, that vociferous debates and claims to Brazilian national identity were explicated. Indeed, the mass upheaval socially, politically and economically - that abolition brought in 1888 and the transition 
from empire to republic engendered in 1889 created ripe terrain for vigorous debates over what the nascent nation of Brazil was, could and should be.

While many proto- and pro-nationalists concerned themselves with questions of sexuality, progress and development and urbanization via literary media (Kristal and Passos 2006), or of 'civilization', order and political authority via public monuments (Green 2006), none of this was free of racial undertones. Famous literary works, such as José de Alencar's $O$ Guarani, released in 1857, celebrated indigenous collaboration in the nation-building project. However, this celebration served to regulate the image of the ideal Indian through national discourse - that is, to appropriate indigenous tropes for use by white elites and deny the ability for independent cultural expression. As Bradford Burns has pointed out, "beneath the heavy romanticism of O Guarani lies a profound nationalist message: that Brazil is the product of the union of the New World with the Old. But the domination of the values of the Old World was explicit" (Burns 1976: 11-2).

Early silent cinema in Brazil echoed the unequal caboclo fusion of literary circles, to the exclusion of Afro-Brazilian characters and themes. The ever-present image of the 'noble savage' in film reflected elite attitudes that praised the indigenous population as almost European - if, of course, they could renounce their cultural identity, language, and social customs and assimilate into the 'civilized' European way of life. As Robert Stam points out

...Indians were symbolically favored but concretely marginalized...The indigenous peoples were the continuing object of genocidal policies and at the same time the ambiguous (and merely symbolic) beneficiaries not only of the romantic Indianist movement but also of a positivist philosophy that preached a certain 'progressive' tolerance $(1997: 75,78)$

In practice, it was easier for early national elites to marginalize the indigenous population under the auspices of shared contribution to the Brazilian project much in the same way 
that the Portuguese Crown and the Catholic Church exploited indigenous labor under the mantle of religious salvation and the aldeia system (Garfield 2001: 4).

Roger Bastide points to the "tiresome monotony" of black stereotypes that pervade the entire late romantic literary canon. Eager to integrate free blacks into the Brazilian community, discourse shifted from fixed presumptions that blacks had "servile souls" made to "obey and submit", to those that offered limited room for inclusion into Brazilian society. Distinctions were made between two types of blacks: those who were "dedicated [and] affectionate" and "loyal", and those who were "swindlers", shiftily superstitious and animalistic (Bastide 1973: 119-24). Such a shift provided limited inclusion within a national rhetoric that had, up until the late $19^{\text {th }}$ century, been explicitly anti-black. However, it clearly sought to impose constraints upon the identity of black citizens that prevented their full inclusion within a nascent national culture - what loyalty and dedication meant was always subject to reinterpretation, determined by the dominant elites in power.

Many cultural products and their interpretation reflected the colonial fetish that enraptured Brazilian elites from the end of the empire to the beginning of the republic, an obsession with the Other - i.e.: non-European - and the gnawing concern of how to fit them into the national imaginary (see Bhabha 1994). The subtext of so many cultural products engaging with the issue of Brazil as a nation necessarily drew from established assumptions of 'race' being produced and processed by Brazilian academics, politicians, professionals and their counterparts in Europe, often quite explicitly. Graça Aranha's 1902 novel Canaã, for example, grappled with the tenets of pseudo-scientific racism alongside notions of whitening through miscegenation as potential solutions to the 
nation's 'dilemma' through the lens of two German immigrants ${ }^{13}$. Skidmore points out that by using white Europeans as interrogators of Brazil's civilizatory promise, Aranha appealed to Brazilian elite "fascination" with European viewpoints towards the country (1993: 112). Indeed, much of the concern of the Brazilian elite revolved around establishing equal status with the European colonial powers within the concert of nations. As we will see shortly, much of Brazil's racial thinking up until the 1930s internalized and occasionally reinvented the scientific racism of late nineteenth century Europe. However, given the postcolonial system of interstate domination in which the former colonies of the Americas were enmeshed, and despite their pandering to the more oppressive ideas of the European "enlightenment", they remained subaltern members.

What we see throughout the cultural products of the period engaging with the notion of 'Brazil' as an emergent construct is an ever-present concern with the demographic composition of the territory, frequently linked to aspects of Brazil's geography and tropical climate. Hence, what appears as an ostensible divide between elements of culture assembled under the rubric of brasilidade and the rooted assumptions around 'race' and color, is in fact a fictitious one. Culture is diverse, transitory and agency-oriented. It manifests itself complexly - like the blooms of a garden - from a myriad of sources, in a plethora of forms, and with a certain distinctiveness emanating from its parts. Yet, just like a garden, these cultural products have roots that draw inspiration from a deeper, often common, pool. Indeed, it is precisely the foundation on which culture is built that warrants deeper interrogation. As Fabrício Maciel admonishes, what appears to be common sense about who Brazilians are is actually "an ideology that

\footnotetext{
${ }^{13}$ Thomas Skidmore poses the question succinctly, "could a tropical land, luxuriously endowed by nature, become a center of civilization through the fusion of European immigrants and Brazilian mixed bloods?" (1993: 111)
} 
omits the more subtle sources of our social contradictions" (2007: 103). What prompted Pelé to reach for a social explanation for the fairly rigid barriers limiting nonwhite ascension in the country's political and economic culture rather than a racial one is the subtlety of Brazil's contemporary racial ideology at work in obfuscating those sources. ${ }^{14}$ This “sorcery of color", as Elisa Larkin Nascimento has called it, confuses "race and culture in a national ideal of miscegenation that masks the aspiration of whiteness" (2007: 74). This chapter turns to this ideological substratum of Brazilian national culture perpetually obsessed with questions of 'race' next by looking at its developmental trajectory as articulated by influential elites.

\section{Simmering in Society: Racism from Colony to Empire}

Brazil, like all 'New World' colonial holdings, was founded on subjugation and exploitation. From Pedro Álvares Cabral's initial landing in 1500 and the subsequent coastal trading posts established to extract hardwood and indigenous slaves, labor was a constant requirement of the Portuguese (Eakin 1998: 14-8). Whether contracted to extract these commodities in exchange for trinkets and small tools, or as a commodity itself through slavery, indigenous labor served as the foundation of the early Portuguese colony (Johnson 1987: 9; Levine 2003: 37-41). With the introduction of sugar (around 1530), coerced indigenous labor continued to play an important role until it was gradually replaced by African slaves over the late- $16^{\text {th }}$ century $^{15}$ (Schwartz 1985: 16, 28-33, 65-71). Such a scheme of both indigenous and African slavery required deeply rooted and passionate beliefs of the inferiority of these two groups of people in relation to the white

\footnotetext{
${ }^{14}$ Emilía Viotti da Costa draws comparisons with the American dream as an ideological mechanism that "helped to blind Americans to class differences" (1985: 235).

15 The reasons for this transition are varied, however Stuart Schwartz concludes that higher mortality and lower productivity rates of indigenous labor versus African labor likely played the largest role (1985: 71-2).
} 
enslaver. Whether one posits, as does Foucault, that European racism arose out of these early interconnections between different groups of humans perceived to be distinct (2003: 77; Jordan 2000), or predates it and stems rather from classical antiquity (see, e.g.: Isaac 2006), by the time of regular colonial administration by the Portuguese Crown in the 1530s, African and indigenous peoples, as well as children of intermarriage, were systematically denigrated by Portuguese settlers. ${ }^{16}$ As one official noted, "experience has demonstrated that they are less able because of their inferiority and because unrest and trouble is more natural to them" (Schwartz 1987: 138).

This hierarchy was explicitly supported by the Portuguese Catholic Church, who despite lacking the wealth and political power of its Spanish counterpart, played a key role as a "major institutional buttress" of Portuguese power in its South American colony (Burkholder and Johnson 2001: 92-3). The Jesuits, the first concerted evangelical group to play an influential role in the colony with the invitation of Manuel da Nóbrega by the first Governor-General of Brazil Tomé de Sousa in 1549, established villages (aldeias) designed to house the indigenous population and teach them European customs and Christian doctrine (Burkholder and Johnson 2001: 96). Bound by the papal bull of Paul III in 1537 which declared the indigenous population "truly men" and formally prohibited their enslavement, the Jesuits sought to Christianize indigenous peoples, and 'protect' them from encroachment by settlers eager for labor (Burkholder and Johnson 2001: 69). The Jesuits upheld the notion of the indigenous population as potentially capable of civilization along the European mold, which put them into increasing judicial and

\footnotetext{
${ }^{16}$ George Reid Andrews provides a good overview of the roots and consequences of racism in colonial Brazil, reviewing contemporary work on limpeza de sangue [purity of blood] laws in $15^{\text {th }}$ century Portugal that provided "both the ideological justification of that labor system and the organizing principle of the multiracial society that it spawned" (1984: 210$)$.
} 
political conflict with the settlers (Burkholder and Johnson 2001: 96). Yet, Jesuit opposition to African slavery was weak, limited, and never challenged the institution itself $^{17}$. As David Sweet points out, "comments on the suffering of [African] slaves were intended rather to move people to obey the law than to prod them into trying to change it; and they did not produce the vigorous debates and eventual reforms which had resulted from the celebrated "struggle for justice" on behalf of the Indians" (1978: 94). Indeed, contained by the royal patronage (padroado real) which put religion under the tutelage of the Crown, the Church was an effective co-partner with the state in the earliest years of Portuguese colonialism, until the Pombaline reforms of the 1750 s expelled the Jesuits and centralized the power of the Crown (Burkholder and Johnson 2001: 93; 260-1).

We can see then, even in the early colonial period, the emergence of gradations of color linked to perceived purity of blood that played an important role in social stratification. Black slaves, occupying the lowest rung on the social ladder, had little recourse through the nascent legal framework to basic rights and freedoms ${ }^{18}$. Free blacks faced numerous restrictions on employment and their freedom to comport themselves, as well as the reality that their freedom could be rescinded "for disrespect towards a former master". Mulattos and mamelucos ${ }^{19}$, whose social position shifted depending on their distance from the colonial centers of power - and depending on whether their fathers or mothers were white - at times were allowed to participate in public life, though this was hardly guaranteed or practiced by colonial administrators (Schwartz 1987: 138; Daniel

\footnotetext{
${ }^{17}$ After all, Bartolomé de Las Casas, initially predicated his lifelong battle against indigenous slavery on the 'just' enslavement of the African (see Todorov 1984: 170-1). The Portuguese Church had no equivalent counterpart to Las Casas (Burkholder \& Johnson 2001: 70).

${ }^{18}$ Although this structural setting played itself out in complex ways, invoking the varied exercises of agency by involved parties. Though she focuses on the imperial period, Sandra Lauderdale Graham's Caetana Says No "confounds" many of the assumptions of racially inflected patriarchy by showing the struggle of one slave woman to resist a marriage she did not want (2006: esp. 1-82).

${ }^{19} \mathrm{~A}$ term denoting individuals of mixed indigenous and European parentage.
} 
2008: 29; Twinam 1989). Whites, who traced their lineage back to Portugal, occupied the top position in this color continuum, able to alter the rules of the social structure with varying degrees of success in order to suit their own (and often parochial) interests.

This gradation was clearly oriented towards the hierarchical exultation of whites, but it also allowed for a certain degree of fluidity along the linear path towards whiteness. For example, Boris Fausto recounts a 1755 decree that encouraged intermarriage between whites and indigenous peoples as a positive activity which could poise indigenous participants for better jobs and honors. However, some years later the viceroy of Brazil criticized an indigenous militia chief who "displayed sentiments so low as to marry a black woman, staining his blood with this union and making himself unworthy of the office of militia chief" (1999: 26). G. Reginald Daniel claims that there was some limited vertical mobility open to free blacks and mulattos, in part because of the shortage of whites, yet even this possibility for ascension was circumscribed by the need for constant approval by white elites who controlled their advancement (2006: 32-3). Those in the intermediate strata that were hand-picked for inclusion in the 'upper' tiers of society, whether via their progeny through intermarriage, or because of their personal relationships with whites or special skills and talents, were viewed (usually grudgingly) as acceptable partners in the civilizing and later, nation-building, project. Throughout the colonial period, then, white racism was a systemic fact of social life, and yet, it was never formally systematized and consolidated in the form of a white supremacist racial ideology (Daniel 2006: 21-34).

However, the persistence of this view by Brazilian elites would not persevere unchanged. Their fixation on the management of a 'harmonious' society, and the 
significance that matters of 'race' played in this management did not alter dramatically, but the way that 'race' was discursively configured in it began to shift in the nineteenth century. Stein and Stein point to two interrelated factors that contributed to the emergence of what they call "racial pessimism" in Latin America in the nineteenth century. First, as the language of development driven by economic growth and technological advancement intensified, Brazilian elites realized that the gap between their country and those of Western Europe and North America was widening. The fruits of 'modernization', in the form of the steamship and telegraph, demonstrated to Brazilian elites their place in the global system in starker terms, as did increased travel by the bourgeoisie to, and from, Europe (1970: 183). With the exile of the Portuguese Crown to Rio de Janeiro in 1808 , Brazilian society was remade more along the lines of the major European centers. Royal academies, a medical school, a royal library, and a military archive were all established, while a print ban was lifted, which paved the way for an "intensified and accelerated" political socialization of the literate elite ${ }^{20}$ (Schultz 2001: 83; Barman 1988: 44). All of this served to establish more regular and institutionalized ties with the centers of European knowledge while simultaneously displaying the purported 'inferiority' of Brazilians in comparison with certain parts of Europe.

Second, Stein and Stein argue that Latin American elites looked to their own population for explanations of their 'backwardness', locating it in the "apathy, indolence, and improvidence" of the racialized masses (1970: 183). They searched for alternative answers to explain the growing gulf between Latin America and Europe, and found it in the 'inherent characteristics' of the various 'races' present in Brazil. Brazilian elites drew

\footnotetext{
${ }^{20}$ Before the Crown relocated to Rio de Janeiro, Brazil did not have any academic institutions, though religious seminaries provided some degree of higher education (Schultz 2001: 97, fn. 89). National civilian universities did not emerge until 1930 (Davis 1999: 81).
} 
from European thinkers such as Arthur de Gobinau, Gustav Le Bon, Cesare Lombroso, and Herbert Spencer to stoke the embers that had been simmering under the surface of colonial society for centuries but required the challenge of competitive modernization to really flare up. It was during this time that miscegenation was challenged as social practice, even while the seeds were planted that would enable it to emerge as the centerpiece, through whitening, of a positive ideology of the nation.

\section{Grappling with European Racial Views: the Rise of Scientific Racism}

Arthur de Gobineau was one thinker who catalyzed the boiling over of the Brazilian racial order. In the Inequality of Human Races (1855), he provided a thoroughly impassioned critique of eighteenth century liberals proclaiming the basal equality of humans by attacking the notion that culture impacts the modernist drive towards 'progress': "We cannot admit that the institutions thus invented and moulded by a race of men make that race what it is. They are effects, not causes" (de Gobineau 1999: 40). For de Gobineau, innate characteristics of each 'race' formed the base of all and anything that individuals and groups were capable of, and any alteration of those characteristics through miscegenation led to 'degeneration': “...that the people has no longer the same intrinsic value as it had before, because it has no longer the same blood in its veins, continual adulterations having gradually affected the quality of that blood" (de Gobineau 1999: 25). Of course, de Gobineau also established an extremely clear hierarchy of the peoples of the world, with the 'Aryan' squarely at the top. According to his racial schema, all of the accomplishments of the world, in one way or another, stemmed from the purity of this group and any 'degeneration' threatened future progress (Smedley 2007: 263). 
The reach of de Gobineau was profound, even if his ideas did not appear as directly to Brazilian readers as other writers of the time (e.g.: Henry Buckle, see Skidmore 1993: 30-1). His work is widely considered one of the earliest texts of systematic scientific racism, provoking a fury of response and support within the nascent disciplines of physical anthropology and criminology. De Gobineau also served as French ambassador to Brazil from 1869-70 before leaving due to health problems. He abhorred the country, believing it to be a dead-end political posting as well as a dead-end country more generally because "unrestricted miscegenation was leading them to a decline without hope of recovery ${ }^{21}$ (dos Santos 2002: 73). Despite his distaste for Brazil, de Gobineau was an unavoidable referent for proto-nationalist thinkers since, unlike Linnaeus or Blumenbach, he merged racial classification with a coherent social and political narrative, making his work far more amenable to nationalist projects. However, rather than use his work as an incontrovertible and positive tool for nation-building, de Gobineau's work "reminded Brazilians [elites] of the dire consequences forecast by European racial theories", forcing them to respond creatively and in accordance with their national realities to the condemnation thrust upon them (Schwarcz 1999: 36).

The emergence of European scientific racism in such concrete form awoke Brazilian elites to the fabricated urgency of internal dissolution and degeneration through miscegenation, which, prior to the nineteenth century, had been a fact of everyday social life. On the one hand, eager to garner the approval of those in Europe who validated national prestige, many Brazilian elites took the ideas exemplified by de Gobineau vigorously to heart. Moreover, since a hierarchical racial order had existed in Brazil

\footnotetext{
${ }^{21}$ For more on Gobineau in Brazil, see Georges Raeders (1988) and for an alternative reading of his time there, see de Raymond (1990).
} 
virtually from the time of contact and conquest, it was not a far stretch to institutionalize these ideas into 'scientific' (or rather pseudo-scientific) form. However, because Brazil represented a hopeless case to the eyes of many European intellectuals, early Brazilian nation-builders could not easily accept their pronouncements with resignation. Rather, the work of de Gobineau and Renan, of Le Bon and Taine evoked a vociferous debate amongst elite stakeholders as to how to interpret, reinterpret and controvert the judgments given to them (see French 2003: 382). In simplified terms, this reflected itself in the development of two camps: the defeatist doctrinaire racist camp represented by Nina Rodrigues which served to check enthusiastic nation builders who strayed too far from European assertions, and the cautious scientific racist cum Social Darwinist camp reflected in the career of literary critic Sílvio Romero that operated as a forerunner to detailed theories of miscegenation and eugenics in the context of nation building.

Raimundo Nina Rodrigues, despite his formal training as a medical doctor, is credited with producing the "first scientifically respectable ethnographic study of the Afro-Brazilian by a Brazilian" (Skidmore 1993: 57). Raised amongst the children of his family's slaves (Peard 1999: 101), he developed an avid interest in what he called the 'black problem' which he contrasted in lament with that of the United States:

Like the United States, we widely received black immigration, and these blacks [negros] were incorporated into our population. We never had, like the United States, a respectable surplus of whites, and the United States doesn't have, like us, a large part of the country completely in the tropical region [em plena região tropical] (Rodrigues 1977: 6-7)

Nina Rodrigues saw these two issues as especially damning to Brazil's future, and its prospects, according to his analysis, were bleak: "the black race...[would] always constitute one of the factors of our inferiority as a people" (Rodrigues 1977: 7). 
Nina Rodrigues' insistence on scientific racism's hard deterministic view on matters of 'race' forced him to take a position familiar to de Gobineau, concluding that miscegenation led only to further degeneration of a people (Peard 1999: 12, 104). Brazil had no hope of escaping its environmentally and racially determined fate. Rather, as Peard has quipped, "[c]ivilization in the tropics would, at best, be second rate" (1999: 105). This view never quite took hold amongst the Brazilian elite for the obvious fact that it breathed futility into all of their endeavors, yet it still played a major role as a foil against which any racial optimism had to be tested. As Skidmore points out, the narrative of Brazilian inferiority was taken up in the late nineteenth and early twentieth centuries by public officials and academics mourning their predicament. The story of 'Latin decline' beside 'Aryan mastery' was touted by intellectuals in Brazil throughout this period, frequently linked back to geography and always to the demographic makeup of the country (Skidmore 1993: 62-3).

Silvío Romero represents a somewhat less pessimistic, but also extremely ambiguous, spokesperson for Brazilian nationalism. While also taking a deterministic stance towards 'race' in that miscegenation was an unavoidable and extremely consequential aspect of Brazil's future, he was not always as cynical about what outcomes this would bear. He frequently vacillated between foreseeing the ultimate ascendancy of whites in the national territory over the course of many centuries and the completion of the "Brazilian mestiço" project, or some combination in between, and while the future made him uneasy, he was not entirely without hope that the country could be salvaged (Skidmore 1993: 37; Dutra 2000: 28-9). At bottom, he argued in regards to miscegenation between blacks, whites and the indigenous population that "it 
helps little...to discuss whether this is good or bad. It's a fact and that is enough" (qtd. in Skidmore 1993: 35). Thus rather than resign himself to certain foreign viewpoints insisting on Brazil's hopelessness, Romero sought creative, if not radically distinct or well-defined, reformulations of the "facts' as he saw them.

Romero in part viewed Brazil's escape route from desperation in the promises of 'science'. As early as 1870 , he saw promise and opportunity abound in national selfdefinition:

A flock of new ideas has overflown us from all points on the horizon...Positivism, evolutionism, Darwinism, religious criticism, naturalism, scientificism in poetry and the novel, new methods of literary history and criticism, and the transformation of instruction in law and politics. Everything is in flux..." (qtd. in Schwarcz 1999: 177)

These new ideas served as inspiration against hard racial determinists such as Nina Rodrigues, interspersing human agency in social affairs alongside 'natural' inevitability. Positivism especially served to marginalize the hard determinists, since it was so eagerly picked up by the Brazilian elite. As Bradford Burns summarizes it, "by synthesizing the whole of human knowledge and reducing social facts to laws, Positivism could reconstruct society" (1970: 178, emphasis added) ${ }^{22}$. But prior to social reconstruction, knowledge had to be garnered. In the preface to Nina Rodrigues' Os Africanos no Brasil, and on the eve of abolition, Romero criticized the shameful practices of Brazilian science for not seriously studying the languages and religions of Africans available right "at home". He reminds the reader that "the black man [negro] isn't only an economic machine; he is before all, and despite his ignorance, an object of science" (Rodrigues 1977: xv). Through acts of knowledge production about its 'degenerate' population, which was ultimately necessary for their education, Brazil could reinvent itself from a

${ }^{22}$ See also Charles Hale who notes the multiplicity of meanings circulating around this ideology (1996: 148 ), and for a good account of legal positivism as it was eventually applied to the Republican period in Brazil, see Sueann Caulfield (2000: esp. 17-47). 
hopeless tropical backwater doomed to physiological and cultural degradation to a cautiously hopeful triumph over degeneration through racial mixing.

This paradox - of lingering racial immutability and fixed linear evolution alongside the liberal positivist promises of education, technical training, institution building and acculturation - was "fairly typical" towards the end of the twentieth century, and represents the legacy of the European racist thinkers on Brazilian intellectuals (Skidmore 1993: 64, 63). The overlap of competing ideals and labels, reflected in the positions taken by Rodrigues and Romero, produced an anxiety for elite nation-builders in how they were to be reconciled. Many ideas emanating from Europe perpetually denied equality to countries like Brazil because of the perceived racial composition of their populations, and yet it was precisely Europeans (and later North Americans) that Brazilians sought to emulate culturally and economically. As such, they could not be disregarded wholesale. Furthermore, because racial hierarchy served as the bedrock of the Brazilian social system, it could not be dismantled tout court along the lines of the principles of the French revolution. Indeed, as Kirsten Schultz points out, many Portuguese in Brazil welcomed the Crown to Brazil as a positive and "revolutionary" act, in part because it served as a bulwark against what many slave owners worried could become another Saint Domingue ${ }^{23}$ (2001: 3-4). Hence, the concerns of elites revolved around the extremely precarious task of maintaining the white supremacist order while redefining the nation as progressive against the backdrop of European racist thinkers' insistence that Brazil was doomed to degeneration.

\footnotetext{
${ }^{23}$ Incidentally, Brazil was the last country in the Americas to abolish slavery, with Princess Isabella's 'Golden Law' in 1888.
} 
The end of the nineteenth century, with its myriad transformations in ideas and identities, in politics and economics and in culture, was not the rupture it seems to be when examining Brazil's racial ideology. While understanding of 'race' and its role in the makeup of Brazilian society, polity and economy altered dramatically, it did so with a remarkably persistent faithfulness to embedded racial hierarchies which in turn manifested themselves in debates over how to construe the nation. Scientific racism with its glaring hatred and indomitable insistence on the fundamental inequality of human beings forced Brazilian elites to account for their demographic realities in ways that projected a positive image of progress to Europeans. Building upon the work of Romero, elites in the early twentieth century sought to do this by integrating miscegenation as practice within a eugenicist framework of racial purification. No less benign in terms of racist suppositions, yet far less rigid in the discursive prevalence and interpretation of racist views, embranquecimento (whitening) would emerge into the twentieth century as the dominant racial ideology in Old Republican Brazil.

\section{The Reverse Prism: Whitening to Racial Democracy}

These tensions between their demographic facts and the ideology of scientific racism worried elite Brazilians. In 1916, a new magazine called the Revista do Brasil was founded in São Paulo with the "desire, the decision, the commitment to establish a center of nationalistic propaganda" capable of producing positive knowledge about the Brazilian people and nation, especially around issues of racial heterogeneity (Skidmore 1993: 168). The same year, a new schoolbook created by Afrânio Peixoto entitled My Land and My People sought to tackle the issues of 'race' and climate directly. The book exhorted schoolchildren to "acquire the combination of self-awareness and knowledge of others 
that will enable us to create our own destiny" (Skidmore 1993: 169). Critical to this nation-building exercise, Peixoto urged children to seriously weigh the question posed by Graça Aranha in the hopes that the next generation would be able to resolve its tensions (see fn. 13).

Yet the early years of the Old Republic were not idle ones. Brazilian intellectuals began by making cautious adaptations to the self-defeating scheme imposed by European thinkers like de Gobineau and taken up by scientists like Nina Rodrigues. Romero was one of the earliest to suggest that the answer to Brazil's racial question lay in mulattoproducing miscegenation, yet others would take up his views with more coherent and optimistic determination. Francisco José Oliveira Vianna was one of the best known theoreticians of 'whitening'. While couching much of his rhetoric in the language of scientific racism and firmly upholding a hierarchy of 'races', Vianna did not see these differences as immutable. Rather, he utilized census data to argue that the black and indigenous populations were declining, culminating in white "purity" as a reality on Brazil's horizon (Skidmore 1993: 201-2).

Instead of a simple scheme of whitening, whereby miscegenation would always provide 'positive' transformation towards lighter skin, Vianna saw a complex gradation of mixtures, representing the "infinite variations" that arose out of the "hereditary tendencies of each formative element". "It is impossible" he argued, "to confuse the ugliness typical of the Ijexá with the beauty of the Egbas, Fulos and Minas; the gentle and sociable nature of those [peoples] with the ferocity and rudeness of the Efa; the virility and the bravery of the Dahomey with the weak moral integrity of the Angolan and Geges" (Vianna 2005: 170). Hence, the outcome of intermixture was never fixed: 
[there are] inferior mulattos, incapable of ascension, degraded in the lowest rungs of society, and coming from the mixture of the white with the black of an inferior type. There are, however, superior mulattos, Aryan in character and intelligence or, at least, susceptible to Aryanization, capable of collaborating with whites in the organization and civilization of the country (Vianna 2005: 170-1)

Vianna went on to elaborate the best ways to procure the 'good' mulattos, and how to avoid degeneration, a far cry from the view of the hard determinist Nina Rodrigues who saw only degeneracy in Brazil's future. Indeed, Vianna represents an important bridging point between the ideals of scientific racism with their emphasis on immutability and hierarchy and the emergence of a Brazilian solution to the challenges posed by European racist writers. He maintains the white supremacist grounding, but allows for a much more fluid characterization of individuals and groups within the framework, effectively delinking color from character in discourse ${ }^{24}$. Blackness did not innately translate into degeneracy for Vianna, if it did always mean inferiority in relation to whites. Rather, certain blacks were amenable to miscegenation with whites that would ultimately lead to the eradication of blackness within the national territory. This was an important first step in enabling Brazilian elites to transcend the chains imposed on them by European thinkers, critical if they were to formulate their own national destiny. It allowed Brazilian elites to look at their demographic realities and see the possibility of 'progression', if distantly according to some estimates, and put the promise of that progress firmly within their own capability. As Thomas Skidmore points out,

In one sense, the contradiction between assumptions and conclusions [in Vianna's work] was enormously reassuring [to Brazilian elites]: if an erudite scholar who knew and believed so much of the (increasingly less) prestigious scientific racist theory from Europe and North America could conclude that Brazil's ethnic future was safe, then Brazilians could feel truly confident (1993: 202)

\footnotetext{
${ }^{24}$ Of course, discourse and practice are two separate matters. See Chapter 2.
} 
The eugenic strategies underpinning the writing of authors like Vianna were highly attractive to elites in the post-WWI era, and impacted national culture in very real ways though they never became institutionalized as in Europe (Stepan 1990: 114-5). As a result, and especially moving into the 1920 s, the 'racial pessimism' that had characterized national dialogue until then was replaced with an impetus "toward education, social reform and sanitation as answers to the "national problem"' (Stepan 1991: 156). The supposed degeneracy implicit in indigenous and black blood was challenged by emergent interests in etiology spearheaded by the Bahian Tropicalista School of Medicine, which were in turn ameliorable by active governmental policy (Peard 1999).

However, this shift towards social and environmental roots of inequality also destabilized the notion of white supremacy as an indisputable fact underpinning discourse of Brazil's national identity. No longer could one simultaneously uphold beliefs in inherent racial inequality and the ability to address it through policy without facing the logical contradiction implicit in the relationship, nor without being challenged as the 1920s wore on. Indeed, Vianna, though an important placeholder linking nineteenth and twentieth century beliefs in the role that 'race' played in the fate of the Brazilian nation, increasingly saw himself distanced from the language of mainstream Brazilian elites, and began to be attacked by revisionists like Edgar Roquette-Pinto and Gilberto Freyre (Skidmore 1993: 202-3).

Freyre was born in 1900 in Recife, and through his attendance at the American Baptist College there, ended up pursuing his education at Baylor and Columbia University, taking courses with Franz Boas and Franklin Giddings at the latter school (Burke and Pallares-Burke 2008: 23-7). Freyre owed a considerable amount to the 
culturalist position of Boas, who would later become known for his groundbreaking contributions to cultural anthropology:

[Boas]... first revealed to me the black and the mulatto in their fair value - separating racial features [from] the effects of the environment or cultural experience. I learned to consider as fundamental the difference between race and culture; to discriminate between the effects of purely genetic relations and those of social influences, cultural inheritance and of environment" (qtd. in Medeiros 1984: 21)

This separation of 'race' and culture was an integral step in the discursive deconstruction of white supremacy. If 'race' was not a fixed signifier replete with prejudicial stereotypes, and culture was highly mutable, shaped by environmental and social interaction, then white supremacy was an unfounded myth. At base, so Freyre's epistemological foundation asserted, people were fundamentally equal, but it was environment, culture and society that created the system of differences between the 'races', and hence some environments and cultural configurations mitigated this inequality or at least predisposed more egalitarian societal relationships. Freyre, who presents his work with impressive reflexivity, viewed this as his prime task in his two major works from the 1930s, Casa Grande e Senzala and Sobrados e Mucambos ${ }^{25}$ :

What I wanted to save from conventionally narrow points of view was a number of such LusoBrazilian achievements as miscegenation and the fusion of cultural values which pseudosocial scientists like Gustave Le Bon have represented as absolutely disgraceful or harmful to so-called progress (1963b: xix-xx)

Within a very short time, Freyre would achieve this task and solidify himself as Brazil's preeminent social thinker, drawing praise from Aldous Huxley, The Economist, as well as an entire generation of Brazilian commentators who sought to transform him into a cultural icon in the years after World War II (Medeiros 1984: 15; Skidmore 2002: 1-2).

\footnotetext{
${ }^{25}$ These two books were published in 1933 and 1936 respectively. The English translations, which appeared in 1946 and 1963 respectively under the titles The Masters and the Slaves and The Mansions and the Shanties, are cited here, though in the case of The Masters and the Slaves, the second English-language edition is used (1963a).
} 
Central to Freyre's thesis was the notion of a Luso-tropical exceptionalism that proposed that Brazil's history of close-contact slavery and forcible miscegenation between masters and slaves resulting from the lack of Portuguese women, as well as Luso-tropicalist cultural values (such as acceptance of African and Indigenous languages, religious practices, and cuisine) contributed to the development of a unique Brazilian culture incapable of seeing anything but a single people. Though Freyre did not immediately use the term 'racial democracy', adopting it only in the 1940s, he attempted to draw the distinctions between European political democracy which was "often inefficient, unjust and anti-human" with Brazil's achievements in 'social democracy' through "democratizing, and even anarchic" miscegenation within Brazil's "aristocratic" and "patriarchal" organization of the family (qtd. in Guimarães 2005: 121-2). For Freyre, the Portuguese culture was more flexible than other cultures, derived in large part from the half millennia of Moorish occupation which predisposed them to sexual encounters and civil relations with “darker-skinned peoples” (Telles 2004: 34; Degler 1971: 226; Freyre 1963a: 9-10, 222-4). Hence, because of the peculiarities of Brazilian history specifically the high degree of sexual relations between masters and slaves - 'Brazilians' had emerged as a distinct people who were uniquely suited for life in the tropics.

In one sweep, Freyre corrected both the climate and racial 'problems' by unifying the contributions of each racial group into a single Brazilian 'race' under the banner of a shared national civilizatory project. The irony of this seemingly anti-racist theory of Brazilian society was that it saw the laudable characteristics necessary for this exceptionalism emanating from the Portuguese male, hence upholding, if less explicitly, a 
notion of white, 'Western' supremacy (Hasenbalg 1992: 11) ${ }^{26}$. In no way, for example, was the intelligence of mulattos of any mixture inherently weaker than those of whites. However, mulattos could only break their 'cultural' shackles of intellectual inferiority by following the teleology of the white Portuguese intellectual who in turn looked to Europe for guidance (Freyre 1963b: 416-7).

At the time, this inversion of scientific racism while tacitly maintaining racial hierarchy proved to be both a powerful and subtle method of reconceiving Brazil's racial relations. The subtlety lay in the way white supremacy was upheld: formally attacked, rebuked, and rejected within the discursive field, there was neither need nor ability (from the standpoint of white elites) to interrogate in detail the lived experience and daily realities of racialized groups to determine whether something as insidious as racism actually existed. If all people were inherently equal, then minor inequalities could be 'corrected' through concerted policy effort - mainly education - and whatever remained could be chalked up to individual failures, not structural discrimination. However, it was an incredibly powerful revision to Brazil's racial logic, since it was so amenable to projects of state and nation building. From a superficial viewpoint, Freyre's narrative of racial democracy did reflect Brazilian reality when contrasted with the herrenvolk democracy of the United States, which by the 1930s was Brazil's principal point of reference (Winant 1999). Without legal segregation, widespread lynching, or 'race' riots, Brazil appeared to be the "racial paradise" that Freyre was trying to reconstitute through

\footnotetext{
${ }^{26}$ As Michael Hanchard notes, "In Freyre's reconstruction of preindustrial Brazil, miscegenation first occurs between white, landowning males and females from indigenous and enslaved social groups only, not between enslaved men and white women. Therefore, regardless of the degree of humanity that Freyre infers from these relations, they were, objectively, relations of dominance and subordination between owners and owned in which racial and gender roles were commodified in accordance with the preferences and choices of slaveowners" (1994: 53).
} 
his intellectual project (Hellwig 1992). Such a comparison was widely made, and worked to reaffirm the Brazilian exceptionalism that underpinned the notion of racial democracy, which in turn bolstered national pride and its concomitant sense of national identity. Wielded in conjunction with expert statecraft, the notion of racial democracy would serve as the foundation upon which the pillars of brasilidade were constructed, able to withstand decades of transformations in thinking about 'race', and 'scrutiny' by foreign observers $^{27}$.

Traversing Discursive Fields: Racial Ideology and State Machinery

Though it was largely literary critics, medical doctors, social scientists and other intellectuals who agonized over the plight of their country's future regarding its racial makeup, there was little distinction drawn between these various fields and the political sphere. Indeed, many intellectuals, like Silvío Romero for example, were picked up by regional political bosses for political office both during the late Empire and the Republic $^{28}$ (Skidmore 1993: 81). In any case, these elites were all vociferous contributors to national political discourse as public intellectuals, and their ideas served to stimulate policymakers in how best to direct the exertion of the state. For the state was no bystander to the negotiation of national identity undertaken by cultural elites, but rather

\footnotetext{
${ }^{27}$ Though it is hard to label the work of many early twentieth century American social scientists as critically scrutinizing the notion of racial democracy; for the most part, they bought into it for the same reasons as Brazilian intellectuals who pictured their racial system in contrast with other countries. For example, Donald Pierson, a well-known American Brazilianist wrote, "This general tendency to absorb all diverse ethnic elements has been persistently characteristic of Brazilian society...There is no deliberate segregation as one finds where races have been embittered for a long time...The entire organization of society tends to take the form of a freely competitive order in which the individual finds his place on the basis of personal competence rather than racial descent...Miscegenation has now proceeded to the point where Bahians anticipate, and take pride in predicting, that the Negro will, within a reasonable period of time, be completely absorbed" (1939: 532-3). We can see all the elements of Freyre's texts (which is cited) at work in Pierson's article, with the emphasis on whitening made all the more clear.

${ }^{28}$ Gilberto Freyre, though his indirect impact on Brazilian political life was far greater than his direct contributions could ever have been, was elected in 1945 to the Chamber of Deputies for the Constituent Assembly under the banner of the Democratic National Union party (Burke and Pallares-Burke 2008: 1156).
} 
an active consumer, actualizing agent, and original producer of adjusted and competing perspectives to those advanced by some of its clients. Indeed, state officials frequently worked to cultivate and integrate ideas that served to bolster their own power and serve their own interests, as well as those of the shifting economic classes they served. The following brief examples demonstrate the way in which the ideas of our representative thinkers on 'race' were incorporated into state constructions of national identity, serving as segue for what this meant for constructions of citizenship in Brazil.

The ambivalence of Romero regarding the future of Brazil - his vacillation between embracing the mulatto as alternately a positive and negative centerpiece of the country's demographic reality - is hard to pin down in government discourse, in part because Romero defined himself as an agitator to the status quo. The end of the nineteenth century saw the Empire in considerable decline, with Dom Pedro II holding onto power in whatever fashion he was able, and Romero an avid cheerleader of the promise of change that the future was sure to bring. However, if we characterize Romero's position as an ambivalent flirtation or pre-internalization of the ideology of scientific racism, then the internal contradictions of state officials become slightly clearer.

Emilia Viotti da Costa offers the example of Joaquim Nabuco, the eminent white Brazilian statesman and leader of the abolitionist movement. In honor of the death of Machado de Assis ${ }^{29}$, the foremost Brazilian novelist of the twentieth century, his close friend José Veríssimo referred to him as a mulatto. Nabuco responded to Veríssimo by scolding him for this, arguing that the "the word is not literary, it is derogatory...For me Machado was a white and I believe he thought so about himself'. On one hand, Nabuco had spent his life fighting for the freedom of slaves and the formal equality of all

\footnotetext{
${ }^{29}$ Incidentally, Silvío Romero was his biggest critic (see Schwarz 2001; Kristal and Passos 2006)
} 
Brazilians, yet he simultaneously shies away from open discussion of racism, clearly shows discursive disdain for the mulatto, and emphasizes his discomfort with Veríssimo's terminology, stating that it "caused me chills" (1985: 241). State officials of Romero's generation also shared his paradoxical and ambivalent views towards the Brazilian racial makeup.

The views of Nina Rodrigues, as stated, were always marginal to some extent for the self-defeatism they implied. For the new cadre of political elites that rose to power with the proclamation of the republic, influenced by positivism and eager to make their mark, this was hardly a desirable attitude to hold when constructing a positive philosophy of government. Still, at times, state officials could be heard parroting the doom and gloom of Rodrigues. For example, Joaquim Murtinho, as minister of Roads, Industry and Commerce, complained that "We cannot...take the United States of America as the model for our industrial development, because we do not have the superior aptitudes of their race, [the] force that represents the principal role in the industrial progress of their large country" (1897: xvii). The hopelessly negative views of state officials regarding Brazil's future driven by its racial composition certainly played an important regulatory role in state discourses of national identity by cautioning nation-builders to exercise conservatism when reshaping the image of the nation.

As the dominant racial ideology for much of the Old Republic, Vianna's position was reflected in political discourse fairly concretely when the Brazilian state employed their whitening campaign through immigration policy ${ }^{30}$. Later, while his overtly racist

\footnotetext{
${ }^{30}$ Though Lesser notes a dispute between two senators in 1888 over Chinese immigration predating Vianna: In response to Alfredo d'Escragnolle Taunay's incessantly vicious attacks on the Chinese, senator Viriato de Medeiros criticized him for not recognizing "the good Chinese with the bad Chinese". Taunay
} 
language would for the most part be discarded, Vianna's intellectual work, in calling for a strong nationalist state, would be immensely influential for the rise of Getúlio Vargas (Needell 1995: 1-2). Indeed, while holding numerous political appointments during the Vargas regime, Vianna would be appointed to head a special committee to 'examine' the question of Assyrian immigration for Brazil (Lesser 1999: 72). Debates raged over who should be allowed to enter the country in the years after an 1890 ban denied all Asians and Africans entry without congressional approval. Initially, Italians, Portuguese, and Spaniards were desired for their perceived ability to "re-create the Old World in the New" (Lesser 1999: 11). Yet as concerns over the radicalism of these immigrant groups grew, planters and capitalists pressured for alternative sources of external labor that could both serve their immediate economic interests, and whiten the population over time. Chinese, Japanese, and Arab workers were recruited, though their perceived contribution to Brazil's national demographic makeup wavered as the tension between white supremacy and whitening shifted one way or the other.

For example, while initially praised for their work ethic, the Japanese soon evoked fears amongst politicians and diplomats as the scientific racist side of Vianna's ideology held sway and Japanese ascension loomed as a reality. Luiz Guimarães, a secretary attached to a diplomatic delegation in Tokyo, and who would later be promoted to the ambassador level, feared that “...to inject Asian blood into an organism that is still ethnically stammering will impede the march toward the homogeneity of a national type...we will lose the cohesion necessary for a great country, the nation of Brazilians". With its own nativist concerns over miscegenation, many in the Brazilian political class

responded by stating "the bad Chinese, they come from China. How is it possible to make a distinction?", anticipating one of the central concerns that Vianna would take up some thirty years later (1999: 33). 
saw the Japanese - and other groups - as potentially playing a "'fatal' blow to the 'whitening' process" if they were introduced too early (qtd. in Lesser 1999: 86).

However, while all of these ideas continued to swirl to greater or lesser degree in the currents of political discourse, it was Freyre's conception that would play the biggest role as underwriter for state policy when it was taken up by the transformative government of Getúlio Vargas when he was swept to power by his Liberal Alliance supporters in 1930 (see Wirth 1964; Levine 1970). Indeed, the power of racial democracy was so apparent that it became the effective racial ideology of the state from Vargas onwards. While the Old Republican period had been characterized by a decentralized federal state, with a café com leite [coffee and dairy] oligarchy alternating control over the presidency, and increasingly tenuous control over radical elements arising out of nascent but rapidly expanding industrialization, the Vargas years sought to centralize state power and expand its capacity, nowhere more prominently than in the area of nationalist propaganda ${ }^{31}$.

Vargas consolidated his power by reconceptualizing Brazil as a national corporate family, strung together through populism and authoritarian nationalism. Central to this construction was a notion of a homogenous Brazilian past and a harmonious Brazilian present working towards a glorious Brazilian future, and Vargas assiduously cultivated relationships with leading intellectuals expounding nationalist messages amenable to this vision (Davis 1999: 83). Vargas, a master statesman, maintained broad support from ideologically diverse intellectuals while simultaneously hewing closely to "a public policy that [held] a 'Brazilian essence', did in fact exist, and that miscegenation under

\footnotetext{
${ }^{31}$ This thesis cannot expand on the political economic backdrop of Brazil's transition from Republic to the Estado Novo [New State], though it was significant. For more information, see especially Topik (1987).
} 
Portuguese tutelage had played crucial parts in its creation"32 (Davis 1999: 87). Using new technologies, such as radio, and contemporary techniques, such as press censorship, Vargas created a discursive environment in which everybody had a place, but all were subservient to the larger national construct. As a result, the contributions of racialized groups were celebrated in culture, yet any attempts at real political mobilization or systematic address of the material inequities facing these groups were discredited as being "un-Brazilian" or worse, racist (Davis 1999: 79). Yet, this static image of Brazilians, as Davis points out, "necessitated an ideal: naturally male and white" (1999: 103). Every Brazilian was incorporated into this scheme, regardless, as the 1934 Constitution stated, of “...distinction, for reasons of birth, sex, race, profession or parentage, social class, wealth, religious beliefs, or political beliefs" ${ }^{\prime 33}$ (Constituição do Brasil 1934: Art. 113, $\S 1)$. However, as we will see in the next chapter, systematic inequality persisted (and was even exacerbated) for non-whites under the roof of the big Brazilian family.

This discursive veneer of formal equality and cultural valorization belied the system of discrimination that, as we have seen, structured social relations in Brazil in a highly persistent, if varying, form reaching back into the earliest years of conquest and colonization. It was rather difficult to make claims on the state, when members of government, like the head of the National Council for the Protection of Indians (CNPI) Cândido Rondon, exuded that

\footnotetext{
${ }^{32}$ Indeed, despite having his work admired (and appropriated) by Vargas, Freyre was hassled by police under his administration - including an arrest in 1935 for criticizing a national security law, and brief imprisonment in 1942. Even so, Freyre remained ambivalent towards Vargas, both praising and critiquing him throughout his life (Burke and Pallares-Burke 2008: 114-5; 127-8). For more on the enigmatic figure and curious statecraft of Vargas, see Levine (1998) and Williams and Weinstein (2004).

${ }^{33}$ In any case, this was only a temporary provision, however, and was removed in 1937 with Vargas' autogolpe [self-coup].
} 
Of all the precious things that befall us in this new march to the West, all relevant to the greatness of Brazil, none surpasses the Indian...They have given us the base of our national character, resistance, bravery, generosity, and modesty, contributed by the Indian to the formation of our people, as much in the past as it still is in the present (qtd. in Garfield 2001:33).

Never mind that while the mouth praised, the hands worked to intensify land invasions, legally infantilize, and systematically impoverish indigenous peoples assembled in ‘demarcated indigenous territory' - reservation land (Garfield 1997: 752; Garfield 2001: 43).

Yet racial democracy would remain the dominant racial ideology of brasilidade for much of the twentieth century, demonstrating striking success in deflecting criticisms of structural racism levied by the increasingly organized anti-racist movements ${ }^{34}$. While it too underwent revisions as the decades wore on and new empirical realities confronted and challenged it, state officials consistently sought to hammer the notion of Brazilian racial exceptionalism into their citizens through virtually all the socializing tools available to the state, especially education. This institutionalization of discourse became the common sense of the nation, parroted by poor Brazilians and foreign scholars alike, and was only slowly eroded over successive generations beginning with the UNESCO studies mentioned above ${ }^{35}$.

\section{Discourse and Citizenship in a Racial Democracy}

What this chapter has demonstrated is the remarkable contiguousness of white supremacist values throughout a period of apparently dramatic transformation of national identity discourse. While the maneuverings of state elites initially paid little attention to the way their objects of discourse - i.e.: the population - might react to their

\footnotetext{
${ }^{34}$ See especially, Andrews (1991), Hanchard (1994) and Nascimento (2007).

${ }^{35}$ Important contributions to this erosion include Fernando Henrique Cardoso and Octavio Ianni's Côr e Mobilidade Social (1960), and the statistical work undertaken by Carlos Hasenbalg and Nelson do Valle Silva throughout the 1970s and 1980s. For more information, see Daniel (2006, esp. ch. 7)
} 
constructions, focusing instead on the perception of their nation by their counterparts in the idolized nation-states of Western Europe and North America, the shift to the discourse of racial democracy opened up some room for disadvantaged racialized groups to mobilize and make claims against the state. However, it was simultaneously an incredibly powerful deflective tool of such claims. Internalized as common sense, the claims of the organized Afro-Brazilian movement, of the descendants of early twentieth century immigrant groups, and of indigenous peoples denouncing state paternalism and cultural oppression were dramatically out of sync with the received wisdom regarding the Brazilian social structure and 'compact'.

This had extremely consequential impacts on the tangible fruits of societal organization provided through various dimensions of the welfare regime as a component of national citizenship. All Brazilians were deemed equal in discourse and law, and individual groups were frequently praised in official government publications. Yet the underlying values of white supremacy shaped the actions of those involved in distributing welfare, whether through state-run education, health and social security or privately organized through the capitalist labor market, which led to strikingly systematic patterns of inequality organized along racial lines. The ideology of racial democracy obfuscated the ways in which, as we will see in the following chapter, this inequality was not simply a class issue, which could in turn be deflected far more readily through a variety of justifications - particularly ones that planted responsibility for social ascension firmly in the capacities of the individual, or demanded that individuals subordinate their demands to the greater good of the nation. It covered up the way that social ascension was systematically delimited along the axis of 'race', and that this inequality was a structural 
legacy logically embedded within the development of discourses of Brazilian national identity. Brasilidade focused attention on the expressions of the societal structure - its music and sport, characteristics and nature - without seeing how these branches, ostensibly contributed by different boughs united in the single tree, in fact grew from the same white supremacist roots.

Returning the focus of national identity discourse to these historical roots shows that 'race' was an ever-present - indeed dominating - concern of elites in thinking about how to frame their nation, and this filtered up into the growth of the whole tree. Yet, as the next chapter will pursue, this was hardly limited solely to Brazil's material or even tacit culture, but had profound effects on the political economic organization of the country, especially in distribution of resources. Here, these discourses of national identity collided with conceptions of citizenship over access to rights and resources provided by the welfare regime. 


\section{Chapter 2: Citizenship and Welfare Stratification in a Racial Democracy: $1870-1950$}

For my friends, everything; for my enemies, the law - old Brazilian saying (Levine 2003: 156)

Where do Brazilian blacks really stand in relation to citizens of other racial origins, at all levels of national life? - Abdias do Nascimento (in Levine and Crocitti 1999: 379)

Thus far, this thesis has pursued the discursive interrelationship between 'race' and nation - the ways in which ideas and assumptions coalesce into dominant ideology. However, Brazil's racial ideology has not been confined to discussions amongst cultural elites, or to policymakers debating ideals. It has structured the entire landscape of social relations by encouraging specific actions while rendering others "unthinkable" (Trouillot 1995: 82). Or, for example, by infiltrating into one point where discourse becomes tangible practice: state policy and its consequences. This chapter seeks to provide a framework for testing the ideology of racial democracy against empirical reality, focusing attention on the state and its agents. To what extent has racial democracy, reiterated in discursive plays by state officials and intellectuals, lived up to its rhetorical content? Has the language of Brazil as a harmonious melting pot par excellence been mirrored by the actualization of substantive equality within the national territory for members of different racialized groups? Clearly, as already suggested, this has not been the case. Indeed, as this chapter will demonstrate, the ideology and discourse of racial democracy concealed intense welfare stratification that aligned neatly along the axis of 'race'. In doing so, the assumptions that undergird Brazil's racial ideology - namely white supremacy - will be laid bare.

Before delving immediately into empirical accounts of inequity in welfare provision, however, it is critical to outline the process by which discourse becomes part and parcel of policy. Part of this process - the deeply intertwined transition from racial 
beliefs and statements to pronouncements about the nation - was addressed in the previous chapter. How a surface feature of national identity discourse - universal equality - was imbibed into Brazil's official concept of citizenship while it was superseded by an unofficial citizenship derived from the subsurface racial ideology permeating national identity discourse, which in turn was formalized into a welfare regime in Brazil from the Vargas period onward, are the next components that this chapter will briefly articulate. This interplay will be clarified by examining the experience of Afro-Brazilians and indigenous Brazilians under state rhetoric, law, and practice. In the process, this chapter will deconstruct the systematic way in which social exclusion from welfare provision by the state was, in fact, heavily racialized.

\section{Citizenship as National Identity, Rights, and Welfare}

The process of encapsulating the nation as a discrete entity with specific characteristics, of ascribing it a telos and a particular history, is quintessentially a process of simultaneous inclusion and exclusion ${ }^{36}$. In Brazil, as we have seen, this process began first by subjugating and excluding non-white populations from belonging within the social, political and economic institutions of the nineteenth century. It proceeded by incorporating these populations in limited and marginal form, constantly subsumed to the white European archetype that served as its anchor, and finally, by providing the semblance of full and equal membership through the discursive maneuverings of racial democracy. In doing so, stakeholders of Brazilian national identity were defining not only belonging in the public realm, but the rules of participation in it. A whole host of agents vied to force through their own versions of national identity, representing the negotiation

\footnotetext{
${ }^{36}$ Carl Schmitt effectively makes this argument, though motivated by a different ontology, when he defines the political in terms of the 'friend/foe' binary. For a cursory genealogy of thinking on the modern nationstate, see Poggi (1978: 1-15), also Winant (2001: 22-31).
} 
of Brazilian citizenship as much as national identity. State officials mobilized to harness snippets of these constructions into a coherent narrative that enabled the expansion of the state and extended its capacity, capital and the agricultural elite intervened to ensure that their preferences were served by this construction, while everyday actors actualized, reinforced, internalized, challenged, distorted and reconstructed it.

Citizenship is often viewed at its point of fixity, as a rigid and official legal definition developed from the outcome of this struggle ${ }^{37}$. Yet in doing so, the historicity of these constructs are too easily forgotten, and more importantly, that they continue to undergo transformation resulting from ongoing struggle. Citizenship is best defined as the flux of power that surrounds debates on national identity: the constant negotiation of exclusion from full membership in the social institutions - broadly understood - of the national territory. Even T.H Marshall, whose classic developmental account of the civil, political and social rights of citizenship generalized from the specificities of the British experience, understood that each 'element' emerged out of distinct struggles to redefine Britain - for example, the Toleration Act, Catholic emancipation and the struggle over freedom of the press (1965: 81-2). Indeed, at its most basic level, as Ruth Lister puts it, citizenship "represents an expression of human agency in the political arena, broadly defined" (1997: 36).

Defining what a nation was, is, and should be, necessarily involves demarcating what kind of participation is acceptable within its territory, and in turn specifies just who is eligible for participation. Citizenship as legal codification, or 'official citizenship',

\footnotetext{
${ }^{37}$ For example, Castles and Miller posit certain legal constructions of citizenship that they suggest produce significantly different outcomes within their respective national contexts, including for welfare provision (1993: 43). While the two authors do critically assess the problem of empowering these models beyond their ideal-type usage (1993: 40), they put more weight on legal and other tangible structures than on informal structures and discursive mechanisms.
} 
whether established in constitutional form, statute, or decree (or indeed the concept of the national territory itself in the hazy realm of interstate law), grows out of this initial discursive contestation, though it has immediate consequences for ongoing struggles over the subsequent redefinition of national identity. As Janine Brodie points out with reference to Canada, the variability of competing imaginaries of the social or the nation put forth by antagonistic ideological camps is circumscribed by the law, historical "accidents", and the unpredictable forms of resistance encountered (2008: 23). These regimes - of law, economy, or culture - subsequently have a staying power that is often difficult to erode without long-term concerted (and sometimes fortuitous) action (see e.g.: Ebbinghaus 2005; Streeck and Thelen 2005). Such insight is useful in understanding the persistence of white supremacy in Brazil alongside radical attempts to erase it from discourse - for some like Gilberto Freyre, as we saw in the last chapter, redefining the epistemological underpinnings of Brazilian national identity was, at least according to his stated intention, a way to change it. Yet, as we will see, discourse and intent are not always sufficient for producing change in practice, or in the material experience of discourse: law, for example.

Focusing on the tangible side of discourse - the various regimes that emerge out discursive contestation and negotiation - is absolutely essential for any evaluation of Brazil's racial democracy. When this is done without situating the fixity of citizenship in the context of struggle (even when that struggle is not the object of study per se), however, it risks capitulation to the temporarily dominant construction of it, that is, whichever ideological position 'won' the moment. Hence, we need to conceive of citizenship, understood in Ruth Lister's formulation, as an integrated feedback loop 
interweaving national identity discourse, official citizenship, the rights regimes that flow from it, and the combination of these various sets of rights into a distinct production of welfare. While in reality these seemingly disparate components are fluid and overlapping currents of socio-political action, for heuristic purposes, it is practical to understand them as relatively distinct links of a chain. Although space restraints prohibit detailed analysis of each particular node, this chapter endeavors to schematize the interconnections between national identity discourse, official citizenship, and welfare established in Brazil from the late Empire through the Vargas era - a watermark of modern Brazilian politics and society.

\section{Brazilian Citizenship: Janus-Faced Rights}

As explained in the last chapter, the orientation of Brazilian intellectuals operating in all fields tended outwards, specifically towards France and later the United States, throughout the nineteenth century and into the twentieth. This especially impacted lawmakers who under the direction of a vibrantly emerging positivism needed to formulate legal frameworks that reflected their nascent modernity. Weak state capacity and authority were perpetual problems facing state builders from 1822 onwards however, and the dominant approach for the conduct of day-to-day business during the Imperial period relied on patronage based on personal political relationships (see Graham 1990). Hence, despite the focus on French and U.S. constitutional developments, Brazilians could not easily implement foreign frameworks of legal citizenship, even if the will to circumvent existing political culture existed. Instead, as James Holston points out, elite state builders craned towards these cases while making important adaptations that suited their local reality (2008: 43). 
Legally, nationality clauses of citizenship were well defined immediately after independence with the 1824 constitution. The constitution allowed for universal jus soli citizenship (circumscribed by civil status, i.e.: slavery) and restricted jus sanguinis, a regime which effectively persists today (Holston 2008: 63). Yet the law itself was of less importance for Imperial Brazilian statesmen, for the constitution rejected universal equality of rights while upholding equality before the law, effectively avoiding any “concept of fundamental substantive equality" (Holston 2008: 27-8). Instead, the relative lack of state capacity outside metropolitan centers ensured that the law was meted out locally, parochially and according to the customs and prejudices of the people most capable to deliver $\mathrm{it}^{38}$. As an English naval officer reported during his travels in Northern Brazil, "The fact is... 'might makes right'...The emperor may send forth edicts, and the president [of the province] orders, but the isolated branco [whiteman] is himself an emperor, and much more absolute than Don Pedro at Rio [de] Janeiro" (qtd. in Holston 2008: 323).

Thus, while one conception of Brazilian national identity - the inclusion of all native-born individuals - forced Imperial statesmen to erect one face of the law, one that in theory all free Brazilians could approach equally, the other face, equally derived from a different current of national identity - the anxiety over Brazil's demographics within the context of white supremacy - led to a rather different expression of law in practice. Such a system ensured the differentiated experience of citizenship, but also that differentiation would not so easily be institutional, as for example in the United States. Rather, differentiation emerged out of the distinction between official inclusion under the

\footnotetext{
${ }^{38}$ In Brazil, owing to the semi-feudal character of land distribution and authority, these were ultimately the plantation aristocracy. See Graham (1990) for a detailed account of the interrelationships of coercive authority.
} 
law, and the impossibility of substantive inclusion as it was determined in everyday life. Hence, legal citizenship during the Empire held the peculiar function of being present while superseded by extrajudicial powers - whether held through formal political channels (e.g.: executive power) or more frequently, through the arbitrary power of local landowning elites.

Two examples help illustrate this complex landscape of citizenship during the nineteenth century. Sidney Chalhoub highlights the case of João José da Costa, a rich planter elected to the post of Justice of the Peace in an 1876 election. After a resident of his parish complained about the election by accusing da Costa of being a freedman, born of a slave womb, and therefore ineligible for office - citing the Constitution and electoral legislation - the Council of State decided to disallow the charge. Even though baptismal records and testimony (hearsay) from a parish priest were procured that stated that da Costa was born of a slave, the Council decided that there was no way of being sure that the elected João was the same one referenced in the documents. As Chalhoub concludes, because he was a rich planter who operated in the same social circles as the councilors, the whole situation was very uncomfortable, and suggests that the councilors would prefer "that such a story [n]ever surfaced" (2006: 77-8). It should be noted, however, that this case was the exception rather than the rule when it came to adjudicating between competing claims of whites and nonwhites.

The second case revolves around disputes over the proposed scope of the 1871 Rio Branco Law which declared that all children henceforth born to slaves would be born free. However, the wording of the law was debated by deputies: were these children to be born ingênuos [born of a free womb] or libertos [freed, i.e.: after birth]? Besides 
impacting the political rights of citizenship that future children could have, the debates had serious consequences for the relative power of owners within the institution of slavery by either granting or denying them monetary compensation for the children. The outcome was to leave the question undetermined - simply to call them free ${ }^{39}$. Yet, interestingly, out of over 350,000 children born in the thirteen years after the passing of the law, slave owners sent only 113 to government institutions at age eight for the indemnity that was due to them under the law. It is not that slave owners opted to raise these children until the age of 21 , providing them with the resources they needed for future citizenship as the law alternatively required. Rather, they continued to utilize the slave labor of these 'free' children despite what any law demanded of them (Chalhoub 2006: 78-81).

These two examples show that legally designated official citizenship was a nominal construction rarely used to answer social questions substantively. However, it was an important façade that required that continual reference, deference and homage be paid to it. As the councilors ultimately recognized in the case of José João da Costa, if incontrovertible evidence emerged that proved his status as slave-born, his election "would be declared void and he would have to step down from office" (Chalhoub 2006: 78). Yet the caveat of evidence was perpetually subject to redefinition by those making decisions, much in the same way that slave owners decided to ignore the law altogether, knowing that no enforcement would ever be attempted. Both determinations of how citizenship operated in practice in nineteenth century Brazil revolved around particular conceptions of the nation's identity as established through discourse. In the first case, the

\footnotetext{
${ }^{39}$ Chalhoub points out, however, that the Imperial government more or less systematically adopted the term ingênuos in subsequent reports and edicts, despite the fact that no formal decision had been made (2006: $81)$.
} 
wealth and status of da Costa bypassed his alleged civil status. The discomfort of the councilors with the whole situation is reminiscent of Silvío Romero and his attitude towards what miscegenation could mean for the country's future. What did it matter whether da Costa was born a slave, given his ascension to the ranks of wealth, notability and power? Such allegations only served to highlight the incomplete and contradictory vision of the nation that characterized the time period. The decisions made by the slave owners to ignore the laws proclaiming the freedom of the children of slaves, on the other hand, reflect their practical economic interests. Yet these interests were fully supported by scientific racism which was reaching its zenith in the 1880 s. While owners defending the institution of slavery would ultimately lose their battle - much like scientific racism would eventually be displaced in favor of a 'friendlier' expression of white supremacy their actions were facilitated by the discursive environment that these ideas enabled.

This dual-sidedness of Brazilian citizenship persisted into the Republican period (1890-1930), enhanced through alliances of local landowners and the power of the state under the system of coronelismo that made the practice of law all the more arbitrary. The 1891 constitution radically decentralized power to the states, which ended up favoring the coffee and dairy production regions of the center-south, as well as a growing class of urban industrial capitalists, but failed to alter the absence of rights in the wording of the equality clause (Topik 1987: 2; Holston 2008: 27). However, the 1888 Golden Law that preceded it also established nominal citizenship for all native born individuals by criminalizing slavery. This establishment of a modern republican state and the stridence with which elites upheld it, and, for the first time, a nominally universally applicable citizenship scheme signified a shift in the way elites approached matters of rights and 
welfare. This was buttressed by the fact that, with rising expectations, citizens began demanding more of their leaders ${ }^{40}$.

In responding to the pressures of an increasingly mobilized populace, republican elites managed different types of citizens quite differently. While all slaves were freed formally, other mechanisms were found to ensure their stratification attenuating the promise of full inclusion in the public sphere into "contingent and partial citizenship" (Hanchard 1999: 60). With relatively large percentages of slaves in major cities (e.g.: $21 \%$ in Rio de Janeiro), abolition presented concerns for the predominantly white elite keen on maintaining racial inequality ${ }^{41}$ (Drescher 1988: 34). For those in the camp of Nina Rodrigues, newly freed blacks were completely rejected as potential contributors to the nation, while they were viewed with extreme suspicion by those subscribing to Vianna's ideological package. In either case, white European immigration was favored as the dominant approach for filling the labor market 'shortage' created by the combined facts of abolition and the exclusion of former slaves from the labor market. George Reid Andrews' study of two factories in São Paulo - Jafet, a textile firm comprised of mostly women and child workers, and São Paulo Light, a power company employing mostly adult males - illuminates labor market discrimination clearly. Over the course of the 1920s, fully 92.4 percent of Jafet workers were white, of which a full third were immigrants. At São Paulo Light, nearly $80 \%$ were white and just over $27 \%$ were foreign-

\footnotetext{
${ }^{40}$ Although, no matter the 'race' of the claimants, to little avail. For an excellent insertion into the class struggle literature of the period, see French and Fortes (1998).

${ }^{41}$ As Nascimento points out, "In its new role as bearer of citizenship rights, the postabolition majority black population embodied a potential threat to the political power of the minority elite. The fear of this threat was expressed in the discourse of national unity. Enmeshed with the notions of pseudoscientific racism, this discourse considered Africanness and blackness extraneous to the national context" (2007: 52). Hence, part of the legacy of scientific racism forced elites to grapple with defining how blackness fit within the construct of Brazil, a struggle which led to fluctuating restrictions on blacks at the level of policy and practice.
} 
born $^{42}$ (Andrews 1991: 95-6). Although census data did not account for 'race' in the 1900 and 1920 censuses, ${ }^{43}$ the 1890 census recorded only $63 \%$ whites in the state of São Paulo (Andrews 1991: 247).

As a result of this labor market stratification, income differentials quickly grew between the black and mulatto native born population, and the white immigrant population hailing principally from Italy, Portugal and Spain. Indeed, foreign immigrants with limited education were "likelier to advance to skilled administrative positions than nonwhites with equivalent backgrounds", and while nonwhites in factories tended to be better educated than immigrants, they occupied the "bottom of the occupational pyramid" (Adamo 1989: 194). This systematic exclusion from the labor market led some urban blacks with no practical options for gainful employment to form gangs engaged in robbery in an attempt to acquire basic means of subsistence, often using capoeria as a technique ${ }^{44}$. Yet state officials too were quick to close off this - albeit violent - option for obtaining a livelihood. The introduction of the 1890 Penal Code specifically cracked down on the practice of these gangs, prohibiting the practice of capoeira in public spaces and allowing for the expulsion of practitioners from the country - a maneuver reflective of whitening attempts of the time (Skidmore 1993: 47). Article 399 solidified this sustained pressure on new black citizens by permitting the arrest of any person "leaving the exercise of a profession, employment, or any service in which one earns a living; not possessing a means of support and a fixed domicile in which one is residing; earning a living in an occupation prohibited by law or manifestly offensive to morality and

\footnotetext{
${ }^{42}$ This was a large improvement over numbers from the 1893 city census in terms of employment parity in São Paulo, $72 \%$ of workers in commerce, $79 \%$ of factory workers, $81 \%$ of transport workers and $86 \%$ of artisans were foreign born (Andrews 1991: 67).

${ }^{43}$ For partial indication of the reasons for this, see Skidmore (1993: 201).

${ }^{44}$ For the multifaceted practices of capoeira, see Assunção (2005: esp. pp. 87-95).
} 
propriety" (Green 1999: 22-3). For those unable to find a job, and recently freed without reparations, such vagrancy laws were tantamount to institutionalized racism. Yet the law made no reference to 'race', for everyone was declared equal under and before it. Rather, according to elite conceptions of national identity at the time, policies and laws were derived that facilitated their intentions while maintaining the semblance of adherence to the nominal equality of citizenship. The fact that capoeira was deeply connected to AfroBrazilian history and heritage, and its penalization simultaneously embodied their denial of cultural recognition in addition to being materially repressive, was of little concern to Brazilians marching towards 'civilization' (Sansone 2003: 71-2).

The Old Republican period, embodying the process of negotiating competing racial ideologies, inched towards the discursive erasure of systemic racial inequality while continuing to entrench it in Brazilian society. Because of intense labor market discrimination, urban nonwhites suffered from inequity in access to other aspects of welfare. Unable to afford sanitary housing, they were jammed into tenement housing (cortiços) or shantytowns (favelas) which through overcrowding and shared water facilities led to high rates of disease. Infant mortality per thousand in 1890 stood at 397 for whites, 407 for mulattoes and 497 for blacks, while rates of death from infectious disease per hundred thousand were 935 for whites, 1133 for mulattoes and 1245 for blacks in 1904. While these numbers declined drastically over the next twenty years, whites saw mortality rates drop by $35 \%$ while mulattoes and blacks saw only 15 and 27 percent declines respectively. Such clear stratification in health is masked further by the fact that black mortality rates were underreported until the 1930s (Adamo 1989: 198-9). Moreover, since most republican welfare institutions were legacies of the imperial era, 
organized through employment-based mutual aid societies or accessed through employment - for example, childcare, medical and dental assistance, and emergency financial aid were all provided by the Worker's Pension Fund of the Companhia de Fiação e Tecidos Corcovado established in the 1890s - systematic labor market discrimination during the Old Republic equaled systematic welfare discrimination ${ }^{45}$ (Kuhlmann Jr. 1996: 68; see also Batalha 1998).

Hence, despite equalizing the formal legal status of all Brazilians for the first time, the republican period clearly established gradations of citizenship that accorded closely with discourses of national identity inextricably tied to issues of 'race'. Whites were preferred in all arenas even to the point that immigrants with fewer qualifications could expect better treatment than native-born blacks and mulattoes, according to the whitening ideal prevalent in the early decades of the twentieth century. What is also evident is that these gradations were not simply issues with formal legal equality that could be addressed with changes to the law, but arose from employers and policymakers playing 'tag' with the law and translated into highly stratified substantive welfare for certain citizens. Despite their proclaimed equal status, blacks could expect to die sooner, earn less income, and obtain lower educational outcomes than whites. ${ }^{46}$ Yet as we saw in the last chapter, racial inequality was carefully excluded as a legitimate factor contributing to Brazilian 'social' inequality by the sunset of the Old Republic. As President Washington Luíz (1926-1930) is supposed to have said, "the social question in Brazil is one for the

\footnotetext{
${ }^{45}$ While generally mutual aid organizations did not impose outright restrictions on membership beyond the 'normal' barriers of the labor market already described, some went further. One organization's 1875 charter barred all blacks and freed slaves of any color from membership (Batalha 1999: 64).

${ }^{46}$ See especially Jerry Dávila (2003), who not only demonstrates that blacks were excluded from the education system, but the ways in which the whitening logic pervaded the entire public education system in Rio de Janeiro during the interwar period.
} 
police": a cleverly duplicitous way of referring to the arbitrary way in which elites managed class conflict which itself masked racial inequality (Hall and Garcia 1989: 163). Indigenous peoples were also placed in a peculiar position with regard to their citizenship. As the Brazilian economy expanded, governmental policy turned to the 'national colonization' of the interior. In 1910, the Indian Protection Service (SPI) was established with Cândido Rondon at its head. Tasked with "bringing basic services (health care, education) to the Indians without destroying their culture or social structure", Rondon hailed indigenous peoples for the role they contributed to the national patrimony (Skidmore 1999: 81). Indeed, to positivists such as Raimundo Texeira Mendes and Rondon, indigenous peoples were at the heart of Brazilian heritage - quintessential citizens - they just needed proper training and socialization to fulfill that role completely (Diacon 2004: 102). The two-pronged approach of Rondon and the SPI involved 'preserving' indigenous land, social organization and cultural practice while 'encouraging' the uptake of 'modern Western' social practices and technologies.

In practice, through residential posts the SPI was involved in extracting resources using indigenous labor, and worked to strip indigenous peoples of their languages, their culture and customs (Diacon 2004: 117). The enabling legislation for the SPI, the 1916 Civil Code, treated indigenous peoples as a "residual category... as objects of guardianship to last [indefinitely] until they became adapted to national society" (Ramos 1998: 18). Declared "relatively incapable", indigenous peoples "could not purchase, sell, or transfer land without the federal government's approval. They could not sign labor contracts or myriad other contracts" (Garfield 2001: 40; Diacon 2004: 118). On the one hand, indigenous peoples were vaunted members of the Brazilian national community, 
and yet disenfranchised through statute law and the practices of a government agency, they were unable to engage in the same sorts of social practices and civil rights as other Brazilian citizens.

The welfare policies of the SPI can be analyzed ambivalently: on one hand, officials planted orchards and offered indigenous people access to them, yet cut down the forest to do so. They offered education, but only in Portuguese (de la Peña 2005: 723). They offered health services, but these were "few in number, sporadic and disorganized" (Langdon 2007: 11; Coimbra Jr. et al. 2002: 192-3). Indeed, when contrasted against the larger backdrop of denial of cultural autonomy, the limited and piecemeal material welfare provided by state officials was not much more than a pittance. For ultimately, as an official SPI conference paper stated, the agency did “...not want the Indian to remain Indian. Our task has as its destiny their incorporation into Brazilian nationality, as intimate and complete as possible" (Garfield 2001: 39).

Despite promises of equality before and under the law and their inclusion as full citizens within the national context, indigenous peoples systematically saw the opposite occur in an intensely totalizing fashion. As Holston points out, "Brazilian inclusion allowed the Indians no existence apart from the Brazilian nation, no autonomous culture, settlement, or even biology" (2008: 71). Such systematic differentiation of the experience of citizenship was less driven by the law ${ }^{47}$ than by certain conceptions of indigenous peoples and how they fit under the umbrella of Brazilian national identity. The discursive

\footnotetext{
${ }^{47}$ Indeed, Imperial legislation spelled out the framework governing indigenous land fairly clearly, although supplementary decrees and decisions created apparent contradictions. Regardless, local governments appropriated indigenous land in potential contradiction with Imperial law - a practice which was validated by the decentralizing constitution of the Old Republic (see Holston 2008: 73-5). In any case, law regarding indigenous land was built upon practice as a secondary consideration of justification instead of as an attempt to produce specific actions and practices.
} 
trend emerging from the Romantic Indian movement may have praised the indigenous contribution to the nation, but of course this occurred only under a specific set of conditions - namely the erasure of 'the Indian' altogether. In practice, their differential treatment corresponds to the racial ideology of the time proclaiming white biologic and cultural superiority. ${ }^{48}$

While the Old Republic was a period of negotiation - of Nina Rodrigues versus Oliveira Vianna and the respective camps they represented - it was also one of consolidation. Increasingly, as the overtly racist positions of proponents of miscegenation became untenable in the face of global shifts in 'race' thinking, Brazilian intellectuals and politicians sought to integrate the white supremacist underpinnings of Brazilian social life with a narrative of 'Brazilianness' that corresponded to the ways in which European and North American thinking were defining the equality of peoples. They found this in the thought and writing of Gilberto Freyre, a product of the U.S. academy, whose theory of racial democracy was quickly taken up by the corporatist populism of Getúlio Vargas. Next, this chapter turns to the significance of the ideology of racial democracy for AfroBrazilians contestation, as it was consolidated during the Vargas era.

\section{Deflective Democracy: Erasing 'Race' from Citizenship and Welfare}

Prior to the rise of Vargas, Brazil's experience with national social policy was limited. In the wake of massive uprisings - most notably the 1917 São Paulo general strike - the federal and state governments intervened only marginally to placate the

\footnotetext{
${ }^{48}$ Of course, control over indigenous peoples was not only an ideological exercise, but reflected increasing concerns with 'national colonization', a product of expanding the boundaries of state power. The principal way in which the state encouraged this over the course of the twentieth century was through economic development - A Marcha para o Oeste. Hence, indigenous dependency cultivated through their placement in 'demarcated territories' was a way of freeing up land for agricultural and mining interests.
} 
working population.$^{49}$ In 1919 , a worker's compensation plan was introduced which made coverage mandatory for workers in transportation and construction, as well as an in factories employing machinery (Dean 1969: 158). Although business worried at first what this would mean for them, the law was poorly enforced and circumvented by employers (Deutsch 1999: 126; Love 1980: 89). Moreover, since nearly 60\% of workers in the transportation sector, and $51 \%$ in industry were foreign-born, and many of the Brazilian workers were children of immigrants, the effect these benefits had on racialized Brazilians was limited (Andrews 1991: 67). In 1923, the so-called Elói Chaves law was introduced which provided retirement and survivor's pensions to railroad workers (Love 1980: 89). Over the course of the 1920s, profession-based benefits were extended to workers engaged in commercial activities, public service, industry, and bank employees, and totaled close to 200 individual programs by the end of the decade (Medici 2004: 2). However, as noted, labor market opportunities for blacks actually declined over the three decades of the Old Republic, especially in the professional areas that received the most attention from policymakers, excluding them from access to these new government programs:

Blacks were almost completely barred from factory work, and black artisans had virtually disappeared from the city [São Paulo]. Poor and working class black people found their job opportunities restricted to domestic services and what today would be termed the informal sector (Andrews 1991: 68)

\footnotetext{
${ }^{49}$ Although welfare benefits were extended narrowly to state employees even during the Empire - military personnel and civil servants for example received pensions. While government employment tripled between 1870 and 1920 - to form $1.5 \%$ of the working population - this expansion was less the result of national social policy, than a way to co-opt the urban middle class under the aegis of the cartorial state - a system whereby superfluous public sector jobs are created in exchange for political support (Malloy 1979: 41, 28; Jaguaribe 1967: 29)
} 
While the 1920s saw increased responsiveness by the political and economic elite to the increasingly militant demands of the masses for social support, black workers were far off their radar.

When Vargas came to power, he rode on grandiose campaign promises that brandished a whole host of improvements to social welfare - "education, hygiene, diet, housing, protection of women and children, invalids and old people, credit, salary relief, and even recreation, including sports and artistic culture" (Platform of the Liberal Alliance 1999: 156). Although his policy direction and efforts would waver ideologically depending on the political landscape,${ }^{50}$ he was steadfast on the notion of Brazil as a racial democracy. As the central pillar of his nationalism, he viewed each 'founding' ethnic group in Brazil as contributing a vital cog to the nation's success. Indeed, Vargas put some of this rhetoric into practice - instituting the Law of Nationalization of Labor in 1931, which required that two thirds of employees be Brazilian born, which, when practiced, translated into increased labor market options for urban blacks and mulattoes, and responding to the demands of the recently-formed Frente Negra Brasileira (FNB) for greater representation of blacks in the São Paulo state militia ${ }^{51}$ (Andrews 1991: 147-51). While this earned him the respect and admiration of many blacks, Vargas viewed groups like the FNB with suspicion for the threat they posed to the homogenous construction of

\footnotetext{
${ }^{50}$ For example, Vargas clearly admired the Axis powers in his speeches, and copied the labor provisions in the 1937 constitution almost verbatim from Mussolini's Carta del Lavoro, yet became the only Latin American country to officially commit troops to the Allied cause (French 2004: 15; Lesser 1995; McCann 1995; Time 1940). Robert Levine has called Vargas an "enigma" (1998: 1), while Williams and Weinstein call him "ambiguous" and imply the likely answer: ambivalence (2004: 295).

${ }^{51}$ Of course, while Vargas' nationalism offered a modicum of improvement to native-born racialized groups, it was particularly virulent in its xenophobia - an ideological package consistent with the thinking of European fascism and the inside/outside binary. For more on this, see especially Lesser (1999).
} 
Brazilians (and the harmony that this implied) that he was attempting to translate into state policy (Daniel 2006: 68) ${ }^{52}$.

The 1934 Constitution attempted to codify this rhetorical commitment to equality by implementing a vague set of rights that citizens could supposedly count on. Article 113 stated that there "Will be neither privileges nor distinctions for reasons of birth, sex, race, profession or parentage, social class, wealth, religious beliefs, or political ideas" (Constituição do Brasil 1934: Art. 113, § 1). This sweeping set of guarantees was little more than a measure to deflect the emerging criticisms of organizations such as the FNB, whose primary aim was to get black candidates elected to the Constituent Congress convened in 1933 to determine the 1934 Constitution (Andrews 1990: 147-8), than a tangible constitutional right that would be enforced through statutory law ${ }^{53}$. Indeed, only three years later, Vargas committed a self-coup, further centralizing his power and eliminating his opponents on both the right and left by outlawing all political activity. ${ }^{54}$ In the newly created constitution of this Estado Novo promulgated in 1937, these generous sets of rights were dropped once again.

Vargas' relationship with racialized Brazilians represents a strategic cultivation that necessarily imposed limitations on the extent of their citizenship. While he attempted

\footnotetext{
${ }^{52}$ The initial years after the 1930 Revolution saw an outpouring of engagement from 'civil society' with aims that did not really accord with Vargas' vision. For example, the National Liberation Alliance - a popular front organization set up by the Communist Party of Brazil - actively campaigned on campuses in Rio de Janeiro and São Paulo for black social equality (Levine 1970: 73).

${ }^{53}$ For example, while the constitution allowed for open immigration, subject to a nation-based quota system (a $2 \%$ limit per year of the "total number of respective nationals settled in Brazil during the last fifty years") and "necessary restrictions to the guarantee of the ethnic integration and the physical and civil capacity of the immigrant" (Constituição do Brasil 1934: Art. 121, § 6), the Vargas government had expanded an Old Republican ban on African and Asian immigration through "secret and semi-public immigration orders that excluded at times Jews, Catholics, Hindus, Muslims, Europeans, U.S. citizens, and those from the Middle East" (Lesser 1994: 25). See also Telles (2004: 38).

${ }^{54}$ Because of its fragmented nature and relatively weak impact on broader society, Vargas permitted the FNB to "die a natural death" - which occurred in May 1938 - instead of forcibly repressing it, as he did the fascist Integralistas, for example (Andrews 1990: 155).
} 
to placate them (and other political interests) with rhetorical flourish and populist promises, their participation in politics was never necessary. For example, while Vargas turned to samba and capoeira for the first time as positive symbols of Brazil, he did so by appropriating them from their cultural roots for use in the national construct. Through strict regulations on radio, his administration forced musicians and radio professionals into submission to directives they rarely broke (McCann 2004: 9). In this way, samba was transformed from a marginal musical genre performed by poor Afro-Brazilians at parties in the favelas of Rio de Janeiro into a huge cultural industry symbolizing the Brazilian nation (Chasteen 2004: 33-50). The Vargas government established regulations governing samba schools and provided subsidies and prizes for those it deemed appropriate, and established the entire program of activities for the Rio de Janeiro Carnival (Green 1999: 207). However, the interpretation of samba and its relationship to Brazilian national identity was mostly off limits to its practitioners, for the "authority of the icon depended on at least the illusion of unanimity and inevitability" - the Vargas government unanimously dictated what its meaning inevitably was, and thus no input from blacks producing the music could be tolerated if they wished to contest the tropes the government was encouraging (McCann 2004: 41). Of course, as McCann explains, these tropes "hooked [the folkloric vision of samba as national essence] to a patriotic celebration of Brazil's march to a bright, exceptional, racially democratic future" (2004: 93).

While with one hand Vargas allotted Afro-Brazilians a place in national identity they had not hitherto had, with the other he inhibited the autonomous expression of the meaning they ascribed to those symbols. Such circumscribed recognition consequently 
forced Afro-Brazilians into a position which limited the extent of their agency: if samba was understood as a paragon of racial democracy, how could blacks complain about their treatment in society when they were able to participate in this illustrious cultural sphere? The difficult situation that the cultural appropriations put black practitioners in with regard to their recognitive welfare carried over into their material welfare as well. The National Liberation Alliance complained that the recording industry was not paying royalties to favela songwriters, many of whom lived in serious poverty, but these accusations were largely ignored by the Vargas regime (Levine 1970: 80).

The notion that Brazil was a racial democracy intensified as Vargas consolidated his power. He frequently parroted the notion both internally and externally that Brazil had avoided the racial dilemmas of other nations (Hasenbalg 1992b: 140). For example, in a 1944 article in The Rotarian, after extolling Brazil's march to modernity and civilization, Vargas added, "Brazilians, furthermore, consider it unworthy of their inmost nature to harbor any prejudices of race or caste" (Vargas 1944: 18). He matched the nation's supposed moral high ground with claims regarding the moral position of the state as well. In a 1938 New Year's address, Vargas acknowledged that “just as a single flag supremely protects all Brazilians, the law also ought to assure, by a uniform method, the rights of citizenship in the entire national territory" (Vargas 1999: 187). Indeed, through strict control over his ministers, Vargas ensured the message of racial democracy was articulated uniformly in all quarters of government and its interaction with society.

Vargas' attempt to construct Brazilians as a singular people was highly successful, and through the near totalizing sweep of his message and the emergent forms of communications his government skillfully utilized, quickly became entrenched in public 
consciousness. Hasenbalg points out that the belief in racial democracy had "assumed the character of commandments: '(1) Under no circumstances should it be admitted that racial discrimination exists in Brazil; and (2) any expression of racial discrimination that may appear should be attacked as un-Brazilian" (1985: 8). Gilberto Freyre, who by the 1940s was involved in politics, found himself the defender of a theory of acculturation that had now become inseparable with hard-line nationalism. He spoke out against the tendencies that he saw emerging (no doubt motivated in part by the activity of the FNB and the Teatro Experimental do Negro, founded in 1944 by Abdias do Nascimento) in Brazilian society and sought to mitigate them:

It is clear that two kinds of racism are arising in Brazil, as rivals: the "racism" of Aryanists who, in general, are under the pressure of the current supremacy of Anglo-Saxon paragons in half the world, and the "racism" of those who, for political or party-related ends, seek to oppose the racism of the "Aryanists" with that of a Brazilian Negro caricatured as North American. This second "racism" is, in general, inspired by individuals who are under the pressure, in Brazil, of the Communist mystique, not always easy to separate from the power of a Stalinist Russia, just as imperial as that of the United States (qtd. in Nascimento 2007: 150)

Freyre deflected the unignorable 'black agitation' bubbling under the meniscus of racial democracy by accusing blacks complaining of their social position as practicing

Communist-inspired racism - a surprising move for someone who was accused of being a Communist himself during his political campaign (Burke and Pallares-Burke 2008: 116). Yet this maneuver also differentiated 'true' Brazilianness from Cold-War foreign influences, effectively closing off debate over acceptable critique by Brazilians. Deviation, at least discursively, from the harmonious notion of racial democracy was a product of 'outsiders', neither the legitimate concern of black citizens struggling to be treated as equal citizens, nor the 'organic' racist beliefs of many Brazilians. In $1950-$ when Vargas returned to power, democratically elected, after a five year hiatus - the African-American dancer Katherine Dunham was denied access to an upscale São Paulo 
hotel room, sparking intense discussion when she sought to complain to authorities. ${ }^{55}$ Freyre again was on the front lines, attributing Dunham's experience to São Paulo provincialism, "where U.S. industrialism and commercialism had taken over 'with a vengeance"" (Telles 2004: 37-8).

The ability to shrug off accusations of racial discrimination, or even to subvert them as 'reverse racism', has retrospectively constituted the hallmark of racial democracy, since by the early 1950s, UNESCO-sponsored sociologists were uncovering that the ideology had little empirical merit. Yet, even without internationally-sanctioned studies or groundbreaking research by domestic academics, cracks in the ideology of racial democracy emerged through people's everyday experience. Racialized labor market discrimination was considered normal, driven in part by help want ads stating "persons with good appearance preferred" (Nascimento 1980: 204). Domestic workers were expected to use the service elevator, but since most domestic workers were not white, it was equally expected that all blacks in certain neighborhoods or buildings should use the service elevator. ${ }^{56}$ Despite the integral element of close contact slavery that defined Brazilian 'race' relations in Freyre's oeuvre, residential segregation in urban areas has historically been a defining feature of Brazil's spatial landscape - to say nothing of regional segregation (Telles 2004: 194-214). Brazilian elites quickly sought explanations to these phenomena and found them in the same justifications that Pelé leant on. For

\footnotetext{
${ }^{55}$ Dunham was told that since Brazil was a racial democracy and thus did not have any laws against racial discrimination, there was little she could do. In response, Afonso Arinos de Mello Franco introduced a bill that made overt forms of racial discrimination punishable by misdemeanor in limited circumstances (Jonesde Oliveira 2003: 103-20). With the exception of the 1934 Constitution, this was the only law dealing openly with racial discrimination since abolition, and the only one on the books until the 1988 Constitution. Predictably, it was not effective.

${ }^{56}$ See Michael Hanchard's excellent essay regarding the verbal and physical assault the daughter of the governor of Espírito Santo received when attempting to use the main elevator in a building in Vitória in 1993 (1999: 59-81).
} 
many Brazilians, 'race' was only significant in that it overlapped with class or social status:

Although nonwhite Brazilians invariably clustered at the bottom of the social ladder, Brazilians were adamant that this was the result of skills, and in a society where family name was often more important than material status, they could claim that there was little or no prejudice in Brazilian life solely on the basis of skin color (Levine and Crocitti 1999: 351)

However, as argued thus far, class and social distinctions were informed by ideological notions of 'race' that upheld, first explicitly then implicitly, the belief in white supremacy. Income stratification may have been the proximate cause of residential segregation, yet the proxy was a result of outright labor market discrimination that favored whites over everyone else. When these class and status distinctions were internalized into national identity over the course of the Vargas years as essential explanatory mechanisms for any lack of 'harmony' or substantive equality that arose out of racial democracy, the erasure of 'race' from citizenship and welfare was complete. ${ }^{57}$

\section{The Birth of the Brazilian Welfare State under Vargas}

The hodgepodge of welfare programs initiated in the dying decade of the Old Republic was seriously addressed by Vargas. As part of his expansionary state advanced under the banner of a uniform and harmonious nation, placation of certain groups within his corporatist network was required to ensure their support. Vargas expertly handled the myriad pressures of an eager Brazilian populace - as mentioned in the previous chapter he courted disparate intellectuals into supporting his vision of the nation. He offered some real improvement for marginalized groups, namely native-born white urban labor who had been excluded under the republican oligarchy, and he ensured that the urban

\footnotetext{
${ }^{57}$ More practically, Hasenbalg points out that the class explanation "produces a sense of relief among whites, who may exempt themselves from any responsibility for the social problem of nonwhites" (1985: $10)$.
} 
industrial capitalists were favored over export-oriented agriculturalists. ${ }^{58}$ Such patronage to his clients even extended to nonwhites to a minimal extent, who as a result of certain “colorblind decrees" saw increased opportunity in the public sector (Levine 1998: 119).

It is not so simple, however, to say that the Vargas years were simply successful attempts at corporatist populism. They reflected a real attempt to expand state benefits beyond simply the elite or bureaucrats to a much larger segment of the population, thus contributing an enduring institutional and cultural legacy to Brazilian politics. ${ }^{59}$ Social protection legislation was introduced that included an expanded worker's compensation plan in 1934 (Frumkin and Câmara 1991: 1620), and Vargas created a unified social security system that absorbed independent plans (and created new ones), which was expanded incrementally over the course of the 1930s (Malloy 1979: 67). All told, nearly two million people were integrated into the pension scheme, although it excluded the rural sector, the urban self-employed and those whose employment was irregular, informal, or part-time (Malloy 1979: 62). Yet, as noted above, these sectors contained significantly higher proportions of nonwhites than those that were covered. The types of people that the Brazilian government felt were worthy of full citizenship through their inclusion in state benefit schemes overwhelmingly focused on whites to the exclusion of others.

This is perhaps most clear in the domestic and informal labor sectors, the latter classified in the 1940 census as 'economically inactive', and thus undeserving of benefits.

\footnotetext{
${ }^{58}$ Brazil represents a rare case of economic development in Latin America, since the rural agricultural class led investment in urban industrial manufacturing, and subsequently the creation of a domestic market, mostly because they saw this as an effective strategy to diversify their holdings and improve their home regions (see Dean 1969: 34)

${ }^{59}$ Indeed, in 2005, President Lula defended himself in the midst of a scandal by drawing upon the memory of his predecessors, saying "I will not do what Getúlio Vargas did, nor will I do what Jânio Quadros did" (Clendenning 2005). Vargas committed suicide in office, while Quadros abandoned his post as part of a very questionable political strategy. See also Cardoso (2006).
} 
While the uptake of nonwhite Brazilians into industrial employment improved over the 1940s, doubling over the decade, 60 percent still worked in sectors that remained outside the scope of Vargas' welfare programs (Andrews 1991: 101). Indeed during the Vargas years, Levine points out, “Brazil's haves...employed more maids and domestic servants than any country in the Western world, because labor was cheap" (Levine 1998: 100). Yet it was no coincidence that the cheapness of domestic servants correlated with the fact that Afro-Brazilian women predominantly performed these services - or also because this occupational group was excluded from minimum wage laws enacted in 1943 (Levine 1998: 11; Pereira 1997: 26).

The urban-rural divide may not seem particularly significant as evidence for racialized welfare stratification since it affected whites as well, but this divide itself was heavily racialized. Urban industrial production, which was the primary source of jobs covered under the Vargas pension plan, occurred predominantly in the Southeast region comprising São Paulo, Rio de Janeiro, Minas Gerais and Espírito Santo where European immigration was historically strongest. The Northeast, which recorded $71 \%$ selfidentification with nonwhite categories in the 1940 census, was systematically underdeveloped by successive governments in Brazil, particularly through extensive state involvement in the economy wielded through state enterprises expanded under Vargas (Cardoso and Faletto 1979: 138). While the Northeast held 35\% of the population in 1940, it accounted for only $14.1 \%$ of national income and $9.4 \%$ of industrial production in 1949 (Baer 2001: 324-5). Limited attempts were made to encourage national integration, for example through a unified federal tax and transfer program developed by state-run Petrobrás during the 1940 s, which was designed to distribute oil taxes to states enabling 
them to fund transportation infrastructure (Wirth 1970: 151). Yet for the Vargas government, these programs were primarily symbolic gestures rather than effective redistributive tools. When Aliomar Baleeiro successfully introduced legislation aimed at increasing the distribution of the tax allocation in favor of the underdeveloped North and West, Vargas ordered one of his supporters to return the quotas to a more acceptable level for the white Southeast: over five years, their rates jumped from $65 \%$ to $52 \%$, then back up to close to $60 \%$, effectively maintaining the Southeast's advantageous access to a primary means of infrastructure development necessary for expanded industrialization (Wirth 1970: 205-10).

While Vargas presided over a significant expansion in the rights of political citizenship for Brazil ${ }^{60}$ - granting women the right to vote in 1932, and lowering the voting age to 18 - he did little to address the literacy requirements electoral law demanded that formed the primary mechanism of disenfranchisement for nonwhite Brazilians (Bethell 2003: 27). Dávila points out how the gap in public spending for education between certain geographic regions was a primary determinant for racialized illiteracy: “...[W]hile in the Federal District it [literacy] peaked at 77 percent [in 1940]...typical of the north, literacy in Bahia was only 21 percent" (2003: 69). Indeed, unsurprisingly, "the states with the highest concentrations of people of African, indigenous, or mixed ancestry also had the lowest rates of educational spending" (2003: 72). Racialized inequality in educational outcomes within states was systematic as well: while a black man in the urban Federal district had a 59\% chance of being literate in 1940,

\footnotetext{
${ }^{60}$ Although no elections occurred in Brazil from 1937 to 1945 during the Estado Novo.
} 
higher than whites in the Northeast ${ }^{61}$, his white counterpart had an $86 \%$ chance (2003: 73 ). Part of this disparity owes to the fact that public education remained under the purview of the state and municipal governments, yet given Vargas' fervor when it came to centralizing the domain of the state, this explanation seems somewhat hollow. Dávila, following Gilberto Hochman, suggests that public education did not benefit the upper classes as public health did, and thus Vargas found it more difficult to justify increased transfer of federal wealth to support local labor markets (2003: 67-8).$^{62}$ Indeed, since the demand for skilled labor could be rectified locally (i.e.: in the industrial powerhouse of the Southeast) bringing poor blacks into the franchise, or into public discourse more generally, was hardly a concern for the national state.

Given the multitude of ways Vargas favored certain groups over others through state action it is surprising that he was able to maintain his official line of national unity and harmony. In fact, under Vargas the opposite occurred - greater stratification in the form of regional, racial and gender disparity occurred. ${ }^{63}$ Yet as a discursive tactic to deflect criticisms of unequal treatment, the ideology of racial democracy taken up as nationalism served him impeccably. Since limited research was conducted that may have raised questions as to how a racial democracy could operate with such unequal distribution of social benefits - even excluding accounting for 'race' in successive censuses - claims of inequality were largely anecdotal. These claimants were frequently disregarded as being either racist themselves (for bringing up 'race' where it was said not

\footnotetext{
${ }^{61}$ In Bahia, $42 \%$ of white males and $34 \%$ of white females were literate with only $16 \%$ of black males and $11 \%$ of black females, and $24 \%$ of brown males and $16 \%$ of brown females achieving the same benefit necessary to exercise their citizenship (Dávila 2003: 73).

${ }^{62}$ On the centralization of Brazil's public health system under Vargas, see Hochman (2005)

${ }^{63}$ Vargas' corporatist welfare policies reinforced women's subordinate societal position by favoring the male as the primary breadwinner. See especially Hahner (1990: 121-180).
} 
to exist) or accused of rhetorical treason for introducing foreign ideas and problems into Brazil. Where such disregard was not possible, racial democracy ideologues like Gilberto Freyre sought to explain away any discrimination uncovered as the product of misunderstandings, a 'few bad apples', or similar tactics for avoiding sincere interest in certain individual's experience.

\section{Discourse over Rights, Law over Practice: Racial Democracy and Segmented Citizenship}

Despite limited improvements in the welfare of nonwhites in Brazil during the Vargas era, there is a remarkable persistence in their exclusion from the formal fruits of citizenship granted to them under the law that began with the 1891 Constitution. However, radical changes in the discourse of 'race' relations occurred, particularly accelerated during the eighty years covered in this chapter: from acceptance of overt racism, to a struggle over integrating racist ideas with the country's demographic reality, to a drastic reconstruction of the history of 'race' relations and the elimination of overt racism. How are we to understand this seeming paradox?

The relationship between discourse and practice or between the formality of the law and the substantive actualization of it, as this chapter has shown, need not accord. Rather, the distinction between the two served as the fount of Brazil's success in winning global admiration, and in ensuring the status quo at home. The ideology of racial democracy served to hide to the world the ways in which the state and the white elite oppressed and marginalized the nonwhite population for their own benefit, and silence internal criticism and mobilization when, inextricably tied to national identity, it was wielded to accuse people of disloyalty to the nation. 
The real power of the ideology of racial democracy as a transformative force altering various regimes in the social imaginary of Brazil was not that it achieved what it stated, but that it enabled the maintenance of white supremacy as the foundation of the Brazilian society, polity and economy while simultaneously deflecting criticisms that the country contradicted its harmonious narrative. As an ideology infused into the discourse of national identity, it became the wellspring from which claims could be drawn and against which all had to contend. In short, it put constraints on the range of acceptable social action and arguments that could be leveled by producing a specific commonsense 'reality' of the nation, and any experience or claim to the contrary was considered properly 'ideological'. At this point, it ceased to be 'only discourse' and impacted the material experience of life in Brazil..$^{64}$

The visions of the Brazilian nation advanced from the 1870s until the post-war era, and even to the present day, implied concomitant visions of how citizenship should be defined officially. While one particular legal codification of citizenship - formally extending citizenship to all native-born Brazilians with the 1891 Constitution - ultimately won out after the abolition of slavery, it was superseded by the absence of substantive rights that went with it, leaving the political and economic elite open to define the rights accorded to citizens as they saw fit in practice. Hence, when welfare programs were established and provided for, they drew not from codified rights in successive constitutions, but from a particular discursive construction of the rights of citizenship informed by a specific idea of the Brazilian nation. However, to complicate things further, this idea of the nation -racial democracy under Vargas - itself belied the discourse, for

\footnotetext{
${ }^{64}$ Of course, this dichotomy is fraught with problems - for speech, text, and images, as this thesis argues as a whole, are radically transformative forms of communicative action.
} 
though it was used to justify the expansion of welfare programs, it was never put into practice in substantive terms. Instead, the discourse of racial democracy masked white supremacist views which continued to pervade the practice of material distribution in Brazilian society and the way in which Brazilian welfare programs were organized (Appendix 1). Such a circuitous relationship adjudicating substantive equality in Brazil, beyond racially stratifying the recognitive and material experience of welfare, made it more difficult for those excluded from substantive citizenship to actually fight for the same treatment other citizens were getting, though they continued to struggle with varying degrees of success as the twentieth century matured. It also raises questions about the foundation of the Brazilian welfare state that the concluding chapter will address. 


\section{Chapter 3: The Historical Foundations of the Brazilian Welfare State: Rereading Traditional Accounts}

The last two chapters have emphasized the radical transformations in discourse on 'race' and nation that accompanied massive upheavals in the economic and political systems bridging the $19^{\text {th }}$ and $20^{\text {th }}$ centuries, alongside the persistence of white supremacy as the guiding ideology directing the substantive distribution of resources in Brazilian society. This was not a dual process, reflecting two separate spheres of discourse and practice, but a dialectic one, in which discourse and practice mutually interacted, if not shaping one another as dramatically as they might have. Indeed, the practice of white supremacy necessitated a new discursive veneer as scientific racism went out of vogue by the early twentieth century, just as the ideology of racial democracy provided marginalized Afro-Brazilians and indigenous groups, albeit in restricted fashion, tools with which to mobilize against their unequal treatment and make claims against the state. Yet this mobilization, until the 1988 Constitution radically redefined the terms under which citizenship operated, was generally unsuccessful in bringing about substantive changes to the material conditions of nonwhite Brazilians, especially under the bureaucratic authoritarian regime of successive military governments which took the ideology of racial democracy to new heights, while backing it with repressive state machinery.

These transformations occurred during a period in which the political economy of Brazil was being redefined as well. With Vargas' rise to power, the role of the central state in all aspects of social life drastically intensified. Nowhere was this seen more clearly than in the economy, where state intervention catalyzed economic growth and industrialization. Driven by a concerted policy of import substitution, Brazil's industrial 
production more than doubled between 1929 and 1939, and by the end of the second Vargas government, industry had surpassed agriculture in terms of share of GDP (Baer 2001: 28, 64). During this time, the Vargas regime introduced new welfare programs, formally creating the country's first welfare state with the expansion and consolidation of pension programs, health services, minimum wage and labor laws, and worker's compensation programs. Yet, as the last chapter demonstrated, the benefits of such programs were distributed highly unevenly, focusing primarily on white urban workers (many of whom had recently immigrated or were descendants of those who immigrated), to the neglect of black and mulatto workers. Although Afro-Brazilians were legitimately viewed as potential clientele of the state apparatus for the first time, their participation was never really solicited, nor did patronage extend to them as a group, as it did for white urban Brazilians. In short, the Brazilian welfare state established by Vargas created and expanded stratification along racial lines, thereby creating multiple tiers of welfare within a national context that purported universality, homogeneity of treatment, and social harmony.

This chapter seeks to reread traditional interpretations of the Brazilian welfare state that have emphasized corporatism and urban class conflict in order to account for the processes the preceding chapters have captured. Rather than offer a wholesale redefinition of the formation of the Brazil's welfare state, this chapter will provide a complementary understanding to the Brazilian Developmental Welfare State (BDWS) by asking what is lost when 'race' is excluded as a central analytic category from studies of the country's welfare state. First, a brief review of the literature will be conducted, before 
turning to a detailed summary of the BDWS. A discussion of the consequences of erasing 'race' from these accounts follows.

\section{What Kind of Stratification? Welfare States and Identity Categories}

The notion that welfare states are agents of stratification is not particularly new, with the explosion of literature in the last thirty years expanding on the primarily institutional or administrative accounts that dominated early work on the welfare state. However, it was Esping-Andersen who was one of the first to remind us that this stratification is a nuanced process, each case with its own logic rather than only a reflection of existing capitalist social relations ${ }^{65}$ (1990: 3 ; 55-78). Yet, even so, in his account and many of the neo-Marxist variants that have followed, class stratification has been the principal analytic focus. How the state intervenes in the capitalist market or shapes its functioning certainly impacts class inequality through alterations in the distribution of income, or relative recognition accorded to one class or another. In doing so, classes are created and reproduced, as both ancillary and direct consequences of concerted policy. Indeed, Brazil reflects this process coherently, since the Vargas policies favored core urban industrial workers, and produced different tiers of workers depending on their proximity to the centre of the corporatist network, and also exacerbated the income differentials between rural and urban workers through the exclusion of the former from most social programs (Schwartzman 2000: 38$)^{66}$.

However, as many authors have demonstrated in the years since the publication of The Three Worlds of Welfare Capitalism, welfare stratification encompasses much more

\footnotetext{
${ }^{65}$ In general, Power Resources Theory (PRT) and its practitioners have been the leaders of this movement, although Esping-Andersen sought to create typologies as well. See O'Connor and Olsen (1998).

${ }^{66}$ This is not to say that rural workers did not struggle to improve their situation. Partly resulting from Vargas' interventions in the labor market, rural São Paulo workers began mobilizing to catalyze the national rural labor movement. See Welch (1999).
} 
than the class dimension, since 'worker' is neither the only, nor for many people the most important, aspect of their multifaceted identities. While the 1990s saw the growth in gendered accounts of welfare stratification building on Esping-Andersen's fledgling inferences (see Korpi 2000), more recently 'race' and ability have been expanded as key analytic factors in understanding the logic of the welfare state. Yet 'race' has been incorporated particularly slowly, with most attention accorded to the United States and Britain, although that has begun to change in recent years ${ }^{67}$ (Piven and Cloward 1971; Williams 1989; Quadagno 1994). What all of these developments have shown, however, is that the welfare state is not a linear vehicle for addressing social contradictions, but a multidimensional instrument that may mitigate social tensions in one area of people's lived experience while potentially exacerbating them in other areas. For Afro-Brazilians, the Vargas era saw minute improvements in limited areas of their material well-being while their cultural autonomy came under attack for the threat that it posed to the state's image of the Brazilian nation. Indigenous peoples in Brazil experienced this as well, although with far fewer improvements to their daily lives, since to a large extent, they stood in the way of the expansion of the industrial state which necessitated the extraction of resources from the interior. In both cases, class was not the most salient dimension of their relation with the state through its social programs, since both urban workers of a different color, or rural dwellers of a perceived different 'race' found they were treated distinctly better.

Indeed, what Esping-Andersen demonstrated through his path breaking book, despite his desire to prove otherwise, was not the definitive account of welfare state formation and its "laws" of operation (1990: 3). Rather, he induced a generation of

${ }^{67}$ See for example, Kymlicka and Banting (2006). 
scholars to approach the welfare state heuristically by applying particular analytical implements to cases and identifying the outcomes. For example, pushing away from Esping-Andersen's 'liberal' regime in his ternary typology, Julia O'Connor et al. have shown how supposedly homogenous liberal regimes, upon deeper comparative inspection and using different foci, in fact are quite divergent ${ }^{68}$ (1999). Indeed, Brazil too is relevant here, for as Peter Fry points out and the previous chapters have demonstrated, Brazil's national identity, and thus its state activity, depended on the liberal fantasy or the aspiration to liberalism, even while competing ideologies of corporatism or technocracy worked to undermine it (2000: 83; Schwarz 2001). Thus comparative scholars of the welfare state have struggled to incorporate Brazil into their typologies, noting certain shared characteristics with the Mediterranean or Southern model (Ferrera 1996), or considering it a 'late-industrializer' and lumping it and other Latin American states into the developmental category (Riesco 2007). They have referred to the package of policies initiated under Vargas as "state patrimonialism" (Malloy 1979: 14) or defined welfare expansion in terms of political regime types (Haggard and Kaufman 2008), and yet Brazil does not fit neatly into any of these categories ${ }^{69}$. Indeed, as a complex and dynamic social formation, the Brazilian welfare system embodies all of these distinct modalities that become magnified when we organize our studies along one analytical axis or another.

As this thesis has shown thus far, highlighting 'race' as the central analytic category in identifying the roots of the welfare state suggests a different logic than only

\footnotetext{
${ }^{68}$ Thus while Ian Gough rightly advocates for the type of middle-range theorization he claims is exemplified by Esping-Andersen's work - avoiding both the universalist tendency of formalist studies and the "postmodern" approaches that advocate historical and contextual specificity - the more we particularize, the more we find new insights that could serve to expand our understanding of the processes of welfare regimes (2001: 167)

${ }^{69}$ Like most countries unified under a single label for that matter, except for those who usually form the ideal-type for a given categorization or typology.
} 
corporate placation of influential state clients, or the products of the peculiar political system initiated under a particularly enigmatic quasi-authoritarian leader. Brazil's welfare state cannot wholly be accounted for by examining the types of class stratification enacted by a state struggling to extend its capacity and authority with limited resources, or by highlighting the informal patronage networks that circumvent formal established law that stem from the Iberian cultural tradition. These aspects of the formation of the Brazilian welfare state are all critical, but each one obscures a different dimension, and all fail to account for how these processes were underpinned by a specific racial ideology emphasizing the hidden logic of white supremacy that was a primary organizing principle of Brazilian society. Focusing on 'race' does not replace, but rather adds, to the plethora of heuristic approaches that inform our understanding of the Brazilian welfare state.

\section{The BDWS: Locating the Source of the Contradiction}

Perhaps the most powerful and enduring account of Brazil's welfare state is the developmental variant, since it encompasses the legacy of patrimonialism and patronage that have been so important in Brazil's societal organization and political culture, rather than simply addresses it tangentially. This perspective sees the growth of Brazil's welfare regime as emanating from timely intervention by the state in the economy at critical junctures in the history of Brazil's development, specifically to resolve 'the social question'. The Great Depression was the central impetus for this, and buoyed by dependency theory pioneered by Raúl Prebisch and the work of economist Celso Furtado, the Vargas regime took it upon itself to act as the "arbitrator among heterogeneous social interests" (Draibe 2007: 254). It did so by weaving capital and labor into a tight-knit corporatist system of labor relations, in which unions were rigidly regulated, and the role 
of domestic capital was usurped by the state when it could not make the strategic investments in the economy the state saw as necessary ${ }^{70}$ (Draibe 2007: 241; SeguraUbiergo 2007: 62-4).

As economic growth continued to be robust, the preferred method of building the new Brazilian corporatist family was to expand social programs, which in turn strengthened the capacity and legitimacy of the state. Sônia Draibe highlights four critical policy shifts that were integral to the social integration of workers: "the nationwide labor union structure, the social security system, labor regulations, and the imposition of a national minimum salary" (2007: 255). Thus, as noted previously, what separates Vargas from classical populists in the developmental account was that his interventions had longstanding institutional implications for the political system, the developmental trajectory of the country, and state-society relations exemplified here through social policy.

Draibe notes the social stratification engendered by this framework. Since the unions were nationally regulated, there were barriers to entry for occupational classes not considered worthy of inclusion, as well as the fact that free and independent representation was a pipe dream. Pension systems were administered through the unions, but regulated by the relevant agency or department overseeing the occupational group, which led to differentiated payouts. The social security system was organized so that “social rights [were] dependent upon, first, a group's participation in the productive structure, and, secondly, the relative political weight of the corresponding professional category". Still, Draibe notes, "however limited and partial they may have been, it has

\footnotetext{
${ }^{70}$ For example, Petrobrás, the successful state-run oil company that continues to operate today, was founded during this time. On the consequences of the consolidated labor laws, see John French's insightful analysis of the CLT (2004).
} 
been under these social institutions that social rights have been inaugurated in Brazil: the right to regulated jobs, unions, and minimum wage" (2007: 255-6).

But for whom? As demonstrated in the last chapter, minimum wage laws did not apply to the vast majority of Afro-Brazilian workers, access to union representation was limited to those who were able to obtain industrial employment, and benefit rates depended on the relative position of the employment within the 'utilitarian' hierarchy of the state. Where Afro-Brazilians were most represented in the industrial structure was in construction, but owing to its low relative position in the hierarchy of 'skilled' labor, this was not a particularly vaunted profession (Andrews 1991: 96). The fact that the informal labor sector was viewed as 'unproductive' and excluded from the material benefits of citizenship undertaken by Vargas was indeed a mechanism to devalue certain types of primarily service-based economic activity. However, this was a highly racialized divide, with the bulk of the urban informal economy performed by nonwhites. Indeed, as demonstrated, all aspects of social stratification enacted by the Brazilian welfare regime directly engendered racial stratification as well. Furthermore, for indigenous Brazilians, access to these basic social rights was non-existent. Life in the demarcated zones operated according to the tutelary rules of the state, rather than those set out by the new expansion of social rights, and during the Vargas period, indigenous Brazilians and caboclos overwhelmingly lived in rural communities that fell outside the established jurisdiction of these welfare programs. Additionally, Vargas' march to the West to develop the interior led the state into a policy of 'pacification' that stripped indigenous peoples of the autonomy to order their own affairs and appropriated their means of cultural expression into the iconography of the Brazilian nation (Garfield 2001: 45-65). 
The developmental account of the welfare state controls for much of this pervasive stratification by chalking it up to the ideological orientation of the Vargas state $^{71}$. Draibe concludes that really the only viable redistributive tool utilized by the state was the minimum wage legislation, for the state was more concerned with serving the economy than society to enhance national prestige, and the capacity of the state. Hence, social stratification was a byproduct of a commandeering regime driving the populace towards its own conception of national glory, which effectively was oriented around a strong federal state. Draibe does concur, however, that the main consequences of the overall thrust of the Vargas regime was to implement a powerful mechanism for political and social control, hence enabling the state to seriously expand its authority and capacity (2007: 257). For Draibe, and other developmentalist accounts of Brazil's welfare state, 'race' is only a tangential factor - recognition of racial inequality is confined to a few sentences noting its persistence and durability. No concern is given to how these racial inequalities may have persisted in large part because of the institutionalization of uneven social welfare policies that also coincided with the state ideology of racial democracy. Instead, in briefly referencing the colonial legacy of Brazil and its importance for the shaping of the context in which the developmental state arose, Draibe points out in a footnote that "the racial question is an enormous and disputed one, shaped by several myths, one of them, widely disseminated, is that of racial brotherhood, linked to the benevolent tradition of the Portuguese colonizers, thought to be immune to racial prejudice as they intermingled freely with Indians and blacks” (2007: 251, 273).

\footnotetext{
${ }^{71}$ It says little and is unconcerned with the way indigenous peoples were, or were not, incorporated into the welfare state, grouping them together with the peasants of the interior.
} 
While Draibe notes the existence of racial democracy, her analytic focus is on a narrow set of political economic processes that shaped the Brazilian welfare state, thus she cannot but recognize it as a corollary factor confined to the social imaginary, and not a tangible catalyst for the way in which welfare programs were designed and delivered. Yet, we have seen the deeply structural ways in which the racialization of the welfare state was carried out by placing the ideology of racial democracy at the mantle of state mythology. This is not to say that white supremacy causally impacted the design of specific programs ${ }^{72}$, hence this thesis aims not to replace the developmentalist account of the welfare state, but to adjust the lens of inquiry to also account for the relations between national identity, citizenship and the creation of welfare states. Doing so reveals that policymakers did not act in a vacuum, nor did their 'rational' calculations necessarily spring from precisely where we think they do.

James M. Malloy demonstrates this with a brief discussion on the "orientation or mentality of the elites who actually elaborated the system". In doing so, he highlights none other than Oliveira Vianna, whom, as we saw in Chapter 1, served to bridge the ideology of scientific racism with racial democracy. Vianna also served as the top advisor for the Ministry of Labor from 1932 to 1937, critical years in the formation of the Brazilian welfare regime, and "social policy was one of his main responsibilities throughout those years" (1979: 62). Thus, the role Vianna saw the welfare state playing in Brazilian society coupled with his writings on 'race' can provide significant insight into the ideological basis of the developmental welfare state.

\footnotetext{
${ }^{72}$ Although more research on the institutional politics and ideological roots of policymakers specifically involved in the writing and passing of the legislation could alter that. Unfortunately, that task is far beyond the scope of this thesis; however see below for more context.
} 
According to Malloy, Vianna had a specific view of how the state should operate, which he dubbed Christian-Corporatism. This involved the emergence of a

...strong leader guided by certain key nationalist objectives who created a framework in which more ideologically oriented persons such as himself could elaborate a set of concepts and principles of sociopolitical organization to give substantive reality to the leader's more general national goals (1979: 63)

Vianna thought that these concepts should primarily be oriented around the placation of class conflict, which he sought to achieve by the "progressive elevation and dignification of the working classes within the capitalist regime". Rather than level social inequality and hierarchy, in a classic corporatist formula, Vianna saw welfare programs as a way for the state to calm any feelings of mistrust between the working classes and capitalists by allotting the former some of the resources of the latter (Malloy 1979: 64). In doing so, these groups would be able to transcend social class to join as equals in the national family, and work towards the harmonious enlargement of national prestige (and state power) (Malloy 1979: 66).

Hence, Vianna operates with a certain conception of citizenship in mind. Welfare policies would work to address historic injustices - though not by erasing them in practice - of class that had pervaded Brazil for centuries. Rather, "by the progressive participation of the working classes in the advantages and goods by which our civilization has for a century been providing the comfort, welfare, and dignity of the superior classes", Brazil could march towards a future nation of equals (qtd. in Malloy 1979: 64). Yet for the thinker who saw the progressive elimination of the black 'race' from the Brazilian nation through selective miscegenation with superior white elements, it is telling who the welfare policies actually targeted. Some urban blacks who were able to obtain industrial employment were worthy of state benefits, or at least they were a 
necessary sacrifice until they could be eliminated in successive generations through intermarriage. The masses who could not, on the other hand, would suffer the vicissitudes of market capitalism until it effectively eliminated them. Rural dwellers, who also presented a threat to the central state through their traditions of decentralized political participation, could either migrate to the cities, or slowly be eradicated by decades of underdevelopment.

Whether or not there is a conscious strategic link between the racial ideology of key policymakers like Oliveira Vianna and the welfare policies that were implemented in the 1930 s and $40 \mathrm{~s}$, it is clear that their views of the nation were influenced by particular racial beliefs, that these intertwined aspects worked to create a specific vision of national identity which in turn led them to a particular construction of citizenship, and that this consequently led them to create policies which reflected, in sometimes disconnected ways, this view of national identity. Such connections require us to look at 'race', or the racial ideology underpinning the Brazilian nation, when attempting to articulate the logic of the welfare state created by the Vargas regime, since it was a pervasive component of the ideational landscape in which policymakers were operating. In no way does this approach replace the class conflict and state power approach emphasized by the developmentalists, but as the above shows, in a country that has been dominated by issues of 'race' since colonial conquest, 'race' and class are rarely far apart.

\section{Towards Decommodification: Why Exclude 'Race'?}

Utilizing 'race' as the central analytic category when charting the roots of the Brazilian welfare state may seem on the surface to be too distant from the nuts and bolts of welfare design, and hence not of practical use in explaining the logic of the welfare 
state. After all, the internal cohesiveness of the class conflict and state power arguments provided by the developmentalists seems to tell us all we need to know about how the welfare state was created, and for what particular purpose. Such an argument, however, avoids breaking new ground to uncover what other analytic tools can bring to the table. This chapter is not interested in affirmatively asserting that the racial ideology of white supremacy led directly (i.e.: strategically) to the creation of specific welfare programs such an argument requires more research on the motivations and individual ideological profiles of policymakers involved in the legislative process. And yet, given the intensity of racial stratification engendered through Brazilian social policy and the labor market and the obsessive manner in which elites worked to resolve the perceived contradictions of their demography and their desired modernity, it is impossible to avoid the fact that the same terrain that sprung Vargas' corporatism and placation of 'the social question' produced the ideology of racial democracy as a guise for the maintenance of white supremacy. Such a complex stage upon which the foundational policies of the Brazilian welfare state were created requires that we interrogate it using the full range of heuristic tools we have available.

Yet there is a more grounded reason to explore 'race' and nation in the context of welfare formation. Fiona Williams pointed out fifteen years ago that "the relationship between nationality, race, and citizenship affects the capacity for decommodification" (1995: 132). Indeed, this is exemplified in the case of Brazil, although Williams was primarily interested in lending her insights to comparative social policy studies, building upon nation-based studies. Left generally unprotected by the state, Afro-Brazilians were forced to seek their livelihood on the margins of the informal economy, where frequently 
the benefits of social citizenship did not reach. Domestic servants, not subject to minimum wage or other labor laws, entered into dependent relations with their employers, who, knowing that they were what stood between food and starvation, could demand from their workers whatever their moral code allowed (Fernandes 1969). Indigenous peoples as well were locked into dependent relationships with state officials who sought to restrict both their physical and cultural autonomy. As the onslaught of commodityhungry settlers ravaged the surrounding territory, they were forced into market relations that kept them below the poverty line (Ramos 2006). The experience of racialized Brazilians confronting the market through the intermediary of the state was far different from those of their white counterparts, who, employed in industry or trades, could expect basic social protections and labor guarantees, even if these favored state power and capitalists first and foremost.

Williams also noted that while 'race' has been a defining social division of the twentieth century, its "constitution and significance vary" (1995: 128) from state to state. In Brazil, the salience of 'race' is of extreme importance to social relations in general, hence welfare policies which reflect social relations through the interactions of state, market, family and civil society ${ }^{73}$ need to take 'race' in account as well. As the first chapter demonstrated, the interlinkage between racial ideas and national aspirations formed the backbone of Brazilian national identity as it moved from scientific racism to racial democracy while maintaining white supremacy at the core of social relations. The outcome was an official citizenship, derived from nationality clauses in the constitution which was belied by its practice. Studies of the Brazilian welfare state that do not engage

\footnotetext{
${ }^{73}$ As noted in the introduction, this thesis has focused primarily on the first node in this 'welfare diamond', with secondary consideration given to the market due to space constraints.
} 
with the deep significance of 'race' for Brazilian social relations are really only grappling with the surface of the role of the state and market in substantively ordering society, and could unwittingly end up perpetuating the myth of racial democracy by erasing 'race' from the discussion.

Yet the most important reason to factor 'race' into studies of Brazilian welfare is to join the struggle leveled by tireless activists from the moment racial democracy initially covered up the lived experiences of Afro-Brazilians and indigenous peoples. For as Abdias do Nascimento, one of the loudest to speak out against the pervasive racism in the supposed racial paradise argues,

Abolition was a façade: juridical, theoretical, abstract. The ex-slaves were driven to the brink of starvation; they found only disease, unemployment, complete misery... Not only the elite, but all of Brazilian society closed the avenues through which blacks might have survived; they shut off the possibility of a decent, dignified life for the ex-slaves...It is imperative for human dignity and a civic duty for Brazilians to struggle - blacks and whites - to transform the concept of racial democracy into reality (1999: 380)

While the ranks of scholars and activists attacking various aspects of the myth of racial democracy within Brazil and internationally has swelled in recent decades, work grappling specifically with 'race' in relation to the historical foundations of the welfare state is still relatively understudied, especially in English ${ }^{74}$. Rereading the formation of the Brazilian welfare state considering the legacy of racism across a field of shifting racial ideologies not only opens up new avenues for study, or reveals a different facet of a logic (e.g.: corporatism) thought to be relatively well-defined, but also joins those in struggle for the substantive realization of the ideology that has worked to obscure their differentiated experience.

\footnotetext{
${ }^{74}$ Jerry Dávila's book (2003) is a notable exception. There is however, excellent work on contemporary racialized welfare stratification following from the impressive work of Carlos Hasenbalg and Nelson do Valle Silva. See for example, Hasenbalg (1983); Hasenbalg and Silva (1999); Silva and Hasenbalg (1992); Telles (2004).
} 


\section{'Developing' the BDWS}

As this chapter has argued alongside the host of scholars advancing the welfare studies agenda, welfare stratification is not confined to class alone, but reflects the relation between the diversity of individual and group identity ${ }^{75}$ and the interests of the primary stakeholders behind welfare policy embedded in the logic of the programs themselves. In Brazil, this is especially clear since 'race', while closely linked with class, has been an enduring feature of the social landscape. Yet contemporary accounts of the formation of the Brazilian welfare state, echoing the historic divisions inherited from European studies of welfare states have largely ignored 'race' as a critical analytic factor in their narratives of the expansion of social policy. Instead, they have emphasized class agitation spurred by an oligarchic regime that was subsequently reigned in by a heavy brand of nationalist corporatism, which took it upon itself to develop the economic capacity of the state. These combined facts of economic expansion and the social dislocation this engendered led the state to enact a series of welfare policies that, while restricted and stratifying along corporatist lines, nevertheless provided the expansion of social citizenship.

This account is a good summary of the complexities of the Vargas years, but it is incomplete since it fails to address other layers of differentiation that were being actively pursued by Brazilian elites throughout the late nineteenth and early twentieth centuries (and even to the present). The welfare policies of the Vargas regime effected and

\footnotetext{
${ }^{75}$ Fiona Williams points out that "people are more than the sum of their class, race, and gender (etc.) social positionings for these interact with biography and identity" (1995: 128). With the explosion of ethnography of racial experience in Brazil coming from anthropology, history, and sociology in recent years, there is fertile terrain for producing accounts that link individual subjectivity and agency to the structural accounts of welfare stratification in Brazil. See for example, Caldwell (2007); Twine (1998), and of course Fernandes (1969).
} 
accentuated racial stratification in the distribution of social goods, whether this was their direct intention or simply a byproduct of the general racial ideology of the time which informed their view of the national family. In any case, the groups targeted by the policies, and the way in which they were delivered (or not), demonstrates a remarkable inconsistency with the discursive portrayal of the nation's identity, and instead reveals the persistence of white supremacy that had survived the tumultuous Old Republican period quite intact. This needs to be accounted for in any model of Brazilian social welfare that claims definitiveness, although I would caution against this claim in favor of heuristic models. Regardless, ignoring 'race' in a country so marked by racial inequality, and by discussion of 'race', is something that borders on the incomprehensible and risks capitulating to the same myth that has only very recently been buried. While studies of 'Southern' welfare states have come a long way in recent years, there is a still considerable work to do if they hope to achieve the same breadth, and depth, of their 'Northern' counterparts, and nowhere is this more evident than when dealing with the issue of 'race'. 


\section{Conclusion: New Paths, New Promises, Persistent Realities}

When Brazil redemocratized in the mid-1980s after over twenty years of military rule, there was hope and promise in the air for a whole host of social actors, including nonwhite Brazilians. The 1988 Constitution sought representation from emergent indigenous groups in its constituent assembly, declaring the country pluri-ethnic for the first time while the Sarney government ratified ILO Convention 169 in 1989 (Langdon 2007: 10). The Constitution reoriented indigenous policy by guaranteeing "the right to self-representation in civil disputes, with recourse to the office of the Attorney General", guaranteed bilingual education, and a change in the legal definition of indigenous land that tied cultural reproduction to geographic territory (Garfield 2001: 212-3). The Constitution also declared that the fundamental objective of the state was to "promote the good of all without prejudice of origin, race, sex, color, age, and any other forms of discrimination" (Constituição 1988 Art. $3^{\circ}$, § IV), and specified that international relations were to be conducted according to the principles of the repudiation of racism. Racism was reaffirmed constitutionally as a crime, this time unbailable and subject to jail sentences (Constituição 1988 Art. 5 § XLII). The passage of supporting legislation seemed to suggest that officials were finally serious about racial inequality. Unfortunately, however, Law 7716 defined racism as limited to an "act of segregation or exclusion based on skin color or race" in public settings - not a very common feature of late 1980s Brazilian life - while failing to address racial insults, profiling, or more subtle forms of appearance-based discrimination (Guimarães 1999: 141).

The election of Fernando Henrique Cardoso to the presidency in 1994, given the important research on racial inequality he conducted in the 1960 s, seemed to signal a new 
era for relations between nonwhites and the state. Although his substantive accomplishments were limited - his most notable achievements were the initiation of limited affirmative action policies, and the appointment of Pelé to a cabinet post - he initiated a critical discursive shift in discussion about 'race' that also provoked intense backlash by the white elite and middle class (Htun 2004). And yet, slightly increased representation could only go so far ${ }^{76}$. As Benedita da Silva, then a Worker's Party (PT) senator noted,

We cannot assume that because today I am a senator racism has ended and that I do not suffer. Quite the contrary. The more elevated the social position of the black in Brazil is, the more uncomfortable this black feels if he or she keeps being a black and keeps defending the black cause (1999: 184)

Largely due to Brazil's turbulent economic environment when Cardoso assumed power, issues of racial inequality in society, or in state policy, took a backseat to neoliberal state interventions that did far more to perpetuate racial stratification than rectify it (see Petras and Veltmeyer 2003).

Indeed, Brazil's approach to addressing the historic racial inequalities perpetuated in large part by the state in recent decades has resulted in a mixed bag of accomplishments. Recently, President Lula has claimed to have raised the income of the black population by $220 \%$ as a result of Fome Zero and its flagship program Bolsa Família over the course of his time in office (Al Jazeera 2010), yet a "black woman still only earns half what a white man makes" (Reuters 2007) and income disparity between the Northeast and the Southeast is still a defining feature of the Brazilian development model. Indigenous peoples have recently played a larger role in asserting their interests, mobilized through creative linguistic tactics and new media (see Graham 2002; Turner

\footnotetext{
${ }^{76}$ According to Cardoso's own estimates, "in 2003, only 9 of the 513 deputies in Congress identified themselves as black" (2006: 253).
} 
2002), and yet they are still treated paternalistically by state organs, and little has been done to contain the influx of forestry and mining settlers that have continued to violently invade the interior. Indeed, in the name of the environment, the Força Verde, a branch of the Paraná state police initially created to protect against illegal environmental degradation, "...due to the avid American interest in the carbon [used as an offset], their mission has taken on a new focus: protecting the forest from the people who live there" (Schapiro 2010). With only minor exceptions, such as Lula's appointment of Matilde Ribeiro, a longtime militant in the struggle for black equality, to head the Special Secretariat for the Promotion of Racial Equality (SEPPIR), a cabinet-level position, the pattern of elite cooptation of Afro-Brazilian and indigenous culture continues to elude any substantive alterations to structural racism in Brazil.

Given what this thesis has demonstrated - the clever discursive maneuvers employed by the late nineteenth and early twentieth century elite to both avoid real changes in the practice of white supremacist exploitation and facilitate it through the workings of the welfare state - could we expect much more? The historic debates over Brazilian national identity culminating in the seemingly unassailable myth of racial democracy ensure that any substantive changes will be subjected to the past, if of course, not completely. While it is true that both Cardoso and Lula have been constrained by the political economic 'realities' forcing their hand, they have been even more constrained by the path dependent, historically-derived discourse of national identity that has been the fount of state power since 1930. As Benedict Anderson has noted, "successful revolutionaries also inherit the wiring of the old state...like the complex electric system in any large mansion when the owner has fled, the state awaits the new owner's hand at 
the switch to be very much its old brilliant self again" (1991: 160). Unfortunately for nonwhites in Brazil, the lights were designed to only work in the upper floors of the house from the outset, and renovations are complicated by the retrofitting impulse brought about by the insertion of new discourses. These structural limitations embedded in Brazil's official nationalism constrain the breadth of change that any single government can undertake. Hence, it is not surprising that Brazil's ambassador to Canada, in 2007, still relied on the myth of racial democracy to translate the Brazilian experience from the perspective of the government to a foreign public (Carneiro Leão 2007). While we have reason to be hopeful for real advancements in the substantive equality of all Brazilian citizens, particularly if the PT (Worker's Party) candidate in the November 2010 election, Dilma Rousseff, is elected and continues the trajectory of her predecessor, we also have reason to be wary, given the way discourse has been mobilized to mask white supremacy in the past.

Understanding the historic interaction between the discourse and practice of racial equality in all of its dimensions is critical for breaking with the white supremacist ideology that still underpins Brazilian society. This is especially the case with the state, since, as the principal actor mediating social relations, it exercises immense power in determining material outcomes. Especially because in Brazil the state was also a central actor in promoting racial stratification, both because of the large role it played in the socio-economy in general, and because of the way it assumed the discourse of racial democracy as a foundational tenet of its actions (or rather, as a deflective justificatory mechanism of its actions), we need to identify the threads linking these processes very closely. How national identity discourse works both to shape the legal and political 
terrain of Brazilian society, and simultaneously serve as the 'unofficial' citizenship driving practice against the law needs to be the subject of closer examination. The recent explosion in citizenship studies attests to the growing awareness of the significance of the interrelated processes of citizenship, 'race' and nation, and welfare in the struggle to redefine the terms of reference in adjudicating claims to (and for) substantive equality.

Yet there is still much research to be done. One area that needs further study is around the mechanisms facilitating the transfer of ideas and policies in the late nineteenth and early twentieth centuries. Obviously this dynamic was shaped by the postcolonialEuropean/North American divide, but the elucidation of the linkages between intellectuals, economic elites, and policymakers would help clarify the trajectory of certain influential types of policy. For this, comparative work is necessary, both between postcolonial states, and between the hegemonic and subaltern states. For example, Japan initiated welfare policies around the same time as Brazil, has also experienced a disconnect between discourse, law, and practice, and defined itself around an equally powerful, albeit opposite, discourse of national identity - ethnic homogeneity ${ }^{77}$. It too looked to Europe for guidance and approval in actualizing its modernity, of which racial ideas formed an important component (Siddle 2003; Said 1994), while its developmental trajectory and level of economic growth share similar characteristics with Brazil, at least until World War II. While recent interest around policy convergence promulgated through major hegemonic institutions, such as the OECD, World Bank and IMF has sparked intense debate over the sources and directionality of social policy formation, more work needs to be done on the origins of social policy regimes that looks for the

\footnotetext{
${ }^{77}$ Of course, through Japan's colonial conquests (in Okinawa and Korea for example), as well as its subjugation of the indigenous Ainu, it was hardly an ethnically 'unified' people.
} 
commonalities driving the differentiation process ${ }^{78}$. Daniel's recent book has started this process with the oft-comparators of Brazil and the United States (2006), while other work has looked at comparisons within Latin America (see for example Hirabayashi et al. 2002), but more research between less frequently compared countries, such as the Japan case may provide for Brazil, will undoubtedly reveal the inner-workings of global racial formations in greater detail (Winant 2001).

More broadly, this thesis has sought to redirect attention to the less regarded aspect of welfare state formation: ethnic and racial stratification. For welfare studies, especially of the comparative sort that focuses almost exclusively on Europe and North America $^{79}$, class and class politics has been the primary analytic focus, although this has begun to change in the last two decades. The powerful insights that Power Resources Theory has procured have undoubtedly been a boon for the expansion of our understanding of the foundational logic of the welfare state against the flat characterizations of the formalist school emphasizing levels of expenditure, but there is still much room to push out even further. A closer examination of the role that nationalism and discourses of national identity played in defining the discursive landscape on which class politics operated would undoubtedly reveal as much about the solidaristic process of welfare state formation as David Roediger's The Wages of Whiteness (1991) did regarding the barriers to working class consciousness in the United States. Examining the disjuncture between official citizenship, exemplified by nationality clauses in the constitution and supportive statute law, and citizenship as a fluid and ongoing flux of power over who has the right to be included in the deliberative and

\footnotetext{
${ }^{78}$ Such a task is consistent with Ian Gough's exhortation, but still does not replace the need to find new analytical avenues as well (see Chapter 3).

${ }^{79}$ Although East Asia, and more slowly, certain countries in Latin America are now being incorporated.
} 
redistributive systems in a given national territory are likely to be as transformative for welfare studies as Aihwa Ong's Flexible Citizenship was for citizenship studies.

The pursuit of intersectional analyses that treat gender alongside 'race' would further reveal this dynamic (see Hahner 1990; Besse 1996). The addition of sexual orientation, as James Green has demonstrated, is also clearly an important stratification marker, and one that is also closely tied to 'race' (1999: 73, 121-6). It is also critical to explore non-elite dissent and contestation to official narratives of national identity, something this thesis does not consider. Significant work has been conducted on the Movimento Negro and other explicitly anti-racist organizations, but how did other social movements approach this issue? For example, anarcho-syndicalist presses flourished in the urban centers of Brazil in the first two decades of the twentieth century, espousing their own conceptions of Brazilian national identity - what role did they play in contesting white supremacy or critiquing racial democracy? However, as noted in the previous chapter, the primary aim of all of these new insights and approaches is not simply to promote greater understanding, but to transform that understanding into concerted action. The better we are able to explicate the jointed, if not seamless, processes binding the exclusion of some people from equal participation in the political and legal regimes of their home countries, the more, I hope, we can aid in combating it. 


\section{Appendix 1: Schematic of Substantive Citizenship in Brazil, 1870-1950}

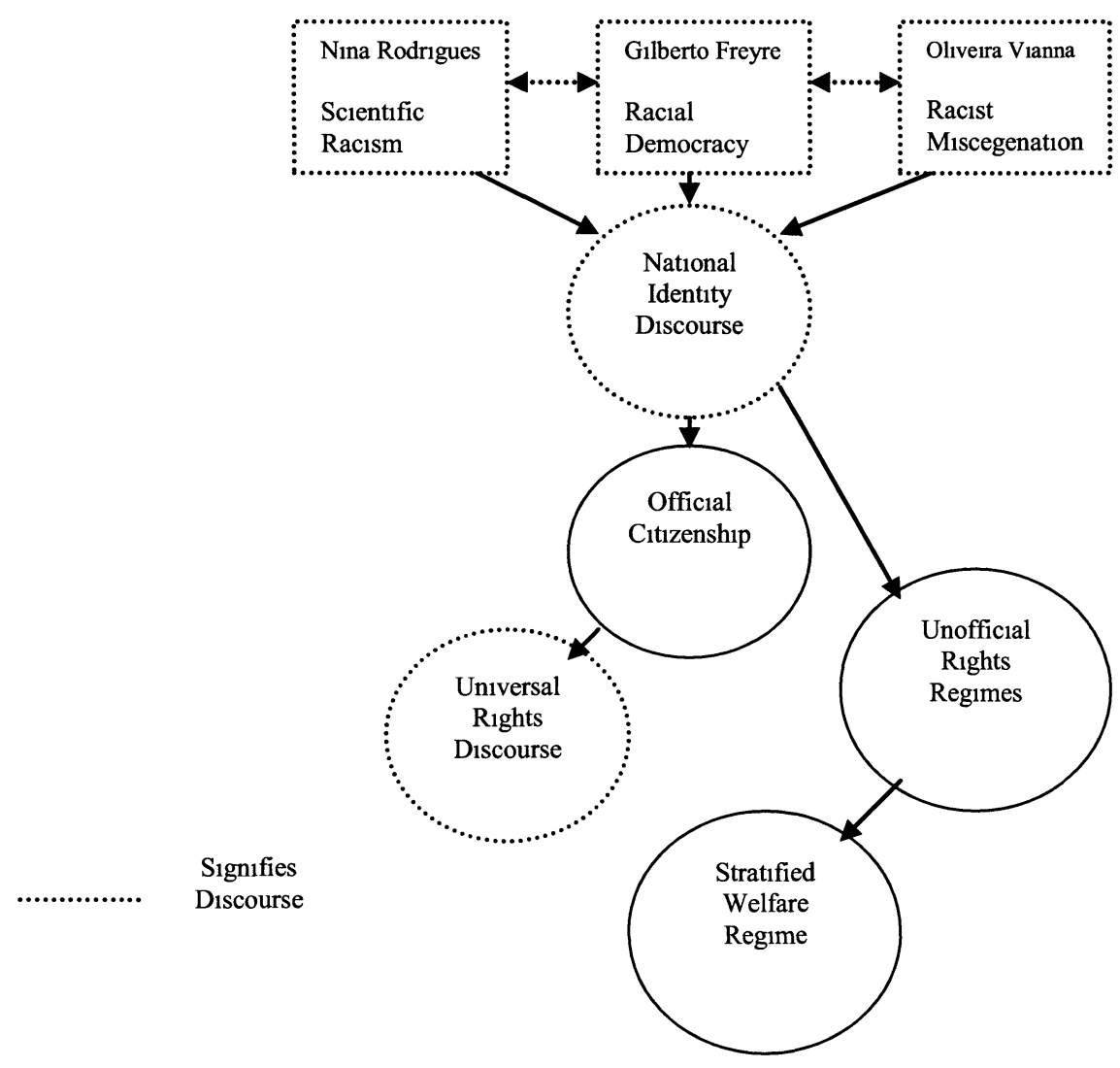

N.B.: This diagram represents a heuristic schematic to help understand the processes described in this chapter, not a model representation of empirical reality. 


\section{References}

Adamo, Sam. (1989). "Race and Povo" in Modern Brazil: Elites and Masses in Historical Perspective. Michael L. Conniff and Frank D. McCann (eds). Lincoln, NE: University of Nebraska Press.

Adelman, Jeremy. (1999). "Introduction: The Problem of Persistence in Latin American History" in Colonial Legacies: The Problem of Persistence in Latin American History. Jeremy Adelman (ed). New York, NY: Routledge. pp. 1-14.

Aidar, Antônio Carlos Kfouri, Clarissa Bueno de Ameida, and Renato Giosa Miralla. (2004). "Recent History of Brazilian Soccer" in International Sports Economic Comparisons. Rodney Fort and John Fizel (eds.). Westport, CT: Praeger Publishers. pp. 245-62.

Al-Jazeera. (2010). "Luiz Inacio Lula da Silva” Talk to Jazeera. Aljazeera.net May 18th 2010.

Anderson, Benedict. (1991). Imagined Communities: Reflections on the Origins and Spread of Nationalism. New York, NY: Verso.

Andrews, George Reid. (1991). Blacks and Whites in São Paulo, Brazil: 1888-1988. Madison, WI: The University of Wisconsin Press.

--------.-- (1984). “Review: Race and the State in Colonial Brazil”. Latin American Research Review. 19(3): 203-216.

Assunção, Matthias Röhrig. (2005). Capoeira: A History of an Afro-Brazilian Martial Art. New York, NY: Taylor \& Francis.

Baer, Werner. (2001). The Brazilian Economy: Growth and Development. $5^{\text {th }}$ Edition. Wesport, CT: Praeger.

Barman, Roderick. (1988). Brazil: The Forging of a Nation, 1798-1852. Stanford, CA: Stanford University Press.

Bastide, Roger. (1973). "Estereótipos de negros através da Literatura Brasileira” in Estudos Afro-Brasileiros. São Paulo: Editora Perspectiva. pp. 113-28.

Bastide, Roger and Florestan Fernandes. (1955). Relações Raciais entre Negros e Brancos em São Paulo. São Paulo: Anhembi. 
Batalha, Claudio H.M. (1999). "Sociedades de Trabalhadores no Rio de Janeiro do Século XIX: Algumas Reflexões em Torno da Formação da Classe Operária" Cadernos AEL 6(10/11): 43-67.

(1998). "Working-Class Societies in Nineteenth-Century Rio de Janeiro: Notes on the Making of the Brazilian Working Class". Paper delivered at the Latin American Studies Association Annual Meeting. The Palmer House Hilton, Chicago, IL. September 24-6.

Baum, Bruce. (2006). The Rise and Fall of the Caucasian Race: A Political History of Racial Identity. New York, NY: New York University Press.

Besse, Susan K. (1996). Restructuring Patriarchy: The Modernization of Gender Inequality in Brazil 1914-1940. Chapel Hill, NC: The University of North Carolina Press.

Bethell, Leslie. (2003). "From Elections Without Democracy to Democracy Without Citizenship" in Brazil Since 1985: Economy, Polity and Society. Maria D'Alva Kinzo and James Dunkerley (eds). London, UK: Institute of Latin American Studies.

-.-.. (ed). (1996). Ideas and Ideologies in Twentieth Century Latin America. Cambridge, UK: Cambridge University Press.

Bhabha, Homi K. (1994). "The Other Question: Stereotype, Discrimination, and the Discourse of Colonialism" in The Location of Culture. New York, NY: Routledge. pp. 94-120.

Brodie, Janine. (2008). "The Social in Social Citizenship" in Recasting the Social in Citizenship. Engin F. Isin (ed). Toronto, ON: University of Toronto Press.

Brown, Michael K. (1998). Race, Money, and the American Welfare State. Ithaca, NY: Cornell University Press.

Burke, Peter and Maria Lúcia G. Pallares-Burke. (2008). Gilberto Freyre: Social Theory in the Tropics. Oxfordshire, UK: Peter Lang.

Burkholder, Mark A. and Lyman L. Johnson. (2001). Colonial Latin America. Fourth Edition. New York, NY: Oxford University Press.

Burns, E. Bradford. (1976). "The Perception of National Reality in Nineteenth Century Argentine and Brazilian Literature". Neohelicon 4(1-2): 9-29.

--ors (1970). A History of Brazil. New York, NY: Columbia University Press.

Caldwell, Kia Lilly. (2007). Negras in Brazil: Re-envisioning Black Women, Citizenship, and the Politics of Identity. New Brunswick, NJ: Rutgers University Press. 
Cardoso, Fernando Henrique and Octavio Ianni. (1960). Côr e Mobilidade Social em Florianópolis: Aspectos das Relações entre Negros e Brancos numa Comunidade do Brasil Meridional. São Paulo: Companhia Editora Nacional.

Cardoso, Fernando Henrique and Enzo Faletto. (1979). Dependency and Development in Latin America. Marjory Mattingly Urquidi (trans). Berkeley, CA: University of California Press.

Cardoso, Fernando Henrique. (2006). The Accidental President of Brazil: A Memoir. New York, NY: PublicAffairs.

Carneiro Leão, Valdemar. (2007). "Brazil into the 21st Century". Carleton University. Jan. 25th 2007.

Castles, Stephen and Mark J. Miller. (1993). The Age of Migration: International Population Movements in the Modern World. New York, NY: The Guilford Press.

Caulfield, Sueann. (2000). In Defense of Honor: Sexual Morality, Modernity, and Nation in Early-Twentieth Century Brazil. Durham, NC: Duke University Press.

Chalhoub, Sidney. (2006). "The Politics of Silence: Race and Citizenship in NineteenthCentury Brazil”. Slavery and Abolition 27(1): 73-87.

Chasteen, John Charles. (2004). National Rhythms, African Roots: The Deep History of Latin American Popular Dance. Albuquerque, NM: University of New Mexico Press.

Clendenning, Alan. (2005). "Brazil Ex-Aide Reiterates Kickback Charges" The Associated Press. Aug. $25^{\text {th }} 2005$.

Coimbra Jr., Carlos E. A. et al. (2002). The Xavánte in Transition: Health, Ecology, and Bioanthropology in Central Brazil. Ann Arbor, MI: The University of Michigan Press.

Constituição da República dos Estados Unidos do Brasil de 16 de julho de 1934.

Constituição da República Federativa do Brasil de 05 de outubro de 1988. Título I. Art. $3^{\mathrm{o}}, \S \mathrm{IV}$.

Daniel, G. Reginald. (2006). Race and Multiraciality in Brazil and the United States: Converging Paths? University Park, PA: The Pennsylvania State University Press.

Dávila, Jerry. (2003). Diploma of Whiteness: Race and Social Policy in Brazil, 19171945. Durham, NC: Duke University Press. 
Davis, Darién J. (1999). Avoiding the Dark: Race and the Forging of National Culture in Modern Brazil. Brookfield, VT: Ashgate.

De Gobineau, Arthur. (1999[1855]). The Inequality of Human Races. Adrian Collins (trans). New York, NY: Howard Fertig Publisher.

de la Peña, Guillermo. (2005). "Social and Cultural Policies Toward Indigenous Peoples: Perspectives from Latin America” Annual Review of Anthropology 34:717-39.

De Raymond, Jean-François. (1990). Arthur de Gobineau et le Bresil: Correspondance Diplomatique du Ministre de France à Rio de Janeiro, 1869-1970. Grenoble: Presses Universitaires de Grenoble.

Dean, Warren. (1969). The Industrialization of São Paulo, 1880-1945. Austin, TX: The University of Texas Press.

Degler, Carl N. (1971). Neither Black nor White: Slavery and Race Relations in Brazil and the United States. New York, NY: The Macmillan Company.

Denevan, William M. (ed). (1992). The Native Population of the Americas in 1492. $2^{\text {nd }}$ Edition. Madison, WI: The University of Wisconsin Press.

Deutsch, Sandra McGee. (1999). Las Derechas: The Extreme Right in Argentina, Brazil, and Chile, 1890-1939. Stanford, CA: Stanford University Press.

Diacon, Todd A. (2004). Stringing Together a Nation: Cândido Mariano da Silva Rondon and the Construction of a Modern Brazil, 1906-1930. Durham, NC: Duke University Press.

Directoria Geral de Estatistica. (1898). “Sexo, raça e estado civil, nacionalidade, filiação culto e analphabetismo" Ministerio da Industria, Vição e Obras Publicas.

Republica dos Estados Unidos do Brazil. Rio de Janeiro: Officina da Estatistica.

Dos Santos, Sales Augusto. (2002). "Historical Roots of the 'Whitening' of Brazil". Laurence Hallwell (trans). Latin American Perspectives 29(1): 61-82.

Draibe, Sônia M. (2007). "The Brazilian Developmental Welfare State: Rise, Decline and Perspectives" in Latin America: A New Developmental Welfare State Model in the Making? Manuel Riesco (ed). New York, NY: Palgrave MacMillan. pp. 239-81.

Drescher, Seymour. (1988). "Brazilian Abolition in Comparative Perspective" in The Abolition of Slavery and the Aftermath of Emancipation in Brazil. Rebecca J. Scott et al. Durham, NC: Duke University Press.

Dulles, John W.F. (1973). Anarchists and Communists in Brazil, 1900-1935. Austin, TX: University of Texas Press. 
Dutra, Eliana de Freitas. (2000). "The Fusion of Races as Locus of Memory" Diogenes 48(191): 25-36.

Eakin, Marshall C. (2007). The History of Latin America: Collision of Cultures. New York, NY: Palgrave Macmillan.

--- (1998). Brazil: The Once and Future Country. New York, NY: St. Martin's Griffin Press.

Ebbinhaus, Bernhard. (2005). "Can Path Dependence Explain Institutional Change?: Two Approaches Applied to Welfare State Reform". Max Planck Institute for the Study of Societies Discussion Paper 05/2. Cologne: Max Planck Institute.

Egerton, Douglas R. et al. (2007). The Atlantic World: A History, 1400-1888. Wheeling, IL: Harlan Davidson.

Esping-Andersen, Gøsta. (1990). The Three Worlds of Welfare Capitalism. Princeton, NJ: Princeton University Press.

Fausto, Boris. (1999). A Concise History of Brazil. New York, NY: Cambridge University Press.

Fernandes, Florestan. (1969). The Negro in Brazilian Society. Jacqueline D. Skiles et al. (trans). Phyllis B. Eveleth (ed). New York, NY: Columbia University Press.

Ferrera, Maurizio. (1996). “The 'Southern Model' of Welfare in Social Europe”. Journal of European Social Policy 6(1): 17- 37.

Foucault, Michel. (2003). "28 January 1976" in "Society Must Be Defended": Lectures at the Collège de France, 1975-76. Mauro Bertani and Alessandro Fontana (eds). David Macey (trans). New York, NY: Picador. pp. 65-85.

French, John D. and Alexandre Fortes. (1998). Urban Labor History in Twentieth Century Brazil. Albuquerque, NM: The Latin American Institute.

French, John D. (2004). Drowning in Laws: Labor Law and Brazilian Political Culture. Chapel Hill, NC: The University of North Carolina Press. . (2003). "Translation, Diasporic Dialogue, and the Errors of Pierre Bourdieu and Loïc Wacquant" Nepantla: Views from South 4(2): 375-389.

Freyre, Gilberto. (1963a). The Masters and the Slaves: A Study in the Development of Brazilian Civilization. Samuel Putnam (trans). New York, NY: Alfred A. Knopf. (1963b). The Mansions and the Shanties: The Making of Modern Brazil. Harriet de Onís (trans). New York, NY: Alfred A. Knopf. 
Frumkin, Howard and Volney de M. Câmara. (1991). "Occupational Health and Safety in Brazil” American Journal of Public Health 81(12): 1619-24.

Fry, Peter. (2000). "Politics, Nationality, and the Meanings of 'Race' in Brazil" Daedalus 129(2): 83-118.

Garfield, Seth. (2001). Indigenous Struggle at the Heart of Brazil: State Policy, Frontier Expansion, and the Xavante Indians, 1937-1988. Durham, NC: Duke University Press.

(1997). “The Roots of the Plant that Today is Brazil': Indians and the Nation-State Under the Brazilian Estado Novo" Journal of Latin American Studies 29(3): 747-68.

Gough, Ian. (2001). "Globalization and Regional Welfare Regimes: the East Asian Case". Global Social Policy 1(2): 163-189.

Graham, Laura R. (2002). "How Should an Indian Speak? Amazonian Indians and the Symbolic Politics of Language in the Global Public Sphere" in Indigenous Movements, Self-Representation, and the State in Latin America. Kay B. Warren and Jean E. Jackson (eds). Austin, TX: University of Texas Press.

Graham, Richard. (1990). Patronage and Politics in Nineteenth-Century Brazil. Stanford, CA: Stanford University Press.

Graham, Sandra Lauderdale. (2006). Caetana Says No: Women's Stories from a Brazilian Slave Society. Cambridge, UK: Cambridge University Press.

Green, James N. (2006). "The Emperor and His Pedestal: Pedro I and Disputed Views of the Brazilian Nation, 1860-1900". In Brazil in the Making: Facets of National Identity. Carmen Nava and Ludwig Lauerhass, Jr. (eds). Lanham, MD: Rowman \& Littlefield Publishers. pp. 181-202.

-----ore (1999). Beyond Carnival: Male Homosexuality in Twentieth-Century Brazil. Chicago, IL: The University of Chicago Press.

Guimarães, Antonio Sérgio Alfredo. (2005). "Racial Democracy" in Imagining Brazil. Jessé Souza and Valter Sinder (eds). Lanham, MD: Lexington Books. (1999). "Measures to Combat Discrimination and Racial Inequality in Brazil" in Race in Contemporary Brazil. Rebecca Reichmann (ed). University Park, PA: Pennsylvania State University Press. pp. 138-153.

Gunther, John. (1966). Inside South America. New York, NY: Harper \& Row.

Haggard, Stephen and Robert R. Kaufman. (2008). Development, Democracy, and Welfare States: Latin America, East Asia, and Eastern Europe. Princeton, NJ: Princeton University Press. 
Hahner, June E. (1990). Emancipating the Female Sex: The Struggle for Women's Rights in Brazil, 1850-1940. Durham, NC: Duke University Press.

Hale, Charles. (1996). "Political Ideas and Ideologies in Latin America, 1870-1930". In Ideas and Ideologies in Twentieth Century Latin America. Leslie Bethell (ed). Cambridge, UK: Cambridge University Press. pp. 133-205.

Hall, Michael M. and Marco Aurélio Garcia. (1989). "Urban Labor" in Modern Brazil: Elites and Masses in Historical Perspective. Michael L. Conniff and Frank D. McCann (eds). Lincoln, NE: University of Nebraska Press.

Hall, Stuart. (1996). "Gramsci's Relevance for the Study of Race and Ethnicity" in Stuart Hall: Critical Dialogues in Cultural Studies David Morley and Kuan-Hsing Chen (eds). London, UK: Routledge. pp. 411-441.

Hanchard, Michael George. (1999). "Black Cinderella? Race and the Public Sphere in Brazil" in Racial Politics in Contemporary Brazil. Michael Hanchard (ed). Durham, NC: Duke University Press. (1994). Orpheus and Power: The Movimento Negro of Rio de Janeiro and São Paulo, Brazil, 1945-1988. Princeton, NJ: Princeton University Press.

Hasenbalg, Carlos and Nelson do Valle Silva. (1999). "Notes on Racial and Political Inequality in Brazil" in Racial Politics in Contemporary Brazil. Michael Hanchard (ed). Durham, NC: Duke University Press.

Hasenbalg, Carlos A. (1992). "A pesquisa das desigualidades raciais no Brasil” in Relações Raciais no Brasil Contemporâneo. Neslon do Valle Silva and Carlos Hasenbalg (eds). Rio de Janeiro: Rio Fundo Editora. (1992b). "Discursos sobre a raça: pequena crônica de 1988" In Relações Raciais no Brasil Contemporâneo. Neslon do Valle Silva and Carlos Hasenbalg (eds). Rio de Janeiro: Rio Fundo Editora. (1985). Race Relations in Modern Brazil. Albuquerque, NM: The Latin American Institute. (1983). "Race and Socioeconomic Inequalities in Brazil" Série Estudos n. 13. Rio de Janeiro: Instituto Universitário de Pesquisas do Rio de Janeiro.

Hellwig, David J. (ed). (1992). African-American Reflections on Brazil's Racial Paradise. Philadelphia, PA: Temple University Press.

Hirabayashi, Lane Ryo, Akemi Kikumura-Yano and James A. Hirabayashi. (eds). (2002). New Worlds, New Lives: Globalization and People of Japanese Descent in the Americas and from Latin America in Japan. Stanford, CA: Stanford University Press. 
Hochman, Gilberto. (2005). "Cambio político y reformas de la salud pública en Brasil: El primer gobierno Vargas (1930-1945)” Dynamis 25: 199-226.

Holston, James. (2008). Insurgent Citizenship: Disjunctions of Democracy and Modernity in Brazil. Princeton, NJ: Princeton University Press.

Htun, Mala. (2004). "From 'Racial Democracy' to Affirmative Action: Changing State Policy on Race in Brazil” Latin American Research Review 39(1): 60-89.

IBGE. (1999). "What Color are You?” in The Brazil Reader: History, Culture, Politics. Robert M. Levine and John J. Crocitti (eds). Durham, NC: Duke University Press. pp. 386-90.

------. (1950). "População de Fato, por Sexo e Grupos de Idades, Segundo os Principais Caracteres Individuais". Censo Demográfico: População e Habitação. Instituto Brasileiro de Geografia e Estatística. Rio de Janeiro: Serviço Gráfico do Instituto Brasileiro de Geografia e Estatística.

Iggers, Georg G. et al. (2008). A Global History of Modern Historiography. Harlow, UK: Pearson Education.

Iggers, Georg G. (2005). “The 'Linguistic Turn': The End of History as a Scholarly Discipline?" in Historiography in the Twentieth Century: From Scientific Objectivity to the Postmodern Challenge. Middletown, CT: Wesleyan University Press. pp. 118-33.

Isaac, Benjamin. (2006). The Invention of Racism in Classical Antiquity. Princeton, NJ: Princeton University Press.

Jaguaribe, Helio. (1967). "Political Strategies of National Development in Brazil" Studies in Comparative International Development 3(2): 27-50.

Johnson, H.B. (1987). "Portuguese Settlement, 1500-1580" in Colonial Brazil. Leslie Bethell (ed.). Cambridge, UK: Cambridge University Press. pp. 1-38.

Jones-de Oliveira, Kimberly F. (2003). "The Politics of Culture or the Culture of Politics: Afro-Brazilian Mobilization, 1920-1968” Journal of Third World Studies 20(1): 103-120.

Jordan, Winthrop D. (2000). "First Impressions" in Theories of Race and Racism: A Reader. Les Black and John Solomos (eds). New York, NY: Routledge. pp. 33-50.

Korpi, Walter. (2000). "Faces of Inequality: Gender, Class, and Patterns of Inequalities in Different Types of Welfare States" Social Politics 7(2): 127-191.

Klein, Herbert S. (2010). The Atlantic Slave Trade. 2nd Edition. New York, NY: Cambridge University Press. 
Kristal, Efraín and José Luiz Passos. (2006). "Machado de Assis and the Question of Brazilian National Identity". In Brazil in the Making: Facets of National Identity. Carmen Nava and Ludwig Lauerhass, Jr. (eds). Lanham, MD: Rowman \& Littlefield Publishers. pp. 17-28.

Kuhlmann Jr., Moysés. (1996). "Welfare Pre-School Institutions in Brazil (1899-1922)" in Brazilian Issues on Education, Gender and Race. Elba Siqueira de Sá Barretto and Dagmar M.L. Zibas (eds). Jonathan Hannay (trans). São Paulo: Fundação Carlos Chagas. pp. 65-86.

Kymlicka, Will and Keith Banting (eds). (2006). Multiculturalism and the Welfare State: Recognition and Redistribution in Contemporary Democracies. New York, NY: Oxford University Press.

Langdon, Esther Jean. (2007). "Cultural Diversity and the Challenges of Brazilian Indian Health Policy" Saúde e Sociedade 16(2): 10-2.

Lauerhass Jr., Ludwig. (2006). "Introduction: A Four-Part Canon for the Analysis of Brazilian National Identity". In Brazil in the Making: Facets of National Identity. Carmen Nava and Ludwig Lauerhass, Jr. (eds). Lanham, MD: Rowman \& Littlefield Publishers. pp. 1-14.

Lesser, Jeffrey. (1999). Negotiating National Identity: Immigrants, Minorities, and the Struggle for Ethnicity in Brazil. Durham, NC: Duke University Press.

"-------------. (1995). Welcoming the Undesirables: Brazil and the Jewish Question. Berkeley. CA: University of California Press. (1994). "Immigration and Shifting Concepts of National Identity in Brazil during the Vargas Era" Luso-Brazilian Review 31(2): 23-44.

Levine, Robert M. and John J. Crocitti (eds). (1999). The Brazil Reader: History, Culture, Politics. Durham, NC: Duke University Press.

Levine, Robert M. (2003). The History of Brazil. Westport, CT: Greenwood Press. (1998). Father of the Poor? Vargas and His Era. New York, NY: Cambridge University Press. (1970). The Vargas Regime: The Critical Years, 1934-1938. New York, NY: Columbia University Press.

Lister, Ruth. (1997). Citizenship: Feminist Perspectives. New York, NY: New York University Press.

Love, Joseph L. (1980). São Paulo in the Brazilian Federation, 1889-1937. Stanford, CA: Stanford University Press. 
Lovell, Peggy. (2001). "Sociology: Brazil" Handbook of Latin American Studies 57. Washington, DC: Hispanic Division of the Library of Congress. . (1997). "Sociology: Brazil" Handbook of Latin American Studies 55. Washington, DC: Hispanic Division of the Library of Congress. --. (1994). "Sociology: Brazil" Handbook of Latin American Studies 53. Washington, DC: Hispanic Division of the Library of Congress.

Maciel, Fabrício. (2007). O Brasil-Nação como Ideologia: A Construção Retórica e Sociopolítica da Identidade Nacional. São Paulo: Annablume.

Malloy, James M. (1979). The Politics of Social Security in Brazil. Pittsburgh, PA: University of Pittsburgh Press.

Marshall, T.H. (1965). "Citizenship and Social Class" in Class, Citizenship, and Social Development. Garden City, NY: Anchor Books.

McCann, Bryan. (2004). Hello, Hello Brazil: Popular Music in the Making of Modern Brazil. Durham, NC: Duke University Press.

McCann, Frank D. (1995). "Brazil and World War II: The Forgotten Ally. What Did You Do in the War, Zé Carioca?" Estudios Interdisciplinarios de America Latina y el Caribe 6(2).

Medeiros, Maria Alice de Aguiar. (1984). O Elogio da Dominação: Relendo Casa Grande e Senzala. Rio de Janeiro: Achiamé.

Medici, André. (2004). "The Political Economy of Reform in Brazil's Civil Servant Pension Scheme". Technical Note on Pension No. 002. Washington, D.C.: InterAmerican Development Bank.

Miles, Robert. (2000). "Apropos the Idea of 'Race'...Again" in Les Black and John Solomos (eds.) Theories of Race and Racism: A Reader. New York, NY: Routledge. pp. 125-43.

Murtinho, Joaquim. (1897). "Relatorio, 1897”. Ministerio da Industria, Viação e Obras Publicas. Rio de Janeiro: Imprensa Nacional.

Nascimento, Abdias. (1999). "The Myth of Racial Democracy" in The Brazil Reader: History, Culture, Politics. Robert M. Levine and John J. Crocitti (eds). Durham, NC: Duke University Press. pp. 379-81.

Nascimento, Elisa Larkin. (2007). The Sorcery of Color: Identity, Race, and Gender in Brazil. Philadelphia, PA: Temple University Press. Black Studies 11(2): 195-216. 
Nascimento da Silva, Edson Arantes. (2001). "Pelé Speaks". In The Brazil Reader: History, Culture, Politics. Robert M. Levine and John J. Crocitti (eds). Durham, NC: Duke University Press. pp. 254-7.

Needell, Jeffrey D. (1995). "History, Race, and the State in the Thought of Oliveira Viana" The Hispanic American Historical Review 75(1): 1-30.

Nobles, Melissa. (2000). Shades of Citizenship: Race and the Census in Modern Politics. Stanford, CA: Stanford University Press.

O'Connor, Julia S. and Gregg M. Olsen (eds). (1998). Power Resources Theory and the Welfare State: A Critical Approach. Toronto, ON: University of Toronto Press.

O'Connor, Julia S., Ann Shola Orloff and Sheila Shaver. (1999). States, Markets, Families: Gender, Liberalism and Social Policy in Australia, Canada, Great Britain and the United States. Cambridge, UK: Cambridge University Press.

O’Donnell, Guillermo. (1973). Modernization and Bureaucratic-Authoritarianism: Studies in South American Politics. Berkeley, CA: Institute of International Studies.

Oliveira, Gilvan Müller. (2001). "Endangered Languages in Town: The Urbanization of Indigenous Languages in the Brazilian Amazon" Cultural Survival Quarterly 25(2).

Ong, Aihwa. (1999). Flexible Citizenship: The Cultural Logics of Transnationality. Durham, NC: Duke University Press.

Orloff, Ann Shola and Bruno Palier. (2009). "The Power of Gender Perspectives: Feminist Influence on Policy Paradigms, Social Science, and Social Politics". Social Politics 16(4): 405-12.

Outlaw, Lucius. (1991). "Lifeworlds, Modernity, and Philosophical Praxis: Race, Ethnicity, and Critical Social Theory" in Eliot Deutsch (ed.) Culture and Modernity: East-West Philosophic Perspectives. Honolulu, HI: University of Hawaii Press. pp. 21-49.

Peard, Julyan G. (1999). Race, Place, and Medicine: The Idea of the Tropics in Nineteenth-Century Brazilian Medicine. Durham, NC: Duke University Press.

Pereira, Anthony W. (1997). The End of the Peasantry: The Rural Labor Movement in Northeast Brazil, 1961-1988. Pittsburgh, PA: University of Pittsburgh Press.

Petras, James and Henry Veltmeyer. (2003). Cardoso's Brazil: A Land for Sale. Lanham, MD: Rowman \& Littlefield Publishers. 
Pierson, Donald. (1939). "The Negro in Bahia, Brazil” American Sociological Review 4(4): 524-33.

Piven, Francis Fox and Richard A. Cloward. (1971). Regulating the Poor: The Functions of Public Welfare. New York, NY: Vintage Books.

Platform of the Liberal Alliance. (1999). "The Social Question" in The Brazil Reader: History, Culture, Politics. Robert M. Levine and John J. Crocitti (eds). Durham, NC: Duke University Press. pp. 156-7.

Poggi, Gianfranco. (1978). The Development of the Modern State: A Sociological Introduction. Stanford, CA: Stanford University Press.

Quadagno, Jill. (1994). The Color of Welfare: How Racism Undermined the War on Poverty. New York, NY: Oxford University Press.

Raeders, George. (1988[1934]). O Inimigo Cordial do Brasil: O Conde de Gobineau no Brasil. Rosa Freire d'Aguiar (trans). Rio de Janeiro: Paz e Terra.

Ramos, Alcida Rita. (2006). "The Commodification of the Indian" in Human Impacts on Amazonia: The Role of Traditional Ecological Knowledge in Conservation and Development. Darrell Addison Posey and Michael J. Balick (eds). New York, NY: Columbia University Press. pp. 248-72. . (1998). Indigenism: Ethnic Politics in Brazil. Madison, WI: The University of Wisconsin Press.

Reis, Elisa P. (2000). "Modernization, Citizenship, and Stratification: Historical Processes and Recent Changes in Brazil". Daedalus 129(2): 171-94.

Riesco, Manuel (ed). (2007). Latin America: A New Developmental Welfare State Model in the Making? New York, NY: Palgrave Macmillan.

Roediger, David R. (1991). The Wages of Whiteness: Race and the Making of the American Working Class. New York, NY: Verso.

Rodrigues, Nina Raimundo. (1977[1933]). Os Africanos no Brasil. $5^{\text {a }}$ edição. São Paulo: Companhia Editora Nacional.

Said, Edward. (1994). Orientalism. New York, NY: Vintage Books.

Sansone, Livio. (2003). Blackness Without Ethnicity: Constructing Race in Brazil. New York, NY: Palgrave MacMillan.

Satzewich, Vic. (2000). "Whiteness Limited: Racialization and the Social Construction of Peripheral Europeans" Histoire Sociale/Social History. 33(6): 271-89. 
Schapiro, Mark. (2010). "Brazil: The Carbon Hunters" Frontline World. Andres Cediel and Daniela Broitman (prod.) May $11^{\text {th }} 2010$.

Schultz, Kirsten. (2001). Tropical Versailles: Empire, Monarchy, and the Portuguese Royal Court in Rio de Janeiro, 1808-1821. New York, NY: Routledge.

Schwarcz, Lilia Moritz. (1999). The Spectacle of the Races: Scientists, Institutions, and the Race Question in Brazil, 1870-1930. Leland Guyer (trans). New York, NY: Hill and Wang.

Schwarz, Roberto. (2001). A Master on the Periphery of Capitalism: Machado de Assis. John Gledson (trans). Durham, NC: Duke University Press. Verso.

Schwartz, Stuart B. (1987). "Plantations and Peripheries, c. $1580-$ c. 1750" in Colonial Brazil. Leslie Bethell (ed). Cambridge, UK: Cambridge University Press. pp. 67144. (1985). Sugar Plantations in the Formation of Brazilian Society: Bahia, 1550-1835. Cambridge, UK: Cambridge University Press.

Schwartzman, Simon. (2000). "Brazil: The Social Agenda” Daedalus 129(2): 29-56.

Segura-Ubiergo, Alex. (2007). The Political Economy of the Welfare State in Latin America: Globalization, Democracy and Development. Cambridge, UK: Cambridge University Press.

Siddle, Richard. (2003). "The Limits to Citizenship in Japan: Multiculturalism, Indigenous Rights and the Ainu". Citizenship Studies 7(4): 447 - 462.

Silva, Benedita. (1999). "The Black Movement and Politics Parties: A Challenging Alliance" in Racial Politics in Contemporary Brazil. Michael Hanchard (ed). Durham, NC: Duke University Press. pp. 179-87.

Silva, Neslon do Valle and Carlos Hasenbalg. (1992). Relações Raciais no Brasil Contemporâneo. Rio de Janeiro: Rio Fundo Editora.

Skidmore, Thomas E. and Peter H. Smith. (1989). Modern Latin America. Second Edition. New York, NY: Oxford University Press. 
Skidmore, Thomas E. (2002). "Raízes de Gilberto Freyre" Journal of Latin American Studies 34(1): 1-20.

University Press.

(1999). Brazil: Five Centuries of Change. New York, NY: Oxford - (1993). Black Into White: Race and Nationality in Brazilian Thought. Durham, NC: Duke University Press.

Smedley, Audrey. (2007). Race in North America: Origin and Evolution of a Worldview. Third Edition. New York, NY: Westview Press.

Stam, Robert. (1997). Tropical Multiculturalism: A Comparative History of Race in Brazilian Cinema and Culture. Durham, NC: Duke University Press.

Stein, Stanley J. and Barbara H. Stein. (1970). The Colonial Heritage of Latin America: Essays on Economic Dependence in Perspective. New York, NY: Oxford University Press.

Stepan, Nancy Leys. (1991). The Hour of Eugenics: Race, Gender, and Nation in Latin America. Ithaca, NY: Cornell University Press. . (1990). "Eugenics in Brazil, 1917-1940" In The Wellborn Science: Eugenics in Germany, France, Brazil and Russia. Mark B. Adams (ed). New York, NY: Oxford University Press. pp. 110-52.

Streeck, Wolfgang and Kathleen Thelen (eds). (2005). Beyond Continuity: Institutional Change in Advanced Political Economies. Oxford, UK: Oxford University Press.

Sweet, David G. (1978). “Black Robes and 'Black Destiny': Jesuit Views of African Slavery in $17^{\text {th }}$ Century Latin America" Revista de Historia de América 86: 87133.

Telles, Edward E. (2004). Race in Another America: The Significance of Skin Color in Brazil. Princeton, NJ: Princeton University Press.

Time. (1940). "South America: Awake at Last”. Time Magazine. 24 Jun 1940.

Todorov, Tzvetan. (1984). The Conquest of America: The Question of the Other. Richard Howard (trans). New York, NY: Harper \& Row.

Topik, Steven. (1987). The Political Economy of the Brazilian State, 1889-1930. Austin, TX: University of Texas Press.

Trouillot, Michel-Rolph. (1995). Silencing the Past: Power and Production of History. Boston, MA: Beacon Press. 
Turner, Terence. (2002). "Representation, Polyphony, and the Construction of Power in a Kayapó Video" in Indigenous Movements, Self-Representation, and the State in Latin America. Kay B. Warren and Jean E. Jackson (eds). Austin, TX: University of Texas Press.

Triner, Gail D. (2005). "Race, With or Without Color? Reconciling Brazilian Historiography" History Compass 3(1): 1-21.

Twinam, Ann. (1989). "Honor, Sexuality, and Illegitimacy in Colonial Spanish America" in Sexuality and Marriage in Colonial Latin America. Asunción Lavrin (ed). Lincoln, NE: University of Nebraska Press. pp. 118-155.

Twine, France Winddance. (1998). Racism in a Racial Democracy: The Maintenance of White Supremacy in Brazil. New Brunswick, NJ: Rutgers University Press.

Vargas, Getúlio. (1999[1938]). "New Year's Address, 1938” in The Brazil Reader: History, Culture, Politics. Robert M. Levine and John J. Crocitti (eds). Durham, NC: Duke University Press. pp. 186-89.

- (1944). "Brazil: A Vast Land Rich in Untapped Tropical Wealth, it is On the Threshold of a Great Developmental Era" The Rotarian May 1944.

Vianna, Francisco José Oliveira. (2005[1920]). Populações Meridionais do Brasil. Brasília: Senado Federal, Conselho Editorial.

Viotti da Costa, Emilia. (1985). The Brazilian Empire: Myths and Histories. Chicago, IL: The University of Chicago Press.

Welch, Cliff. (1999). The Seed Was Planted: The São Paulo Roots of Brazil's Rural Labor Movement, 1924-1964. University Park, PA: The Pennsylvania State University Press.

Williams, Daryle and Barbara Weinstein. (2004). "Vargas Morto: The Death and Life of a Brazilian Statesman" in Death, Dismemberment, and Memory: Body Politics in Latin America. Lyman L. Johnson (ed). Albuquerque, NM: University of New Mexico Press. pp. 273-316.

Williams, Daryle. (2001). Culture Wars in Brazil: The First Vargas Regime, 1930-1945. Durham, NC: Duke University Press.

Williams, Fiona. (1995). "Race/Ethnicity, Gender, and Class in Welfare States: A Framework for Comparative Analysis" Social Politics 2(2): 127-59.

----ons and Class. Cambridge, UK: Polity Press. 
Winant, Howard. (2001). The World is a Ghetto: Race and Democracy Since World War II. New York, NY: Basic Books. (1999). "Racial Democracy and Racial Identity: Comparing the United States and Brazil" in Racial Politics in Contemporary Brazil. Michael Hanchard (ed). Durham, NC: Duke University Press. pp. 98-115.

Wirth, John D. (1970). The Politics of Brazilian Development: 1930-1954. Stanford, CA: Stanford University Press. (1964). "Tenentismo in the Brazilian Revolution of 1930" The Hispanic American Historical Review 44(2): 161-79. 